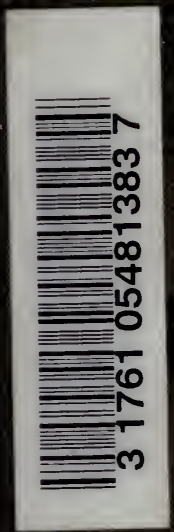




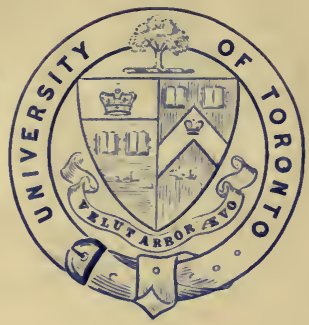

Dresenteo to

\section{The Tibrary} of the

\section{Viniversity of Toronto} by

or. galery H. Secioa 
Te ampbell dmith

d. of. No. is Daughan. 


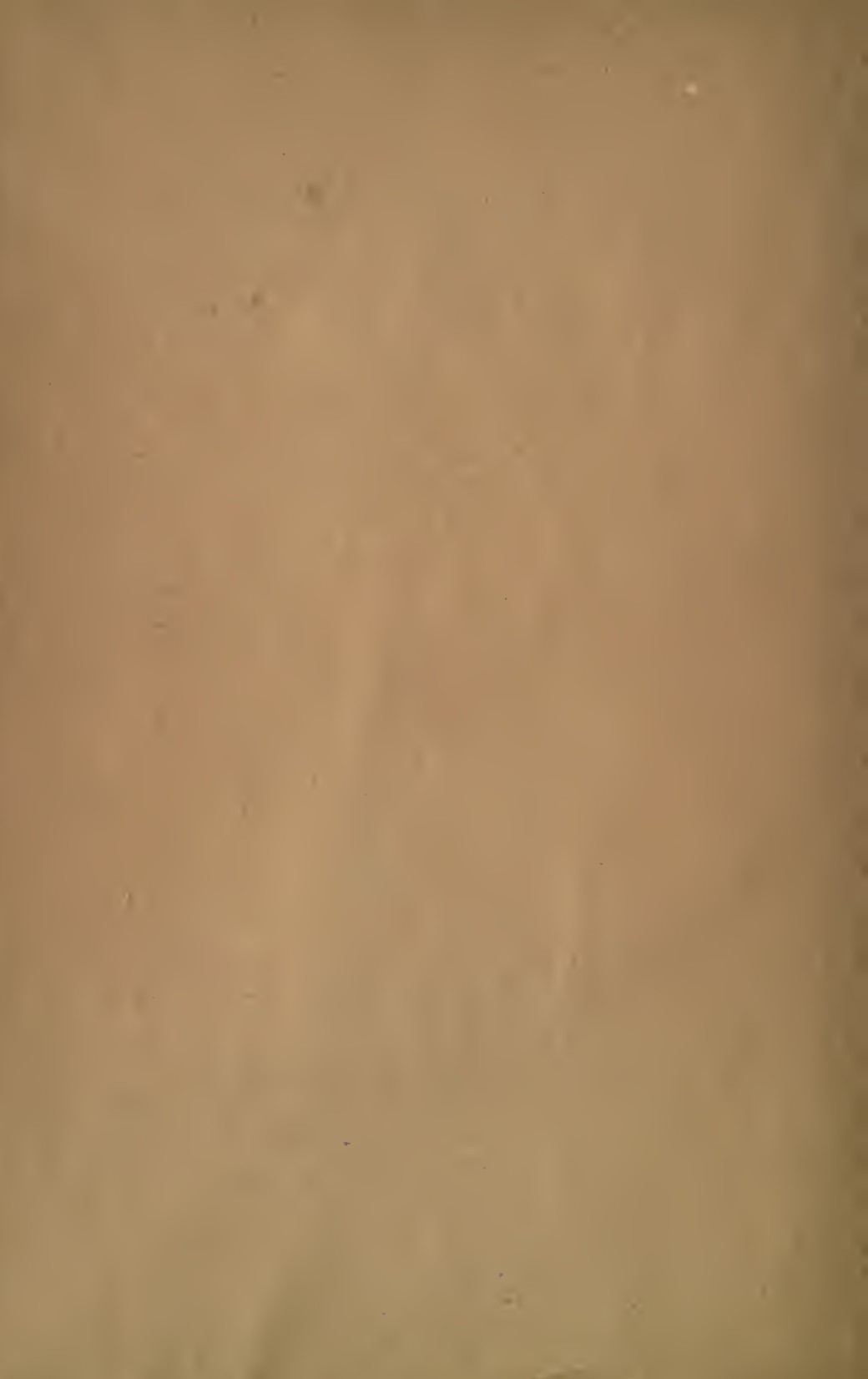


MPhy

PUBLIC SCHOOL

\section{Physiology and Temperance}

BY

\section{WIIL.IAM . NATTRESS, M.D., M.R.C.S. ENG., First-class Provincial Certificate, Grade A.}

AUTHORIZED BY THE EDUCATION DEPARTMENT (ONTARIO).

TORONTO :

WILLIAM BRIGGS.

THE W. J. GAGE CO., Limited. 
Eutered, according to the Act of the Parliament of Canada, in the year one thousand eight hundred and ninety-three, by whulaM BRIGGs, Toronto, in the office of the Minister of Ágriculture, at Ottawa.

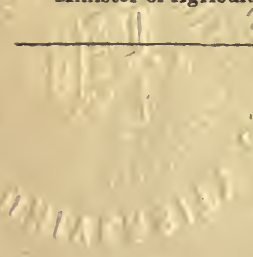




\section{PREFACE.}

IN preparing this text-book, much difficulty was experienced in dealing with a subject of a somewhat technical character without using too freely the technical terins incident to Anatomy and Physiology. The practice of the authors of the best text-books published has, however, been followed. The introduction of a limited number of the simpler scientific names, while partly a necessity, nevertheless affords an opportunity for pupils to become early acquainted with the various parts of the human frame under names which are more correct and more suitable than many of the familiar terms in common use; besides, experience shows it is impossible to fix in the memory a knowledge of any subject, except by the use of its own appropriate nomenclature.

The object of the author has been to put clearly before the teachers and pupils the leading facts concerning the structure and functions of the various organs of the body, and, at the same time, to associate with these facts the physiological action and effects of alcoholic stimulants and narcotics. The pupil is, in this way, at every turn confronted with the evil effects of alcohol and tobacco, the dangers accompanying their use, and the tremendous risk of tampering with such powerful agents of destruction. 
The benefits to be derived from a proper observance of the laws of health cannot be over-estimated, and while teachers inculcate abstinence from stimulants, they should impress upon their pupils the observance of such practices with regard to all the functions as would promote the highest possible development of mind and body.

The author acknowledges his indebtedness to the follow. ing for valuable hints: Martin's "Human Body," Starling's "Human Physiology," Blaisdell's "Young Folks' Physiology," Steele's "Hygienic Physiology," “Manual of Hygiene," Toronto, Sir B. W. Richardson's "Cantor Lectures on Alcohol," besides frequent reference to Gray, Foster, Huxley, Hare, Sajous, Nettleship, Lees, and many others.

\section{WILLIAM NATTRESS.}

'Tononto, October, 1898. 


\section{CONTENTS.}

CHAPTER I.

INTRODUCTORY : The Skeleton-How it is built up . . . . 9

\section{CHAPTER II.}

THE BoNes : The Number of Bones-Uses-Composition-Structure

- -Growth and Repair-Skull-Trunk-Upper ExtremitiesLower Extremities-Joints-Care of the Body-Effects of Alcohol and Tobacco . $. \quad . \quad . \quad . \quad$. . . .

CHAPTER III.

The Muscles : The Structure of Muscles-Arrangement-Classifcation-Tendons-Care of Muscles-Action of Alcohol and Tobacco on Muscular Sense . . . . . . . .

CHAPTER IV.

The SkIN : The Epidermis-True Skin-Glands of the Skin-The Hair-Nails-Care of the Skin-Bathing-Skin AffectionsEffects of Alcohol

\section{CHAPTER V.}

Digestion : Need for Food-Mouth-Teeth-Salivary GlandsPharynx - Esophagus - Stomach - Intestines - Pancreas Liver - Kinds of Food-Action of the Ferments - Appetite - Natural and Prepared Drinks - Action of Alcohol on the Stomach-On the Liver-Effect of Tobacco on Digestion. .

\section{CHAPTER VI.}

Circulation: The Blood - The Heart - Arteries - Veins - How Blood is Made to Flow - Effects of Alcohol on the HeartOn the Blood-vessels-Effects of Tobacco on the Heart. . 


\section{CHAPTER VII.}

REspiration: Why we Breathe-The Lungs - The Voice-The Pleura - The Act of Breathing - Change of Elements in the Lungs - Effects of Impure Air-Ventilation-How Heat is kept up-Need of Clothing-Effects of Alcohol on Respiration-Cigarette Smoking .

\section{CHAPTER VIII.}

The Nerrous Srstem: The Brain-Gray and White Matter-Cerebrum-Cerebellum-Medulla Oblongata-The Spinal CordNerves-Sympathetic System-Growth and Development of Brain-Rest and Sleep-Abuse of Narcotics-Effects of Alcohol on the Brain-On the Nervous System-Tobacco

CHAPTER IX.

The Special Sexses: Taste--Smell-Sight-Hearing-Touch-Relation of Special Senses-Effects of Alcohol and Tobacco on the Special Senses

\section{CHAPTER $\mathrm{X}$.}

First AIds to THE Sick and INJURed: Bandages-Splints-Poultices-Hæmorrhage-Cuts-Bites of Animals-Burns and Scalds -Frost-bite-Broken Bones-Dislocations-Sprains-Insensible Conditions-Intoxication-Drowning-Suffocation by Gas -Foreign Bodies in the Eye, Ear, etc.-Poisons

\section{CHAPTER XI.}

How to Prevent Disease: Preventable Diseases-Infectious and Contagious Diseases-Means of Invading the Human SystemAntiseptics and Disinfectants-The Sick Room-Stimulants in the Sick Room

\section{CHAPTER XII.}

Physical Exercise: The Benefits of Exercise-Kind of ExerciseRegulation of Exercise-Time for Exercise-Necessity for Exercise-Gymnastic Training-Free Gymnastics . . . . 174

APPENDix I.-Regulations of the Education Department respecting the Study of Physiology and Temperance . . . . . 194

APPENDIX II. - Quotations from the License Act with respect to Minors 195 APPENDIX III.-An Act respecting the Use of Tobacco by Minors . 196 



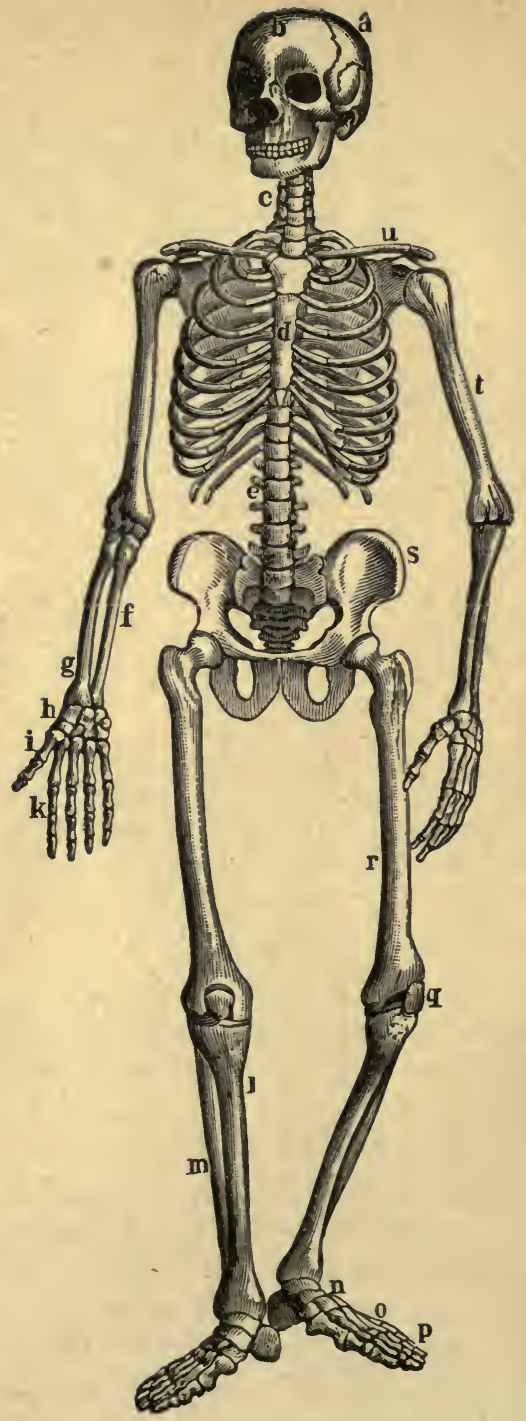

Fie 1.-THE SKELETON 


\section{PHYSIOLOGY AND TEMPERANCE.}

\section{CHAPTER I. \\ INTRODUCTORY.}

1. The Skeleton.-Man is the noblest being God has made to inhabit this earth. Let us examine the human body. First, notice the framework. It is not comely nor attractive, and even appears ill-adapted to form the framework of a living being, with high and noble purposes, capable of great attainments. Yet every bone is a model of wisdom and perfection, adapted to a specific object. The whole skeleton, so irregular in outline and so unattractive to look at, is built and fashioned with a degree of wisdom which taxes the mind to comprehend. Every prominence, every depression, every line, every curve, has a special purpose.

2. The Joints.-This framework is a movable structure, and, to permit of motion, is supplied with a certain number and variety of joints, by which the limbs may be moved in various directions and the whole body from place to place. The utility and the wise construction of these joints will be: pointed out in another place.

3. The Muscles.-The power by which the joints are moved is provided by the muscles, which in a great measure form the bulk of the limbs and body generally. The muscles, stretching from point to point, are attached to the bones by tendons of a fine cord-like nature, and, by a power which 
they have of contracting and relaxing, produce motion of the joints. They act upon the principle of the levers-one or other of the three kinds. In the attachment of the muscles we see the admirable purpose which the various prominences and depressions upon the bones are intended to serve.

4. Fascia.-The muscles are invested and bound down by a fine, thin membrane, called fascia, which protects and keeps them in place.

5. The Nerves.-The muscles are moved and controlled through the nerves supplied to them. The nerves form the connecting links between the muscles at one end and the brain and spinal cord, or marrow, at the other. The brain and spinal cord may be called the headquarters of the nervous system. Nerve cords of various sizes extend from the headquarters to the numerous muscles of the body, where they divide and ramify. Each nerve is like a telegraph wire, along which are conveyed communications from the nerve centres to every part of the muscular system. Orders may be transmitted from the brain to a muscle, when it is to move, how it is to move, and when it is to cease moving. All muscles employed in moving the body are under the control of the will of the individual.

6. Fat.-Outside the muscles, and often filling in the inequality of surface, there is, during the greater part of life, a layer of adipose tissue or fat. This serves very important purposes in the physical economy, and forms a valuable covering and cushion to the parts beneath. It also gives beauty to the figure, by producing graceful form of limb and body. The fat is contained in the cells of a structure known as cellular tissue, which serves also as a connective tissue between parts.

7. The Skin.-The human body thus built up is covered by the skin. The skin not only forms a protective covering to the parts beneath, but, being possessed of nervous sensi- 
bility, it indicates to the system the state of the atmosphere and other surrounding conditions, and gives warning of destructive influences. In some parts, as in the fingers, this sensibility is most delicate and acute. Here the nerves of sense are more closely distributed, and are in freer communication with each other. They act as sentinels to warn the body of danger, and when danger is at hand they telegraph to the brain or spinal cord to move the limb or body from this exposed position, or to assume a position of defence. The lightning speed with which these communications are made may be seen when a finger unexpectedly comes in contact with a hot substance.

8. The Brain and Spinal Cord.-We have now before us a self-moving structure, made up of bones, ligaments to hold together the bones at the joints, muscles, fat, connective tissue and skin, with a nervous system, consisting of the brain, spinal marrow, and nerves communicating with every part, to superintend and manage this movable tenement. The force required to move the system and the heat necessary for life are self-created.

9. Atoms.-The body formed of these several tissues is composed of material of limited durability. There is a limit to life with regard to our individual being, but there is a much briefer limit to the life of the particles out of which the tissues are constructed. Each of these atoms or cells has an individual life. It passes a state of existence of comparatively short duration. During its term of existence it has the ordinary stages of life-birth, growth, development, maturity, decline and death. The cells are the offspring of parent cells, and in turn beget offspring before they die. In infancy, childhood, maturity and old age the body is ever perishing. It is this constant loss of particles, this wear and tear of tissue, which causes the demand for daily food. Until the body is fully matured, food is required for the growth of 
the tissue; subsequently it is only needed to maintain the body, to make repairs and to supply heat. The human body may be likened to a building, composed of many parts, of different forms, size, density and durability. Together they constitute a perfect structure, harmonious in every part. But one or more of these pieces decay, and to retain the integrity of the structure, repair is maù by substituting a sound piece for the one decayed or worn out. Thus repair of a building may be effected by a competent builder, even to replacing the foundation stone. In this manner repair is constantly taking place in the living body. It is a work of nature, and is carried on by wise laws and with unerring precision.

10. Digestion.-The source of supply for repairing the tissues of the body is the food which we eat. To convert the food into blood, the body is provided with the digestive system, consisting of the mouth, teeth, tongue, œsophagus or gullet, stomach, and the intestines. Each of these organs is placed in a position most convenient to serve its purposes. In connection with the digestive system are a number of glands, to secrete fluids required in the process of digestion. First, the salivary glands, which discharge the saliva into the mouth, to be mixed with the food as it is ground up by the teeth. After this first step in the process of digestion, the food passes along the gullet to the stomach, where it is churned up, and at the same time mixed with the gastric juice, secreted by glands placed in the coats of the stomach. The greyish pulpy mass thus produced, called chyme, passes into the intestines, to undergo further changes from the action of the intestinal juice, the bile from the liver and the fluid secreted by the pancreas. The chemical and vital changes which have now taken place have prepared the aliment to mix with the blood, and the chyle, as it is now called, is taken up by a system of absorbent vessels and passes by a duct called the thoracic duct, to be emptied into the great volume of blood 
sirculating through the system. The nutritious fluid thus added to the blood is gradually developed, and has imparted to it the vital properties of the blood, and in due time is in a fit state to become food for the tissues or to repair the loss caused by the death of microscopical cells.

11. The Circulatory System.-This system carries the blood back and forth from the heart to every part of the body. It consists of the heart, arteries and veins, and hairlike canals called capillaries. A second circulatory system carries the blood to and from the lungs to the heart. The first, or long circuit, is to feed the tissues and remove the worn-u material; the second, or short circuit, through the lungs, is to cast out of the system the products of decay and death of tissue, and to receive from the air taken into the lungs the oxygen without which life cannot exist.

12. The Respiratory System.-More immediately necessary for life than the circulation is the process of breathing, and the two lungs, which in the lower animals are called the lights, occupy a large space in the upper part of the body, called the thorax. The bronchial tubes, which extend from the trachea, or windpipe, to the inner surfaces of the lungs, communicate with the external air through the nose.

13. The Excretory System.-Besides the lungs, there are other organs, whose function it is to carry out of the system various elements not only useless to sustain the body, but more or less injurious to the process of life. These are the intestines, the kidneys, and the skin.

14. Alcohol, Tobacco, etc.-This brief survey of the human body, and the manner in which the functions of life are carried on, will prepare us to consider more particularly the structure of the various tissues and organs; how they are nourished and sustained, and what are the requirements to keep the body in health. We will endeavor to show that perfect health depends upon the care we give the body, the 
regularity with which we attend to its many needs, and the judgment we exercise in taking into the system only that which is pure and wholesome, and avoiding those things which tend to irritate, to injure and to destroy.

One of the most destructive agents man has brought into use is ALCOHOL. Owing to its use as a beverage, it has become a powerful evil. Taken into the system regularly, it becomes an overpowering enemy. Alcohol may be presented in many different forms. There are a large number of intoxicating beverages, each of which is supposed to possess some special virtue. They are all alike seductive, and are taken for the alcohol they contain Some have only a small amount of alcohol in them, and are classed as mild drinks. Others are nearly one-half alcohol, and are called strong drinks. No matter in what form it is taken, we will find in the succeeding chapters of this book, that every tissue and every organ of the body is influenced hy its use. We are also convinced that further evidence will not be needed to show that perfect health sannot be hoped for when alcohol is taken in ever so small a quantity.

Товассо, though "the lesser evil of the two," is, perhaps, more universally used than alcohol ; and is, doubtless, responsible for many a headache, a deranged stomach, a weak heart, or a stunted body. Like alcohol, it is also presented in many different forms. Some draw it into the nose, as snuff; others take it into the mouth, to chew; while others, again, smoke it, either in the form of a cigarette, a cigar, or in a pipe. Taken in any form, it is more or less distasteful to those about us who do not use it, while some of the modes of taking tobacco deserve strong condemnation.

The evil effects of opIUM are not to be less dreaded than those of alcohol. We shall find that, while it is a useful drug . in the hands of a careful physician, it is too powerful $\approx$ one to be used indifferently. The opium eater is as much to be pitied as the drunkard. 


\section{CHAPTER II.}

\section{THE BONES.}

1. The Number of Bones.-There are two hundred and six bones in the human body at maturity. They may be arranged as follows (see Fig. 1) :-

I. The bones of the Head :

1. Brain case (Cranium) . . . $(a, b), 8$

2. Face. • • • • . . • . 14

3. Ears . • . • • • • . 6

II. The bones of the Trunk:

1. Spinal column $($ Vertebrce $)$. . . $(c, e) \quad 26$

2. Ribs . • . • . . . . 24

3. Hip bones (Innominata) . . . $\quad$ (s) . 2

4. Breast bone (Sternum) • • • $(d)$. 1

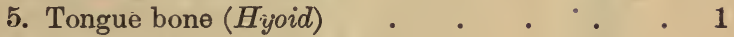

III. The bones of the Upper Extremity:

1. Shoulder (Scapula and Clavicle)

Each-

2. Arm (Humerus)

3. Forearm (Ulna and Radius)

(u) $\cdot 2$

4. Wrist (Carpal)

$(t) \quad \cdot 1$

$(f, g) \cdot 2$

5. Palm (Metacarpal) . . . . $\quad$ (i) 5

6. Fingers (Phalanges) . . . . $(k)$. 14

IV. The bones of the Lower Extremity:

Each-

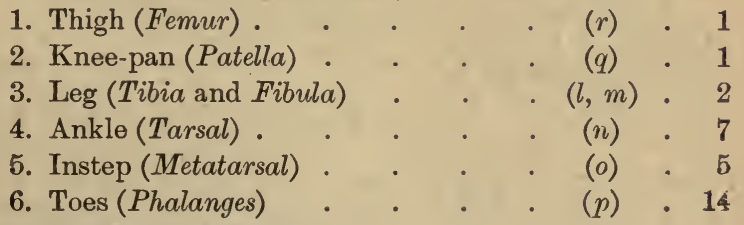

We may also speak of bones as

Long-The bones of the arms, legs, etc.

Short-The bones of the fingers, toes, etc.

Flat-The skull, shoulder blade, etc.

Irregular-Hip bones, heel bones, etc. 
2. Uses.-The bones serve various purposes in the different parts of the body. The skull incases and protects the brain. The spinal column, with its numerous processes, protects the spinal cord within, while at the same time affording convenient points for muscular attachment. So also the bones of the chest, while formed in a great measure to protect the important organs within, give attachment to muscles. It is

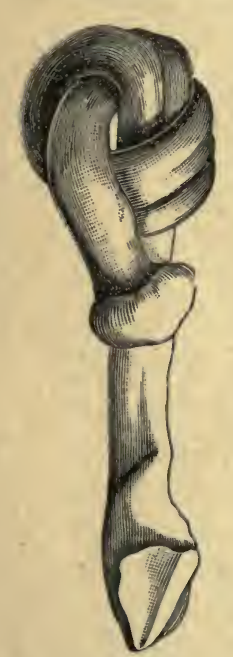
the same with regard to the lower bone:s of the trunk, namely, the hips or pelvic bones. The bones of the arm form a most important member of the body. They are so shaped that the muscles lying upon them afford a variety and freedom of movement to the arm and hand not found in any other part of the body. The bones of the lower extremity are mainly for the purpose of sustaining the body in the erect position, and of moving it from place to place.

3. Composition of Bone.-Healthy bone in a state of nature consists of an organic or animal matter blended with an inorganic or earthy portion, whereby elasticity and firmness are obtained. In youth Fro. 2.-The Fibula, it is about equally composed of animal and or outer bone of the leg, mineral matter, in middle life it is about tied in a knot, after the hard mineral matter has been dissolved out by in old age the mineral matter is largely in acid.

excess. Consequently, in the young the bone may be considerably bent by external force without breaking, and, like a green stick, will rebound when the force is removed. On the contrary, in old age any force sufficiently great to bend the bone will cause a fracture; while in middle life the proportion of animal and mineral 
matter is such as to allow sufficient flexibility and secure strength to enable man to fulfil the duties of life.

If a bone be exposed to the action of certain acids-weak muriatic acid, for instance-the mineral matter will be dissolved, and the bone, although retaining its normal size and shape, will become flexible like a rubber tube. On the other hand, if a bone be placed in the fire, the animal matter will disappear, leaving the bone light in weight and easily crumbled into powder.

4. Ossifying Bone.-In the child at birth the entire framework is made of cartilage or gristle, and the gradual conversion into bone is called ossification. This process commences in the middle of the bone, and gradually extends to the borders. Sometimes there are two or more points of ossification, in which case the several growing areas of bone approach each other and coalesce, the place of the union being marked by a line (see skull, page 21).

5. The Structure of Bone.-The consistence of bone varies, according to its use and according to its mode of construction. In every instance there is manifested infinite wisdom in securing strength without unnecessary bulk.

In a fresh long bone, sawn lengthwise, it is seen that the shaft is made up of two portions, the outer or cortical portion, and

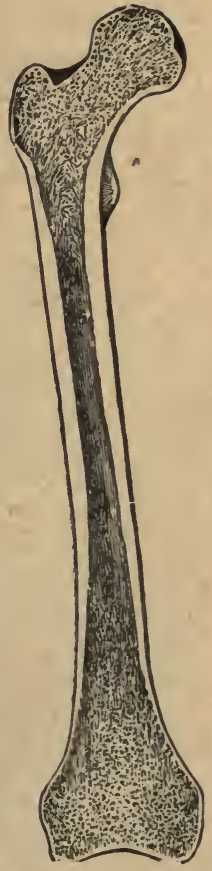

FIG. 3.-The Thigh. Bone, or Femur, sawn lengthwise. the inner or spongy portion. The outer portion is hard and firm, and is covered by a dense fibrous membrane closely attached, and through which blood is supplied to the bone. This is called the periosteum. 
The spongy portion forms the bulk of the shaft, and at either extremity makes an expansion to form joint surface. This spongy tissue consists of elongated bony cells, and the walls of the cells give lightness and strength, while the tiny channels afford a passage for the nutrient fluid to pass. In the interior of the bone is lodged the marrow, composed of fat and numerous blood-vessels, for supplying the central portion of the bone with nourishment. The blood-vessels within the bone are a continuation and subdivision of an artery, which enters the bone through a small opening seen in all bones, and called the nutrient foramen.

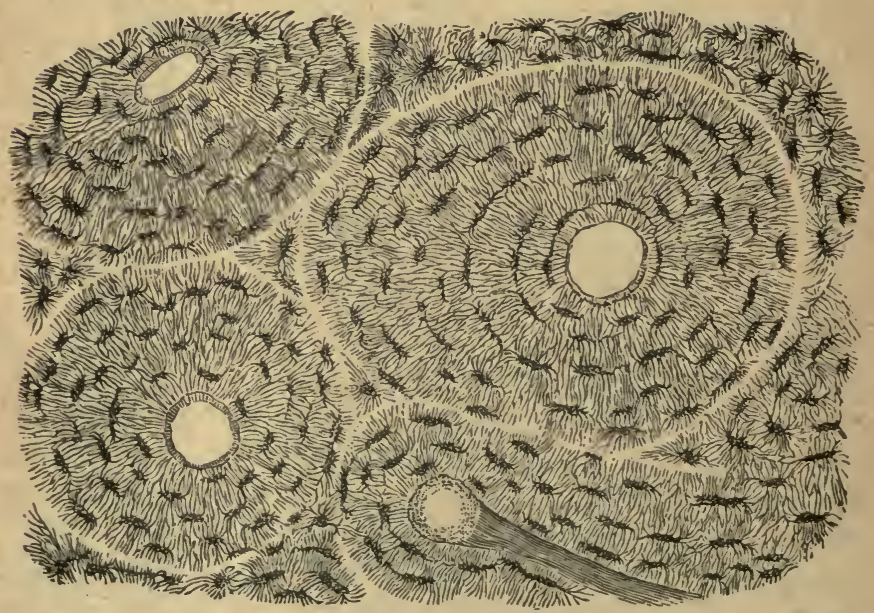

FIG. 4. - A thin slice of bone highly magnified, showing little central canals for the blood-vessels, and tiny tubes for the passage of nutriment to the bone tissue. The black specks are little cavities in the bone.

If we examine a thin slice of bone under the microscope, we find it is mapped out into a number of circular districts, and in the centre of each district is a small canal for the pasage of a minute blood-vessel. These canals do not run parsllal with esch other, or with the shaft of the bone. Soxne 
open intu the marrow, and receive their blood-vessels from it, while others open on the surface beneath the periosteum, and admit blood-vessels.

Each canal is the centre of a complete system of blood supply to the district. Little tubes run outwards, like spokes from a wheel, communicating with each other and with numerous other cavities (seen in Fig. 4, as black specks) in such a way as to carry the blood to every part of the bone.

6. Growth and Repair of Bone.-The system of blood supply in the bone, so admirable in its arrangement, furnishes the osseous structure with nutriment for growth and development; also, for the repair of tissue, as the bone is subject to the same continual decay and death of the minute cells as are the other tissues, and ordinary repair is constantly being made.

7. Healing of Broken Bone.-When the bone is broken, these vessels supply the material necessary for repair or union of the fragments. The plasma of the blood is poured out upon and around the fractured ends, at first gluing them together, and holding them firm until new bone cells are thrown out. In this way the two ends are knit together, ana soon the bone becomes as strong as before it was broken. But in order that this work of nature may properly proceed, the fractured bone must be kept at rest and the adjoining muscles relaxed. This is best done by placing the limb in an easy position and applying suitable splints. When, from carelessness of the patient or uneasiness on his part, the broken bone is not kept in a state of repose, nature attempts to fix the part by pouring out a more copious quantity of plasma. This extra material, callus, as it is called, makes the bone at the seat of fracture much larger. In time, however, this will be ahonrbed.

8. Effects of Alcohol on Growth of Bone-First anongst the signs of the evil effects of alcohol, when taken to 
excess, is a lack of physical development. In many cases the liquor habit dates from childhood. Continuing in this habit, the child's growth is frequently slow and imperfect, and he reaches manhood small in stature and stunted in body and limb.

In France, amongst the peasants regularly drafted for the army, it is noticed that those who drink from childhood fall below the military standard, while those who do not drink develop normally. It is observed that rejections from military service increase as drunkenness increases.

9. Effects of Alcohol on Broken Bone.-A fracture seldom heals as rapidly and as firmly in a drunkard as in a sober person. Nature tries to do her work as faithfully in the one as in the other; but in the one case she has healthy material to build from, and is not likely to fail. In the other case, the material is poisoned with alcohol; perhaps the general system is in an irritable condition or is greatly reduced, and it is not surprising that a faulty union sometimes takes place. The continued uneasiness met with in cases of delirium tremens, and in inebriates generally, is sufficient to overcome all efforts of nature to keep the broken ends of bone steady and in close contact. As a result, union is often very much delayed, and 'when it does take place it will very likely be faulty. This is not all. Union sometimes fails to take place; further operation becomes necessary, the patient runs down rapidly, and the result is often most disastrous.

The careful surgeon now recognizes the necessity for restricting the use of stimulants in cases of fractured bones, especially in persons of full habit. A moderate diet, without stimulants, promotes a restful condition of the system, and avoids disturbances of digestion which are apt to arise from want of exercise. 


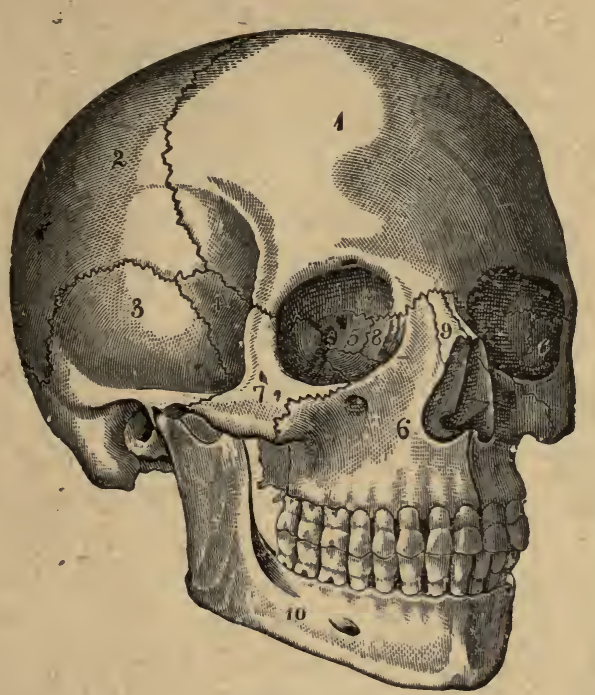

Fig. 5.-The Skull. 1, 2, 3, 4, 5, bones of the skull proper; 6 , upper jaw: 7 , cheek bone ; 8 , lachrymal bone; 9 , nasal bone; 10 , lower jaw.

10. The Skull.-The bones of the skull are so constructed as to make an admirable case for enclosing the brain. It also lodges and protects the organs of special sense, namely, sight, smell, taste and hearing. When the head receives a severe blow, unless it is very direct, the rounded shape causes the weapon to glance off without injury to the brain itself. Even a bullet may be turned from its course, and pass around the skull without penetrating the bone. Besides being round, the skull affords a further protection to the brain by being made up of an outer and inner table of hard, firm bone, closely united by a spongy layer. In the more exposed parts these plates are thickened and the outer layer is considerably separated from the inner, so that blows severe enough to break the outer may not injure the inner or disturb the brain. The spongy packing also helps to deaden the blow. 
In infancy, the skull is made up of several distinct bones. The child, when learning to walk, stumbles about and bumps his head without doing serious harm, the bones being more elastic and freer to move. As the brain enlarges, these bones grow, and when fully formed they are dovetailed into each

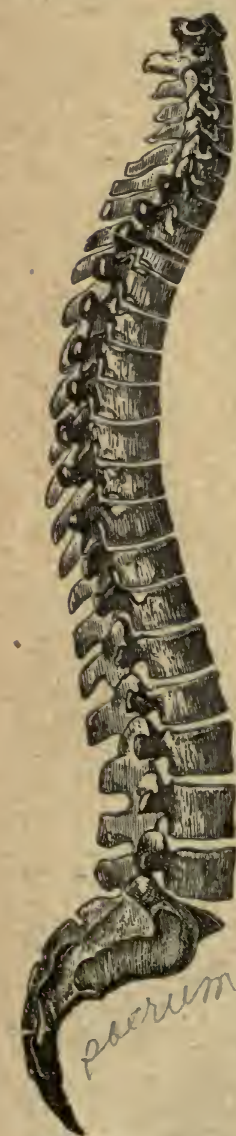

Fig. 6. The Spine. other, something after the manner in which a carpenter joins his pieces in making a box. The only bone which remains separate is the lower jaw.

There are a number of small openings in the skull for the passage of nerves and vessels. There is one large one at the under part or base of the skull, through which the spinal cord is connected with the brain.

11. The Bones of the Trunk.-In classifying the bones, we mentioned one belonging to the trunk, called the hyoid. This is a snall bone shaped like a much bent bow with the arch in front, and placed high up in the neck, to support the tongue and give a firm point of attachment to its numerous muscles. In addition to this bone, the trunk comprises the bones of the spine, the ribs, the breastbone, and two very irregular bones which extend forward from the base of the spinal column, spreading out on the sides to form the hips, and meeting again in the front of the body. They form, with the spine, a complete basin, called the pelvis. On the lower and under surface of the hip bone is a deep socket, for the head of the large bone of the thigh.

12. The Spine.-Of all the wonderful arrangements of bones in the human frame, 
that of the spine is the most striking. It is firm, and yet elastic. It is capable of carrying a great weight, and yet easily bent in any direction. It is made up of a number of separate bones, and yet in its centre there is formed a perfect canal throughout nearly its whole length, just as a continuous canal is formed by placing a number of spools evenly one upon another. The main portion of the spine consists of twenty-four separate and distinct pieces, and these rest upon one large solid mass of bone called the sacrum. In early life, the five bones which form the sacrum are separate; so also are the four small bones beneath these, which in adult life unite and form one bone. In infancy there are, therefore, thirty-three bones in the spine, and in the adult only twenty-six.

The individual bone is called a vertebra, hence the whole is sometimes called the verteliral column. Each separate vertebra consists of a solid piece of bone called the body, and projections (processes) rumning outwards and backwards. Those running back wards incline towards each other and soon unite, so as to form the canal for the spinal cord. It then continues backwards for varying lengths at different parts of the spine, and is called the spinous process. This is why the vertebral column is sometimes called the spine. These are the various projections of bone we feel immediately under the skin, from the back of the neck downwards. The other projections run out sidewise, and are for attachment of long, slender muscles to strengthen the whole column, very much in the same way as ropes strengthen and support the masts of a ship.

The bodies of the vertebræ are placed one upon another, with a layer of elastic cartilage between, as bricks are placed one above another, with mortar between. They are not cemented firmly together, as is the case in a brick wall; the cartilage, being elastic like rubber, allows the bones to bend 
upon each other in all directions. If we keep the spine bent a long time, these cushions will not readily resume their proper shape, and in this way people become stooped, especially in old age, when the cartilage is less elastic. In a young person it is sufficiently yielding to make nearly an inch difference in the height between rising in the morning and at bedtime, after standing upright all day.

A side view of the spinal column shows it to be curved. In the neck it bends a little forward. Just below this it is bowed backwards. This increases the capacity of the chest. Then bending forward, it affords an advantageous restingplace for important organs in the abdomen, and gives behind favorable points of attachment to large muscles extending to the legs. The large wedge-shaped part of the spine, filling in the space between the hip bones behind, forms a well-marked curve backward and then forward, and secures a perfect resting-place for the organs contained within. This double curving of the spine tends also to disperse the force of a fall. These gentle curves have besides the effect of giving to the body a pleasing and graceful outline, but if they are much increased it becomes a deformity. In rickets, for example, the bones of the spine are softened. The weight of the body, especially if the child is kept standing a great deal, presses the soft bones closer together in front, and increases the curve at the back.

The various bones of the spinal column fit so nicely into each other, and are bound together so firmly by strong ligaments, that fractures and dislocations are very rare. The head moves freely backward and forward as it rocks upon the first bone of the spine. It turns from side to side around a pivot in the second bone, carrying with it the first. We bend the spine in some cases almost double, as may be seen in the performances of an athlete, and yet there is no displacement nor injury to the delicate cord within. 
13. The Walls of the Thorax.-The cavity of the chest contains the heart, lungs, and larger blood-vessels. It is cone-shaped, with the apex at the top. The walls consist of bone, muscle and elastic cartilage. Behind is the strong spinal column. In front, extending from the neck to the pit of the stomach, is the breast bone, or sternom. The floor or base of the cone is formed by a broad, flat muscle, the diaphragm, which stretches across the body, and divides the thoracic or chest cavity from the abdominal cavity.

14. The Ribs. - The greater portion of the chest walls is formed by the ribs. They are twenty-four in number, twelve on each side. They do not lie close to one another, the space between being occupied by muscles running obliquely to and fro. These muscles assist in expanding the chest. The ribs are firmly attached behind to the spinal column. They curve forward, and are joined to the sternum by elastic cartilage. Those at the top

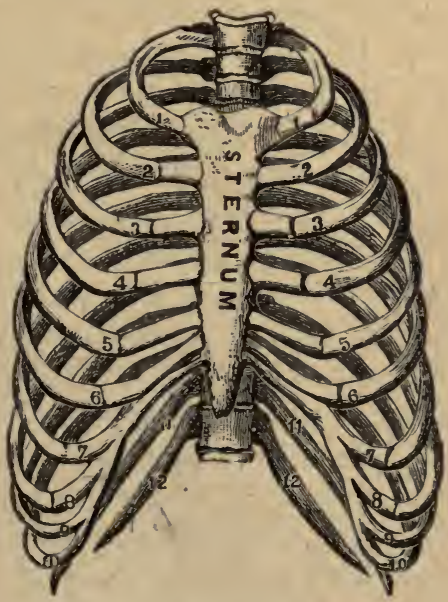

FiG. 7.-The Ribs and Sternum. are short, with a greater curve; at the middle of the chest the ribs are long and bowed. The two tower ribs on each side have no attachment in front, and are hence called the floating ribs. The great function of the chest walls, after giving protection to important organs within, is to expand and contract, thus increasing and diminishing the capacity of the chest, and thereby carrying on the life-long process of breathing. The variation of space in the cavity is effected 
not only by the ribs and the rib (intercostal) muscles, but by the diaphragm, which, in contracting, extends the cavity downwards. In case of the upper portion of the walls of the chest not acting, as in tight lacing - a habit so much indulged in by the lady of the period, that the chest is even smallest where it should be the largest-the diaphragm descends and crowds the organs low down into the pelvis. Such persons are doing themselves a double injury. In the first place, tight lacing is productive of small, weak lungs; and secondly, the lower organs in the abdomen are so pressed upon that they perform their functions with difficulty, and are often in a constant state of congestion from want of freedom in the return of the blood to the heart.

15. The Walls of the Abdomen.-The lower portion of the trunk is bounded above by the diaphragm, the partition which separates the trunk space into two cavities: below by the pelvis, behind by the spine, and in front by a muscular wall. The floating ribs occupy a small portion of this space at the top and on each side. The bony protection to the contents of the cavity is limited in front, excepting when the body is bent forward. 'The greater part of the front wall is made up of flat tendons and musces, in order that we may have more freedom in lending. - If the ribs extended down to meet the bones below, we should be vert stiff and rigid in our movements. We would be obliged to sit or stand, like the warriors of old when they donned their steel coats of armor.

The cavity of the abdomen contains the liver, stomach, intestines, kidneys and other organs.

16. The Upper Extremities.-The arms are so placed at the upper and outer part of the chest as to give them an extensive sweep over the body. The arm is the member above all others which contributes to man's welfare, supplies the wants of his body, gives him a means of defence, and by 
which he performs many of the duties of life. By this member the blacksmith wields_his heavy hammer, to fashion with precision the piece of iron; and by it the musician, with exquisite skill, produces upon his instrument the finest and loftiest notes of melody.

17. The Scapula and Clavicle.-The arm is attached to the body by a flat, triangular bone, the scapula or shoulder blade, which rests upon the ribs on the back part of the thorax, and is held to the side by a layer of muscles, thus giving freedom of motion to the whole shoulder. The apex of the scapula is marked by a pear-shaped concavity, which forms with the upper end of the arm bone the shoulder joint. This joint inclines somewhat forward, and is retained in position by an $f$-shaped bone, the clavicle, or collar bone, which extends from the shoulder blade inward to the breast bone, and is easily seen on the uncovered neck.

\section{Number of Bones in the Upper Extremity.-In} addition to the bones which attach the upper extremity to the body, the arm has thirty bones; one in the upper arm, called the humerus; two in the forearm, the ulva and raitius, lying side by side; eight in the wrist, the carpus; five bones form the hand, the metacarpus; and fourteen make up the thumb and fingers, the phalanges.

19. The Shoulder--At the shoulder we have a good example of what is called a ball and socket joint, and the degree of motion is here much greater than in any other part of the body. Almost every inch of the surface of the body can be reached by the fingers. To permit of such free motion, the socket of this joint is quite shallow, and its articulating surface linited, while the rounded head of the humerus has a large articulating surface. Dislocations more frequently take place in this joint than elsewhere, notwithstanding the provision existing to keep it in place by ligaments and muscles. 
This is due to the shallowness of the joint, to its exposed position, and to the varied functions of the arm.

20. The Elbow.-The elbow presents the best instance of the forward and backward movements of a hinge. It is formed by the lower end of the humerus and the upper ends of the ulna and radius. The arm bone at its lower extremity is wide and flat, while at its very end is a rounded, smooth surface, which fits into a deep notch in the ulna. The radius is quite small at this end, and forms very little of the elbow joint. With its smooth head it rolls against the side of the ulna as we turn the palm of the hand upward or downward.

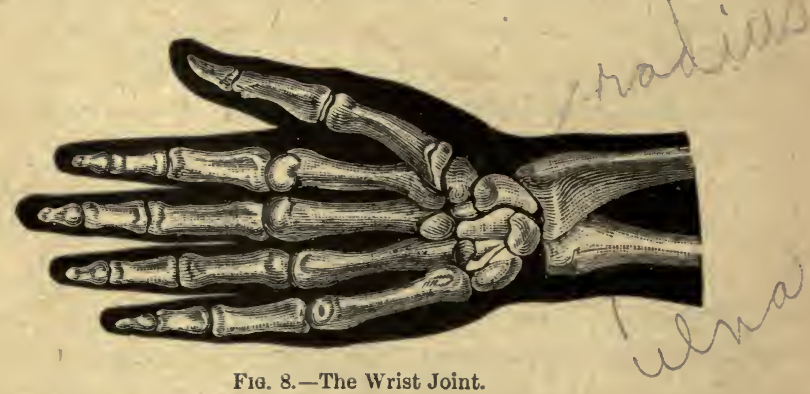

21. The Wrist.-When we come to the wrist, we find the relative size of the two bones is changed. Here the ulna is quite small, and rolls in a similar way against the side of the radius when the hand is turned. The end of the radius is sufficiently large to form the whole upper surface of the wrist joint. The bones of the wrist are small and mostly wedgeshaped. They are arranged in two rows of four bones each, and are so placed as to form a gentle curve when the wrist is bent, giving it a graceful outline, instead of a sharp angle, as in the ordinary hinge joint.

22. The Hand.-In the hand, including the thumb and fingers, we see displayed the most perfect and complete mech- 
anism. Its wonders have been the subject of frequent admiration, not only of the anatomist, but as well of many writers and students in the higher walks of literature and art. In a thousand ways the hand, in the daily course of life, serves the body with quickness and precision; now with the delicate touch of educated skill, then with the bold unerring stroke; now to bring to its use all that contributes to man's comfort and welfare, then to put away whatever may be dangerous or offensive to the body; now to grasp the weapon of defence or warfare, then to be reared aloft in mute adoration or in

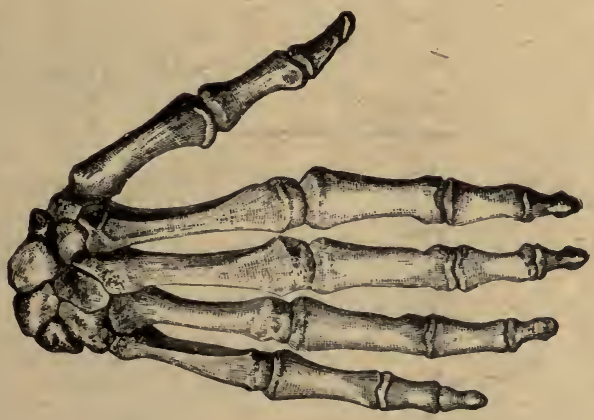

Fra. 9. - The Bones of the Hand and the Wrist.

inexpressible despair. The hand in itself is a harp of a thousand strings.

23. The Metacarpal Bones.-Four of these bones lie parallel, and form the framework upon which we have in front the palm of the hand. The fifth stands out slightly, to form the thumb. It has a much freer movement than the others, and is covered with muscles, forming the ball of the thumb.

24. The Phalanges.-The bones of the thumb, two in number, and those of the fingers, three to each, are called the phalanges. The forefinger, from its free position and relation- 
ship with the thumb, is the most useful and important of the fingers. The fingers are of unequal lengths. The longest is called the middle finger; the next in length is the ring finger, which is only slightly longer than the fore or index finger, while the little finger is the shortest. When the fingers are flexed to form the fist, the tips are almost on an even line. The number of hinge joints in the fingers, together with the additional side motion in the joints which attach the fingers to the hand, gives great freedom of motion to this member.

25. The Lower Extremities.-While the lower limbs have not the many uses of the upper, they perform the distinguishing functions of sustaining the body in the erect position, and of moving it from place to place at the command of the will.

\section{Number of Bones in the Lower Extremities.-} In each lower extremity there are thirty bones. In the thigh there is one bone, the femur; one in front of the knee joint, called the knee cap, kice pan, or patella; two in the leg, corresponding to the two in the forearm, and named the tibia and fibula; seven in the ankle, the tarsal bones; five in the instep, the metatarsal, and fourteen in the toes, the phalanges.

27. The Femur.-The thigh bone is the longest and strongest bone in the body. The shaft of this bone is round, like the handle of a club, and inclines towards its fellow at the knee. It is crowned at the upper end by a head and neck. The neck forms an angle with the shaft, like the turn on a walking-cane, so as to bring the head into the deep socket in the pelvic bone. The upper half of this ball-like head is covered with cartilage, and fits accurately into the socket, forming a ball and socket joint, much like the one at the shoulder, but deeper and stronger, though more limited in its movements. The head of the bone is held in place by strong ligaments attached around the neck. It is also 
steadied or swung in the cavity by a strong ligament running up froin the base of the cavity to the summit of the head, which holds it in place, and prevents jars and dislocations. Some of the muscles, also, which move the thigh bone pass over this joint, and help to keep it in place.

28. The Knee.-The lower end of the thigh bone is so large as really to suggest the idea of a war-club. Indeed, some savage tribes. use the thigh bone as a weapon of war.

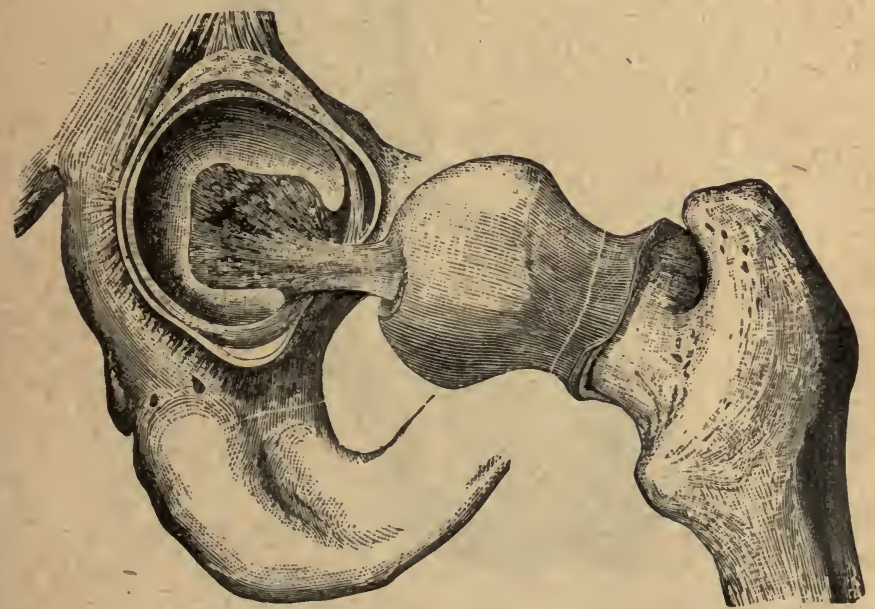

Fig. 10.-The Mechanism of the Hip Joint.

The large end of this bone rests upon the broad, flat end of the shin bone, forming the knee joint. This hinge joint is protected in front by a flat three-sided bone, the patella, or knee-pan. Although the knee is greatly exposed, the broad joint surface, with its strong ligaments and tendons, enables it to resist violence, and dislocation does not frequently happen. Indeed, fracture of one of the bones is more likely to occur. 
29. The Ankle.-This is also a hinge joint, and is formed by the lower ends of the two bones of the leg clasping between them, as sugar-tongs clasp a piece of sugar, the highest bone of the arch of the foot. The larger of the two leg bones is called the tibia, or shin bone. It has a sharp border down the front, which, being covered only by skin, is very sensitive to the touch, as every child knows who bruises his shins.

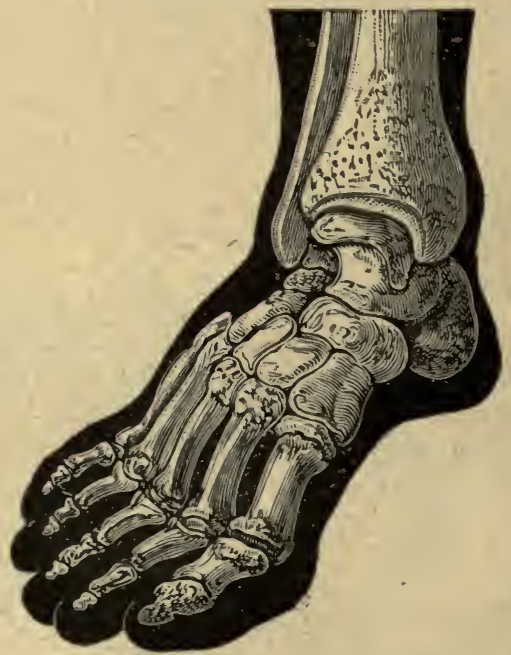

Fig. 11. - The Bones of the Foot and the Ankle.

Lower down, this bone forms the inner ankle bone. The fibula, or splint bone, is a long, slender bone lying along the outside of the leg, and ends below in what is called the outer ankle.

30. The Foot.-While there are eight carpal bones at the wrist, there are but seven bones at the ankle, called the tarsal bones. They are very irregular, and vary much in size, the 
largest keing the heel bone. As in the hand there are five metacarpal bones, so in the foot there are five metatarsal bones. They lie side by side, the inner one not being separated, as in the hand.

31. The Toes.-There are two phalanges in the great toe and three in each of the others, as in the hand, but they are smaller in size and more limited in their movements. It astonishes us sometimes, however, to see the extent of motion training will give to the toes. People born without arms, or who have lost them by accident, have been taught to carve, write, and even to paint with their toes. The bones of the foot, as a whole, are less movable than those of the hand. In its construction the foot is better aciapted for bearing the weight of the body than for varied movements. If a straight line be drawn from the lowest point of the heel bone to the ball of the great toe, it will be seen that a bony arch is formed, the top of which supports the body. It is by this arrangement we secure in walking the light, springy step, while in running, leaping or jumping, this elastic curved spring prevents any jarring of the body, and by the help of the many cushions, pads and ligaments we have already alluded to, carries the brain at the summit of this bodily structure almost without a tremor.

In animals whose habit of life it is to bound after their prey, in addition to this arching of the foot, there is placed under each toe a soft cushion or pad, to further break the shock they would otherwise receive. Examine the cat's paw. You will find it a good example of what we have mentioned here.

32. The Joints.-We have mentioned a number of the joints, and shown how necessary they are for the many movements of the body, and for the performance of the various duties man has to fulfil. We have noticed also that they vary in their extent of motion, according to the use for which 
they are intended. Some joints allow of motion in every direction, for example, the shoulder joint; others have only a to-and-fro motion, like the elbow ; while others again have

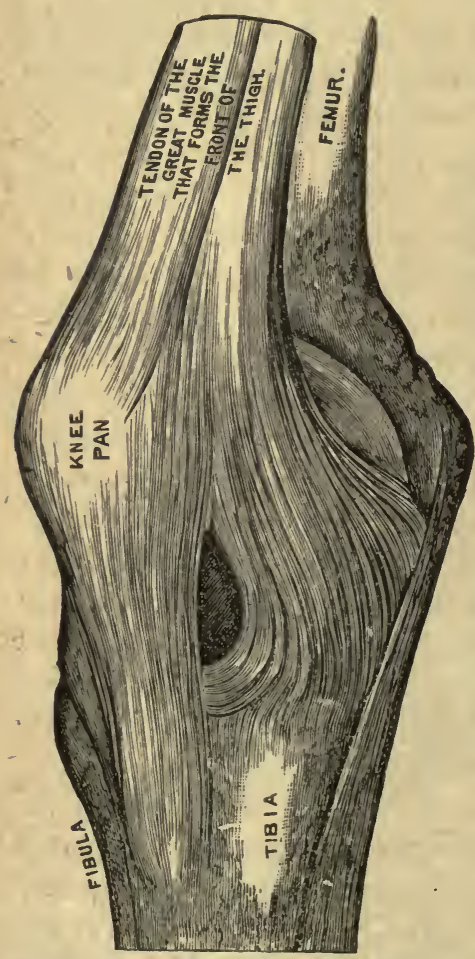

F19. 12.-The Right Knee Joint, showing how firmly it is bound about by ligaments. but little motion, as, for instance, the slight movement of each individual spine upon its next neighbor. Let us examine the construction of a joint.

Fig. 12 represents the knee after the skin and fat have been removed. The ends of the bones coming together to form a joint are covered with cartilage, more or less elastic, according to its thickness. This acts, in a measure, like a buffer, to arrest jars in jumping or in falling. The cartilage, in turn, is covered by a smooth lining, the synovial membrane, which is folded over the inner surface of the joint from one bone to the other, and forms a closed sac. Within the sac is a small quantity of fluid, the synovia, secreted by the membrane. This fluid lubricates the joint, like oil in machinery, and promotes free motion without friction. Outside this is a strong cap, holding the bones together. There are also extra bands, like bands of ribbon, stretching from one bone to another. Still outside all this 
are the tendons of the muscles which move the limb, and filling in and rounding off the joint there is always a certain amount of cellular tissue and fat. Last of all, the skin.

33. Care of the Body.-The degree of perfection with which growth and development from infancy to mature age take place, depends upon the care and attention the child receives. The infant is helpless. It is unable to walk. Its head is out of proportion to the rest of the body, its spinal column is almost straight, and its legs are relatively short. Soon it creeps about on all-fours, and gradually, as growth proceeds, changes of a distinguishing kind take place, and when adult age is reached, the full-grown man walks with his head evenly balanced on the spinal column, supported only by his lower limbs, while these in turn rest upon the arched instep and broad soles of the feet.

During infancy, suitable food must be provided, to enable nature to convert the gristly framework into bone. For this purpose milk alone is sufficient for many months. In childhood some restraint will be necessary, to avoid the taking of those things which tend to poison the system and stunt the growth of the body.

The waking hours of a child, when in health, are spent in constant motion of body and limb. This exercise is necessary to promote the growth of bone and muscle. Equally necessary are the long periods of sleep the healthy child will take daily, in order that the brain may rest and develop. As the child gains power over its legs, it will begin its efforts to stand and walk; but it should not be helped or encouraged to do so too early. It should be allowed to "find its legs," and not be put upon them before they are strong enough to bear the weight of the body. Like a green twig, the soft bones of the leg may bend, and cause "bow legs," so often met with. Children should also be watched in their habits of sitting. When weary, they may slide down into the seat, 
or incline to one side or the other, or bend over too much when reading, writing, or at other work. Round shoulders and curved spines are too frequently the outcome of children

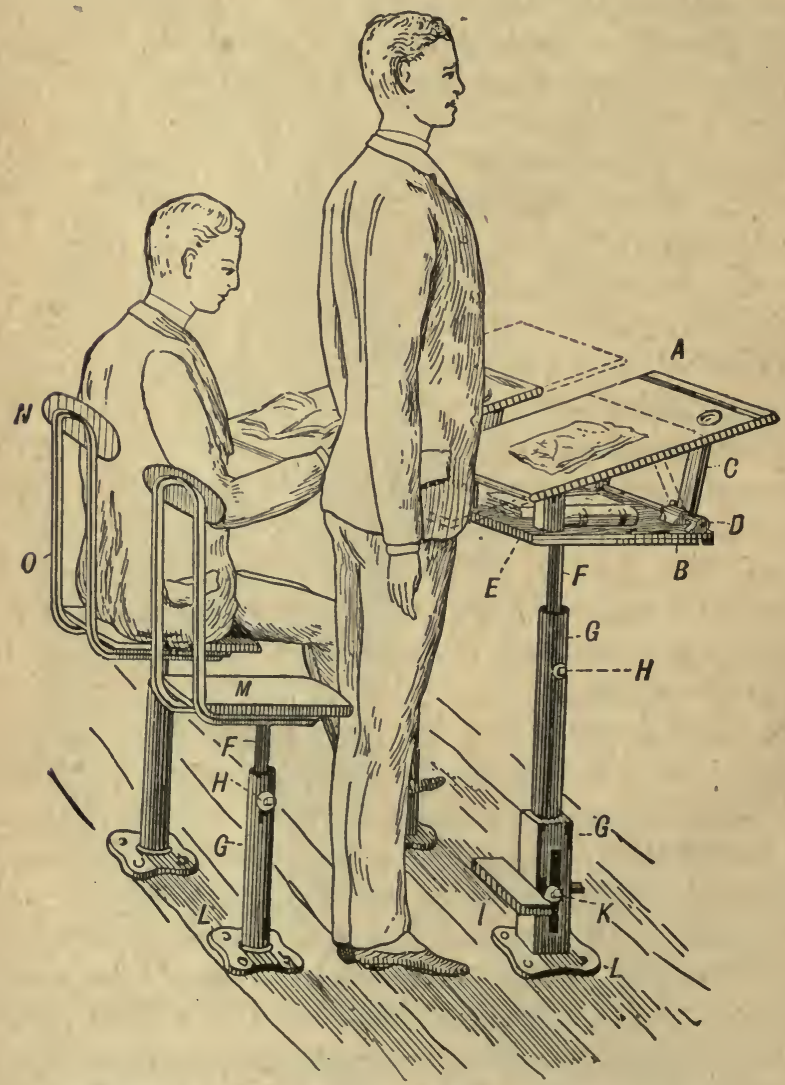

Fia. 13.-Adjustable Seat and Desk, the latter with sliding top.

being allowed to fall into such positions as these. Very often it is owing to faulty desks. If a desk is too low, it causes a forward stoop. If too high, the shoulder is likely to be too 
much elevated, causing a side curve to the spine. Desks should be regulated according to the size of tho pupil. The teacher should remember that the school period is also the growing period of a child's life, and make frequent changes in the seating of his pupils. These changes can be most readily made by having adjustable seats and desks, as in Fig. 13.

The seat $M$ and desk $B E$ are each supported on a sliding pin $F$, which works in a socket $G$. The seat and desk can thus be raised or lowered, according to the size of the pupil, and may be fixed at any height by the set screw $H$. The foot-rest $I$ may be raised or lowered in a similar manner. The top of the desk is attached to the movable rest $C$, the hinge at $D$ allowing the desk to slide forward to $A$, and giving the child room to stand immediately in front of his seat.

It is astonishing how easily the soft and gristly bones of a child bend, and even grow out of place. Long continued strain or pressure is sure to have this effect. We have all heard how Chinese women bind the feet of the baby girl with strong bands, to prevent them from growing. These poor girls, when grown into women, are not able to move about with ease and comfort. This foolish custom is common in China, because it is thought low-bred for women to be useful and have natural feet.

Let us compare this with what we see daily amongst our own people. Is it not equally as inconsistent for us to wear tight and high-heeled boots and shoes because it is the fashion? They throw the weight of the body forward, and force the foot down on the toes. This has the tendency not only to crowd the toes out of shape, but

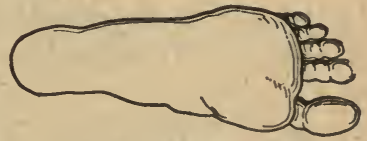

Fig. 14. - Natural Shape of the Foot.

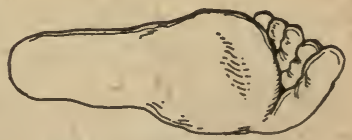

Fre. 15.-Distorted Foot. 
to cause corns, bunions, ingrowing nails and swollen joints. It also makes the natural gait stiff and awkward. Children should wear comfortably fitting boots or shoes, with broad toes and low, wide heels.

\section{Effects of Alcohol and Tobacco on the whole} Framework.-Individuals vary in form and height, according to the shape and length of the various bones. The size of the body depends upon the size of the framework. It is not. wise to risk our chances to become well developed and manly in appearance, by indulging in habits that are injurious while young. Neither the drinking of alcohol in any of its many forms, nor the using of tobacco in any way, is a manly act, nor does either help in any sense to promote the growth and development of our bodies.

It has often been observed that children of intemperate parents frequently fail to develop into manhood or womanhood. They may not be deformed, but their growth is arrested, and they remain small in body and infantile in character. One physician reports a child five years of age, who measured only two feet three inches, and weighed twenty-two pounds; and he says further, that he has known such children to live to twenty and over, and still remain permanent infants. Such are examples of a species of degeneracy, and are evidences of the visiting of the sins of the fathers upon the children, which may extend even unto the third and fourth generations. 


\section{CHAPTER III. A}

\section{THE MUSCLES.}

1. The Structure of Muscles.-The lean meat of the dead animal, as seen cut up in a butcher's stall, or when cooked and brought on the table for dinner, is what we call muscle. In a joint or roast of beef there are several muscles. Each is surrounded by a delicate, thin membrane. This membrane or tissue is loosely attached, and serves to hold the muscle together and to separate it from neighboring ones. From its inner surface this membrane sends off partitions, which divide the muscle into several bundles. The larger bundles are divided into secondary ones by a finer membrane, and these are again divided into

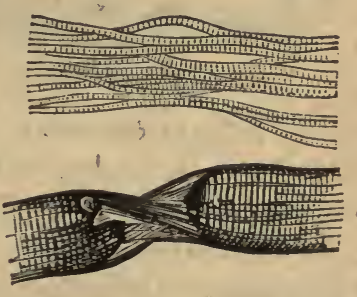
fibres. Looked at under the microscope, it is discovered that even these fine fibres are made up of a number of very. fine threads or fibrils, and that each fibril is simply a row of cells, like a string of

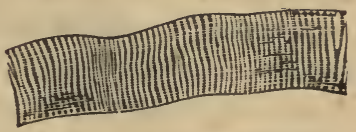

Fig. 16.-Portions of Muscular Fibre highly magnified.

fine beads. This gives the fibril a striped appearance.

2. How Muscles Work.-A muscle has the power of contracting and relaxing. Each little fibre, under nerve influence, can be made to draw itself together, becoming shorter and thicker, and this change taking place almost at the same time amongst the thousands of fibres in a muscle, the result is that, instead of lying loosely extended along the limb, the 
muscle is drawn up into a large solid lump at its middle. Now, if one end is firmly attached to a bone, its origin, and the other to a strong tendon which passes down to the bone below, its insertion, the lower bone will necessarily be drawn

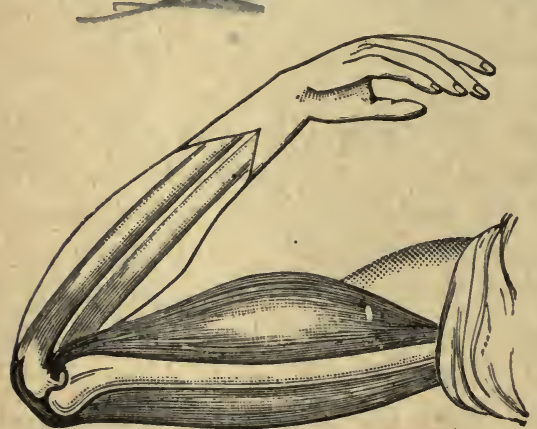

FiG. 17.-Biceps and Triceps Muscles. towards the upper. This may be understood by bending the elbow with the arm bare. As the body of the biceps muscle swells out and becomes hard and firm, the forearm is drawn up. When the nerve influence is withdrawn, the muscle relaxes and lies evenly in its place.

3. Arrangement of Muscles.-The muscles are usually arranged in groups, and these have opposing groups on the opposite side of the limb. Take, for example, the leg. One set of muscles bends the knee, so that the leg is flexed upon the thigh. These are called flexors. Another set brings the leg forward, and extends it out until it is in a line with the thigh. These are called extensors. It is by this nice adjustment of opposing systems of muscles throughout the body that we are able to stand erect and to move about with ease and comfort.

This even action of the many pairs of muscles all over the body also maintains its symmetry. If one muscle or group of muscles acts more strongly than the opposite, the limb is twisted. This is the case in the deformity known as clubfoot. The foot may be drawn outward by the muscles on the outside of the leg acting more strongly than those on the inside, or it may be drawn inward if the inner muscles are stronger than the outer. In the same way the spine may 
be pulled orer or curved to one side by the inuscles of that side overcoming those of the other. Club-foot is a deformity at birth, while side curvature of the spine is very often the result of sitting daily at an unsuitable desk or form at school.

The proper action of the muscle depends upon the nervous supply. If the nerve branch to a muscle be injured or diseased, its action is interfered with, and the proper balancing of a certain pair of muscles lost. Squinting of the eyes may be caused in this way. If the nerve on one side is divided or seriously injured, the muscle is powerless, and a state of paralysis exists. For instance, one side of the face may be paralyzed when the muscles of the other side, having no opponents to act against them, draw the mouth over to that side, and give a distorted appearance to the face.

Deranged muscular action may be due to injury or disease of the nerve centres. There exists a close sympathy not only between the end nerves and the nerve centre, but also between different and distant parts of the whole system. This is seen in various affections. The irritation of a "cutting" tooth in the infant may cause general convulsions. This is reflex or transferred action. The control of the brain or spinal cord may be imperfect, and the muscles contract irregularly. Instead of the measured contraction, there is the spasmodic action of a group of muscles or of the whole body. Sometimes the muscle contracts, and has not the power to relax. If it is in the face, we have lock-jaw. This is a serious and very often fatal affection, and it is sometimes brought about by a very simple injury, such as the prick of a pin or a fish-hook in the finger. In chorea, or St. Vitus' Dance, certain muscles have ceased to be obedient to the will, and persist in irregular contraction, on account of the diseased condition of the nervous system; so likewise in shaking palsy. The physician meets with various forms of 
disease due to a want of harmonious action between the muscular and nervous systems.

4. Classification of Muscles.-A very large number of the muscles of the body are wholly under the control of the will. These are called voluntary. A certain number act independently of the will. These are called involuntary. As instances of each class, the muscles of the extremities are voluntary, while those which send the food along the alimentary canal are involuntary. Certain muscles partake of the character of each kind, as the respiratory. One may hold his breath for a time by a voluntary act, but breathing proceeds without any effort of the will, particularly during sleep. Although we have no will-power over the involuntary muscles, yet they are under the control of the nervous system.

The voluntary muscles are also known as striped. They are so named from their appearance under the microscope, as already pointed out. The involuntary are unstriped, being made up of slender spindle-shaped cells, which do not appear striped under the microscope. They are not attached to bone. These muscles are made to act by some stimulus. Food, for instance, the taking of which into the mouth and chewing is voluntary, when it passes a certain point is beyond the control of the will. It acts as a stimulus to the involuntary muscles of the gullet, and is passed along to the stomach by a worm-like motion.

5. The Levers of the Body.-Special reference to a few of the voluntary muscles will show the principle upon which they cause movement of a limb. The movement is accomplished by leverage. There is a weight to be moved, a fulcrum for the lever, and the application of the power. The limb or bone is the weight, the joint is the fulcrum, the power is in the muscle.

The lever of the first kind, where the fulcrum is between the weight and the power, is not common, but is seen in the 
nodding of the head, the fulcrum being at the articulation of the skull with the first vertebra. The second kind of lever, where the weight is between the power and the fulcrum, is also uncommon in the body. An instance of this is seen when the body stands on the toes. In this case the fulcrum is at the point where the front of the foot rests upon the ground, the body forms the weight, and the large muscles of the calf of the leg constitute the power. In assuming this position the calf of the leg becomes hard and firm. The third kind of lever, where the power is between the fulcrum and the weight, largely prevails in the human body. In this form of lever the power is applied at a disadvantage, but it is the only kind suitable with a view to economy of space and compactness of body. This variety of lever is well shown in the flexion of joints. The bending of the elbow is by the action of the biceps, which is attached above by two heads to the scapula, and below to the radius, a short distance from its head. The forearm and hand are the weight, which is increased by any object the hand may hold. The fulcrum is the elbow joint.

In walking, rowing and swimming most of the voluntary muscles are at work, and with healthy, properly developed muscles we see exhibited the perfection of motion, power and grace.

6. Tendons.-The strong, flexible, inelastic cords or bands which we see playing along the back of the hand when we move the fingers, are called tendons. Follow them up the limb, and we find they each belong to a muscle. In fact, each tendon in the body is a sort of rope, by which the muscle pulls upon the part it is intended to move. It is an arrangement by which muscles can be placed in unexposed positions and nicely grouped, so as to give symmetry to the limb. These cords take up less room in the hands and fingers, for instance, and do away with the bulky appearance 
muscles would give. In passing over exposed parts and over joints the tendons occupy less space, and are less sensitive to pain when pressed upon.
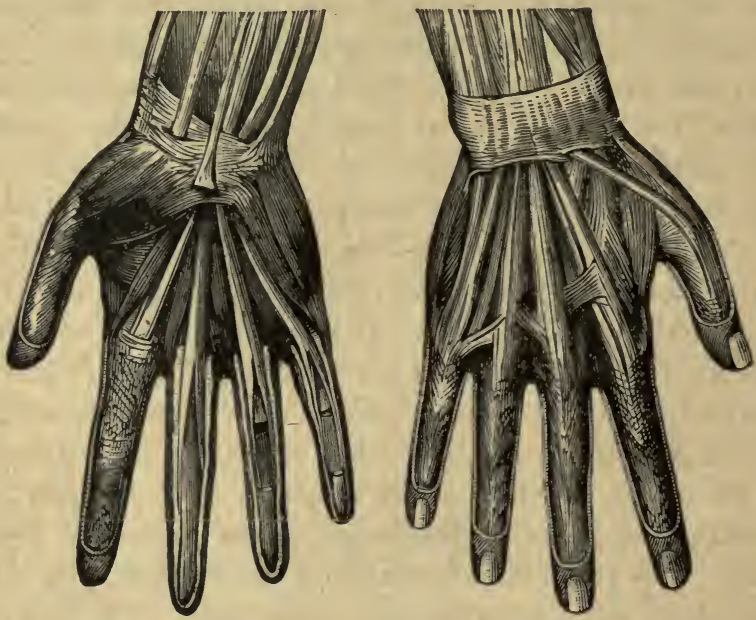

Fia. 18. - The Muscles and Tendons of the Hand.

The tendons vary in length, in size and in strength, according to the work they have to do. The longest and strongest tendon in the body is the one by which the large muscles of the calf of the leg draw upon the heel. Stand upon the toes, and this tendon can be distinctly felt above the heel. It is called the tendon of Achilles. The large muscles at the back part of the thigh are attached by tendons to the bones of the leg. These stand out when we flex the knee. They form the hamstrings. The tendons of the hand and those of the foot can be very distinctly seen as we move the fingers or toes. The tendon of the biceps can be easily felt in front of the elbow. Some muscles have very short tendons. The large triangular muscle fitting over the shoulder, and called the deltoid, is attached by a short tendon to the arm bone. 
Occasionally, instead of having a long tendon, the muscle itself is long. The tailor muscle, as it is sometimes called, extends from the upper part of the hip bone to the inner surface of the knee. This is the longest muscle in the body.

7. Care of Muscles.-At all periods of life the wellbeing of the muscular system is most important. To secure healthy development of muscles the body generally should be in a state of health. The blood supplied to the muscles must possess the properties necessary for growth and repair, and the products of wear and tear must be promptly removed. Close attention should, therefore, be given to food and drink. Equally important are pure air and proper exercise. When the athlete is under a course of training, strict dietary rules are observed, and temperance in both food and drink is practised. Perhaps no better argument to show that alcoholic drinks are injurious is afforded, than the fact that persons training for contests of muscular strength absolutely abstain from all such beverages.

Without exercise the muscle will not only cease to develop, but it will degenerate, and finally nearly all its elements will be absorbed. We see this waste of muscle, and consequent loss of strength, in an arm that has been carried for weeks in a sling, owing to a fracture of one of the bones. This change is even more marked in a paralyzed limb, where power over the muscle is absolutely lost. For a time the muscle retains its natural size and condition. Gradually, however, it undergoes changes, and in time it wastes away, until the limb is almost "skin and bone."

The incessant action of the little child while awake is intended to promote the development of muscle. By this constant movement of its limbs it acquires the power to carry objects to its mouth, and then to creep, and finally to walk. The child should be dressed with a view to the greatest freedom of motion, and every opportunity afforded for 
daily exercise in the open air. This daily exercise should be kept up during the whole period of youth from childhood to maturity, and unless the child is restrained or kept too closely confined in the school-room, its natural inclination is towards activity of limb. It is possible for a child, however, to go beyond the bounds of healthy exercise. It may be too violent or kept up too long for its strength. When a boy comes in so tired from play that he does not want any supper, and seizes the earliest opportunity to steal off to his bed, that boy has done more harm than good by exercise.

After maturity there are degrees of healthy development. A limited amount of exercise, such as is necessary in going about the daily duties of life, will keep the muscles healthy and in a condition to furnish a moderate degree of strength. The careful and constant training of the athlete, on the other hand, will greatly increase the size of his muscles and give him power to perform almost miraculous feats of strength. Look how the daily vigorous exercise of some particular region of the muscular system will develop that region. The powerful right arm of the blacksmith is the production of a constant wielding of the heavy hammer.

8. Effects of Alcohol.-We have already referred to the fact that those who wish to attain to the greatest perfection of muscular strength and agility know that they must abstain entirely from alcoholic liquors. Alcohol lessens muscular strength exactly in proportion to the amount taken. For a very brief period after taking a glass of liquor there may be a slight increase in muscular force, but so soon as sufficient alcohol is taken to show its constitutional effects, muscular force begins to fail ; and as sip after sip or glass after glass is taken, the muscles become more and more helpless, and at last the inebriated man sinks beneath the table, an example of the complete triumph of alcohol over muscular power.

It now remains for us to speak of certain changes which 
take place in muscular tissue from the use of alcohol. We have observed that if a muscle is not exercised it will gradually lose its natural character, and if not used at all it will finally lose its power to contract. Another important change which now and then occurs is a gradual alteration by which oily matter finds a place in the fibres of the muscle. The muscle loses the power to contract, becomes soft and flabby, and is easily torn across. This disease most commonly affects the heart, and is known as fatty degeneration. It is only one of the many evil effects of alcoholic drinks. The daily and oft-repeated use of beer is likely to cause this disease, especially when little or no exercise is taken.

\section{Action of Alcohol and Tobacco on Muscular} Sense. - The sensation by which we know the position of our limbs, also the force and the extent to which they have been moved, is called muscular sense. We use this sense in judging of weights. By experience we know how much force to use to lift an object, or how to balance ourselves against an outside force. In walking we throw ourselves forward, and to prevent falling we carry one leg in front of the other. From constant habit we do this without thought. Muscular sense enables us to do so. The muscles are educated. But this training, this education, is all upset by indulgence in alcohol. The fingers fail to do work they have been trained to do almost without mind influence. The voice fails, and the lips and tongue fail to utter words clearly; even walking, the lifelong habit, is imperfect, and the drunken man staggers.

Only in a less degree does tobacco weaken the nerve control over muscles, causing unsteadiness of hand, relaxation of muscles generally, and want of firmness in gait. 


\section{CHAPTER IV. \\ THE SKIN.}

1. The Covering of the Body.-The body is ererywhere covered and protected by the skin. It varies in thickness, according to the use of the part. It is also loose in some places and close-fitting in others. In the fingers and palms it fits snugly. The scalp, or skin of the head, is quite loose. This makes it a better protection to the brain, for a blow that might break the skull sometimes glides off without further injury than carrying a portion of the scalp with it.

2. The Epidermis.-There are two layers of skin. The outer, called the scarf-skin, cuticle or epidermis, serves as a covering to the second layer, the true skin. The epidermis protects the delicate little blood-vessels and the net-work of sensitive nerves which form a large part of the true skin. The sense of touch, which belongs to the true skin, is only bearable when the sensation to the nerve is made through the outer coat. Strip off this outer covering, and the part is sensitive to pain rather than to touch. The two layers are not easily separated. If we receive a burn sufficiently severe to form a blister, the fluid which collects raises the outer from the inner layer. The outer layer consists of a hard, horny-like material, the surface part of which is constantly being detached in thin, flat scales. Thus the skin is all the time wearing out and being cast off. It does not become thinner, however, as this loss is regularly supplied from the true skin. It sometimes happens that the outer skin is worn off faster than it can he supplied, and the part becomes tender. Put a man at handling bricks for the first 
time, and before the day's work is done his finger-ends are worn tender. The ruagh bricks wear away the epidermis faster than the new supply from the true skin is formed.

The skin in those parts of the body most in use, as the palm of the hand and sole of the foot, is thick and hard. In the hand of the laborer the palm becomes horny. In the barefooted boy the sole of the foot grows thick and tough. In ill-fitting boots parts of the foot are so pressed upon and rubbed that corns and bunions are formed.

In the deeper portions of the epidermis are minute cells containing coloring matter, called pigment cells. This coloring matter in the white race is of a pinkish hue; in the negro it is brown or black. The varying shades from white to black are owing as much to the thickness of this layer of coloring matter, as to the coloring matter itself. The sun's rays affect these pigment cells, rnaking the skin darker. The tanned skin in summer is much darker than the skin of unexposed parts. The inhabitants of the sunny south are

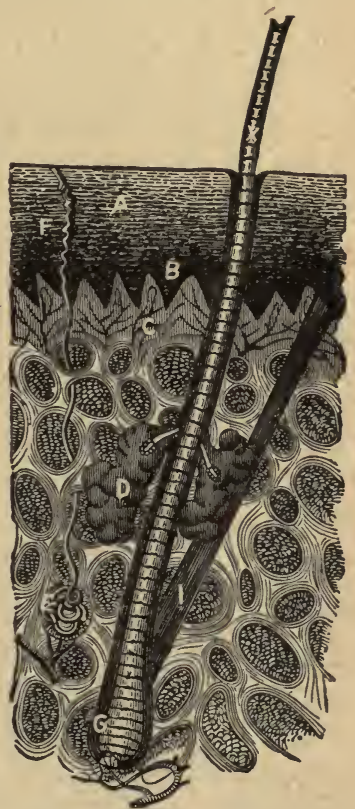

Fig. 19.-Section of Skin: $a$, superficial layer and, $b$, deep layer of the epidermis; $c$, papillæ; $d$, oil gland; $e$, sweat gland; $f$, spiral termination of sweat duct; $g$, hair bulb; $h$, hair shaft; $i$, muscle which erects the hair. darker than those of more northern regions. Sometimes the action of the sun affects the coloring matter in spots, and freckles are the result.

3. The True Skin.-Beneath the epidermis is the cutis, or true skin. It is formed of fine elastic tissue. This tissue 
becomes looser and more open in the deeper parts, so that the whole skin can be pinched up from the flesh. Forming a part of the true skin are the nerves, blood-vessels and oiands for secreting the sweat and oil. It is the white fibrous tissue forming the body of the true skin, or dermis, in animals, which is made into leather by action of the tannin contained in the oak bark used by the tanner. The outer surface of the true skin is markeri by small elevated points, the papillc. These papillæ are well supplied with loops of capillaries, and they have special nerve endings. They are very numerous all over the body, but are more prominent and more thickly set in some parts than in others. On the palmar surface of the hand and fingers, where the sense of touch is most acute, they are very abundant, and are arranged in rows. These rows are visible to the naked eye. Where these papillae are most densely set, the finest needle cannot penctrate the true skin without causing pain nor without drawing blood.

4. Glands of the Skin.-There are two kinds of glands in the skin, lying deep down in the loose tissue. One is the gland for secreting sweat, and the other is the oil gland, found in connection with the hair. The sweat gland consists of a minute tube coiled up below, and running in a zigzag manner to the surface of the skin. These glands are found in all parts of the body. In some places they are more plentiful than in others. In the palms of the hands and the soles of the feet they are very thickly set. They are more plentiful on the forehead than on the cheek. The total number in the human body is said to be between two and three millions. The most important duty these glands have to perform is to regulate the heat of the body. Heat is carried off from the body by the process of evaporation. This evaporation is regulated according to the amount of heat the body finds it necessary to get rid of. The sweat poured out on the skin evaporates and cools the surface. Perspiration is constantly 
going on, and while the evaporation is equal to the amount of fluid poured out the sweat is not seen. This is called insensible perspiration. When the body becomes heated, and the sweat increases so as to form in drops, it is known as sensible perspiration. Under certain nervous influences the skin becomes bathed in sweat, as in the cold sweat of fear. The quantity of sweat poured out varies with the season. In hot weather it is much more profuse than in cold. Violent exercise increases the flow, so also will too much clothing. Sudden changes in the weather, or in the amount of elothing, or sitting in a draught after being heated, are very apt to arrest evaporation and cause a chilliness of the body, followed by a "cold" or by "congestion of the lungs."

Perspiration is a colorless fluid, consisting mostly of water. It has a peculiar odor, more marked in some persons than in others, and more in some races of people than in others. There is also solid matter in sweat. Salt can be detected by tasting it. The worn-out tissues of the borly and of the skin are found in it; but these vary very much, according to the attention paid to the skin.

5. The Oil Glands.-Besides the sweat glands, there are also oil glands in the skin. These are little sacs found in connection with the hairs, and clustering around them, sometimes in pairs, but often as many as from four to eight to one hair. Each little sac communicates with the hair by a duct, along which the oil flows to the root of the hair, and then finds its way out to the surface of the skin. It is nature's dressing for keeping the hair from becoming crisp and brittle, and for keeping the skin soft and moist.

These glands are more numerous on the face and where the hair is thick. They are not usually found where there is no hair, as on the palm of the hand. It often happens that some of these glands get blocked up, forming unsightly little 
black specks on the face, or they may increase to quite a size producing the large lumps sometimes found on the head.

6. The Hair.-The hair and nails are in reality outgrowths of the epidermis. The root of the hair, called the hair follicle, passes obliquely down to the loose cellular tissue. It is a portion of the true skin dipping down, forming a little hollow, from the bottom of which rises a tiny bulb. The cells of the epidermis line this hollow, and form around the bulb. They are pressed together lengthwise, and being added to from this little bulb, they form a slender tube, which pushes its way out beyond the surface of the skin. (Fig. 19.) Very small muscles extend from the side of the hair follicles to the skin close by. It is the contraction of these minute muscles which causes the hair to stand in moments of fear.

The color of the hair is due to the presence of pigment matter. It is said that the many shades of color in the human hair are owing to the mixture of three colors-black, yellow and red-in different proportions. As age advances, the pigment gradually disappears, leaving the hair white. Instances are recorded where, from some strong emotion, the hair has lost its color in a single night. This would show that even the hair is under the influence of the nervous system. The welfare of the hair is dependent on the condition of the skin. The roots of the hair in a healthy skin will be likewise healthy. Pulling out a hair by the root does not prevent its growing again. To stop hairs from growing, as is sometimes done where it disfigures a lady's face, it is necessary to destroy the hair bulb. This is a very delicate operation.

Baldness is a name applied to the want of hair on the top of the head. There are many causes for this loss of hair, but perhaps the chief amongst them is the tendency there is in some families to the early loss of vitality in the hair. Want of proper care, in allowing the scales from the skin and oil from the glands to become crusted on the scalp, is another 
cause. On the other hand, too much care, in the way of too frequent brushing, combing and shampooing, is the reason given by some writers on the subject for the early falling of the hair. To prevent baldness, keep the head clean, by avoiding the use of oil or any of the so-called hair dressings, and by thoroughly washing the head occasionally. Have the hair cut regularly - say, once a month-and comb or dress it twice, or at most three times, a day. Use light coverings.

7. The Nails.-The horny material forming the nails on the fingers and the toes is a development of the epidermis. The root of the nail consists of a furrow in the true skin, and the cells of the epidermis so arrange themselves in this furrow as to shape the nail and give it the horny character. The body of the nail rests. upon the true skin, the bed. The growtl of the nail takes place from the root by constant addition of flattened cells, and the thickness is increased by similar growth from the bed. The nail is intended to give protection to the fingers and toes when in use. A nail may be torn off and again grow, unless the bed is destroyed. It may grow in an irregular manner, from the effect of an injury, or more commonly, in the case of the toes, from the pressure of tight boots. The free borders of the nail at the sides of the toe are turned down by this pressure, and; if continued, form the ingrowing nail.

8. Care of the Skin.-Think of the amount of service rendered by the skin.(1) It covers the tender flesh; it regulates the heat of the body by the sweat it pours out, and smoothes and softens its surface with oil ; it assists the lungs and kidneys in carrying off waste material, and it absorbs or takes into the system, to a limited extent at least, whatever may be left long in contact with the body. Knowing all this, should we not look carefully after its welfare?

The scales of the epidermis are constantly falling off, and, mixing with the oil, form a sort of crust on the body. Dust 
or dirt is added to this, and the glands get choked up, and are no longer free to do their duty. The work that belongs to the skin falls to the lungs or kidneys, and overtaxes them, and thus the health is interfered with. Cleanliness of the skin is, therefore, a matter of the first importance.

In health nature will do her work, but the individual should do his. Regular daily washing of the skin is necessary. To omit washing the hands and face is to neglect the first principles of cleanliness and decencý. It would be a great advance in good breeding if a rule to wash daily the whole body were observed. The hands and face, being exposed, are apt to get dirty, and require more frequent attention than the unexposed parts of the body. Often, too, the hands become much soiled from work. In addition to an abundance of water for cleansing them, it is necessary to use soap, an alkaline substance which dissolves oils and fats, and hastens the removal of particles of grease and dirt. For the unexposed parts of the body, water alone, used daily, is sufficient, with a good hand-rubbing of the skin after drying, to brush away the loose scales of epidermis.

9. Bathing.-Cleanliness of the skin is not the only object in bathing. All-important as it is in this respect, it has other beneficial effects. A bath gives increased strength and vigor to the whole system. On rising in the morning, a plunge into a cold bath is to the healthy and robust an invigorating tonic. The less rugged and strong may not receive the same benefit. They may even be injured by it. Cold water applied to the skin causes the blood-vessels to contract, and the body becomes pallid. Reaction soon follows, with an increased redness of the skin and a pleasant glow of warmth. If reaction is slow and so feeble as to subside readily, the bath is too cold, and should not be prolonged. The body should be quickly dried, and rubbed vigorously with a coarse towel until well reddened and all feeling of shivering passes off. 
For all such cases it is better to begin with a warm bath, and day by day make it couler, until such a temperature is reached where reaction is prompt and the bath is refreshing. The degree of coldness that may be safely reached in this way will vary with the age and strength -of the bather. Young children and old people, unless strong and vigorous and well used to it, cannot take a cold bath without sorne risk. The healthy and robust can take a colder bath and endure more exposure to cold water than the weakling.

It would be difficult to say how long a person should stay in a bath. Age and strength are here also the best guides. So long as a prompt reaction, with a pleasant feeling of warmth, is experienced, the bath has not been too long. This is a safe rule. Warm baths are never so refreshing as cold, and though the warmth tempts us to linger, they should never last beyond four or five minutes. Young children should be given a warm bath two or three hours after their morning meal. Young people and grown persons who, from preference or from delicate health, take warm baths, should always do so just before retiring at night. There is little risk of taking cold if they go to bed at once.

It is not always convenient, nor even possible, to have baths with hot and cold water attachments, such as are found in most dwelling-houses in a city, yet it is not necessary to go into a bath to obtain the benefit desired. A tub of water, with a sponge and towel, will answer as well, and is always available. A daily washing of this kind, followed by brisk rubbing, acts as a stimulus, and to some extent fortifies the skin against any evil effects of exposure to cold during the day.

Too frequent bathing is injurious. A general bath every morning in the summer, and a cold sponge-bath every morning in winter, with a hot bath at night once a week, will keep the body clean, promote the action of the skin, and strengthen and refresh the whole system. More than this is 
apt to draw off too much heat from the body and lessen its vitality.

10. Some Common Skin Affections.-The skin is subject to a variety of diseases. Some of them are due to local causes, such as the irritation of vegetable or animal poisons. The sting of a nettle, the effect of poison ivy, the sting of a bee, or the bite of a mosquito, are examples of these. Certain parasites find in the hair and skin suitable ground for lodging. They grow and multiply, and often cause much irritation of the skin. They are contagious in the sense that they are easily transferred from one child to another. Constant care and watchfulness are necessary to prevent these vile little creatures from infecting a school.

Stoppage of an oil gland may produce a pimple. If many are affected together, a sort of boil may result.

The skin may become congested or inflamed from too much heat, as in scalds or burns. The hot sun of summer will burn and inflame parts of the body not accustomed to being exposed to its rays. Erysipelas (St. Anthony's Fire) is an inflammation of the skin, which spreads rapidly and is often very severe. It is contagious, and should be carefully watched.

11. Effects of Alcohol on the Skin.-We will find, when we come to speak of digestion, that a part of the food goes to supply the heat of the body. It is a sort of fuel that is regularly fed to the system to keep the body warm, just as a stove is kept going by fresh supplies of coal. In a stove the amount of heat is regulated by opening and closing of draughts and dampers. In the body the heat is kept at a constant standard by the opening and closing of the pores of the skin. The chief duty of the skin is to regulate the heat of the body. Does alcohol affect the skin in any way, so as to interfere with the proper discharge of this duty?

The first effect of alcohol upon the skin is to dilate the 
small blood-vessels. This allows the warm blood to flow towards the surface in increased quantities. The result is a flushed appearance of the face and hands, and of the skin generally. This flushing causes the body to feel warmer, and indeed the surface is warmer. The body heat is brought more to the surface, and the sensation leads to the feeling that the body is warmer. To "take just a drop to keep out the cold" might, if looked at thus far, seem justifiable, and the old belief that alcohol warms the body might seem true.

Let us go a step further. Just as the fire in the stove, intended to warm a room, first heats the surface of the stove - and then radiates to the air of the room, so the heat which has reached the surface of the body radiates into the atmosphere. It passes off more rapidly than it should do, and the body is actually cooler. Alcohol so affects the nerves of the skin that they lose their control over the surface circulation, and heat is lost faster than it is supplied. The experience of Arctic explorers, and of people who live in the colder regions of Canada and other northern climates, fully bears out this statement. Alcohol is now strictly forbidden when great exposure to cold is to be encountered.

By interfering with the surface circulation alcohol also interferes with the proper nourishment of the skin. Frequent use of liquor causes a frequent flushed condition of the skin. The blood-vessels in certain localities become permanently dilated. The skin of the face and nose in time assumes a dull and blotchy appearance, readily recognized as the "port-wine nose" or the "brandy nose." Dark brown spots appear on the skin in different parts. There is a stronger tendency to skin diseases generally in the case of those who use alcoholic drinks, and when established, they are more chronic and more difficult to manage.

Tobacco alss affects the skin, giving it a peculiar dry and sallow look. 


\section{CHAPTER V.}

\section{DIGESTION.}

1. Need for Food.-It has been explained why the body requires daily food: in the first place, to build up the body, and in the second place, to supply material for renewing the tissues, which are constantly wearing out. The arrangement provided for converting the various food stuffs into blood is as perfect in design as we have seen the construction of the body to be. An immense tube, beginning at the mouth, passes through the body. This tube is not of uniform size. In some places it is dilated, while in others it is quite narrow. The gullet, for instance, is a narrow tube, while the stomach is an expansive sac. This alimentary canal, as it is called, is lined by a-thin membrane, a continuation of the skin. It is seen in the lips, where a sharp line marks the boundary between the skin and this reddish mucous membrane. Outside the mucous membrane are other layers, which go to form the walls of this canal. The muscular layer, or coat, by involuntary action passes the food along the tube. Numerous blood and lymphatic vessels form a part of the walls. These lymphatics are located in the intestinal tube for absorbing and conveying into the system the nutritious portions of the digested food. We find along this canal also the openings of the ducts of the various glands, which provide important fluids to aid in the process of digestion. The glands themselves are mostly situated in the walls. Some, like the salivary gland, are placed at a distance from it.

That part of the alimentary canal extending from the lips to the stomach, may be divided into the portions forming the 
mouth, the pharynx, or throat, and the gullet, a long, narrow tube, passing down through the back part of the thorax and piercing the diaphragm, where it dilates to form the stomach.

2. The Mouth.-The cavity of the mouth has for its boundaries the lips and cheeks in front and at the sides; below, the tongue and lower jaw; and above, the palate. The palate consists of two portions; the front part, resting on the upper jaw, is the hard palate, or roof of the mouth. It separates the mouth from the nasal cavity. The back part, the soft palate, consists of mucous membrane folded upon itself. It is continuous with the floor of the nasal cavity. The soft palate arches downward, and forms a partition between the mouth and the pharynx. In the middle of the lower border of the soft palate is a prolongation, like an inverted cone, the uvula, often called the palate.

3. Mastication.-The first steps in the process of digestion are taken in the mouth. The food is ground up into a pulpy mass by the teeth. While this process called mastication goes on, the saliva is poured into the mouth and mixes with the food. The tongue also aids, in a mechanical way, by keeping the food between the teeth.

4. The Teeth.-These hard, bone-like structures do not appear until some months after birth. They are arranged in two semi-circular rows, the upper and lower teeth. The former are firmly planted in the borders of the upper jaw, the latter in the lower jaw. In infancy, at about the seventh month, the front teeth begin to appear. The point of the tooth gradually pierces the somewhat dense mucous membrane forming the gum, and one after another is cut, until the child, at two years of age, has twenty teeth. But this set of teeth, called the temporary, or milk set, is short-lived. They are all cast off during childhood, and are followed by a new set. These also make their appearance gradually. The same number take the place of the temporary set, and three others are 
added at the back part of each side of both jaws, thus making in all thirty-two teeth. These are the permanent set. They begin to take the place of the others when the child is six and a half years old, and are not completed until the wisdom teeth are cut. The wisdom teeth appear anywhere between the seventeenth and twenty-first year, but are occasionally later. - Each tooth has its root, or fang, the crown, or top of the tooth, and the neck, or portion between the root and the crown.

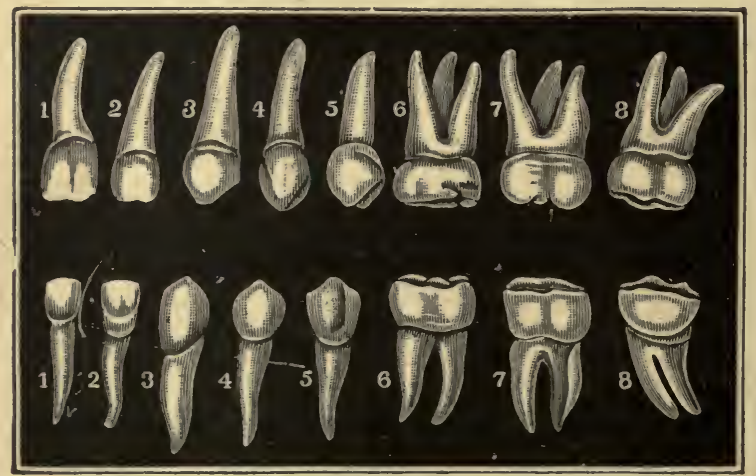

Fve. 20. The Adalt Teeth: 1, 2, the incisors; 3, canine; 4, 5, bicuspids; $6,7,8$, molars.

The teeth are divided into four kinds: incisors, canines, bicuspids and molars. The incisors, four in number in each jaw, placed in front, are for cutting the food. They have sharp edges. The four canines, two in each jaw, one on each side, resemble the teeth in cats and dogs, who use them for seizing and holding their prey. Next to these, two on each side, in both jaws, are the bicuspids, and behind these twelve molars or grinders, in lots of three to each correspond- 
ing portion of the jaws. The crown of the molars is large, with a broad, uneven surface, intended for grinding the food. The first three kinds of teeth have a single root or fang, but the bicuspids, being marked by a groove on each side, are partially divided into two, hence their name. The molars have two, three, and sometimes four fangs.

5. Structure of a Tooth.-The tooth consists of a hard outer portion, the ivory, and the pulp within. The bulk of the outer portion, situated next the pulp, is called the dentine.

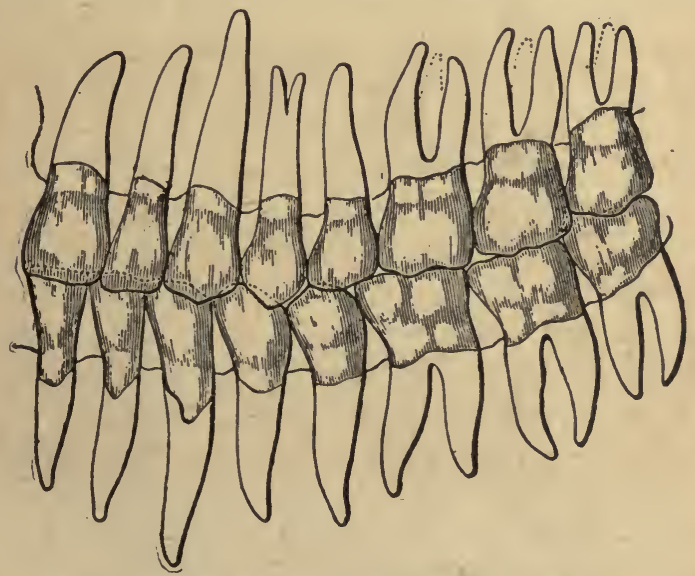

FIG. 21.-Diagram showing how the teeth fit into each other.

Over this, on the crown, is the enamel. Covering the dentine of the root is the cement. Chemically, the dentine is like bone tissue, but the tooth is harder than bone. The pulp is composed of connective tissue, with blood-vessels and nerves. These enter the tooth through the extremity of the fang.

The life of the tooth does not correspond with the life of the body. The permanent set begins to appear, as we have said, when the child is about six and a half to seven years of age. Prior to this the crown has been formed, and the 
growing tooth presses against the milk tooth, loosening and crowding it up, until it finally drops out. Sometimes the milk teeth remain firm in their sockets, and if not removed the coming teeth will be pressed aside, causing unsightly irregularities.

6. Care of the Teeth.-When a permanent tooth is removed, another does not come in its place. Constant attention is necessary to preserve the teeth from decay. The principal source of danger is from particles of food getting lodged between them. If allowed to remain, the food decomposes, and destroys the enamel, causing ulceration around the body of the tonth. To prevent this, the tooth-brush should be used daily, and all food removed from between the teeth. When carefully attended to in this way, tooth powder and severe scouring of the teeth are not necessary. In fact, the enamel may be injured by too much interference.

A deposit from the saliva, called tartar, often forms arounthe root of the tooth. This should be removed, or it may extend toward the root and loosen the tooth; or decomposing, it may injure or discolor the enamel. It is very often the decomposition of the tartar, or of bits of food, which gives rise to foulness of breath. Decay of the tooth may arise from injury to the enamel by biting substances too hard for the teeth, such as bending a pin or cracking nuts. The enainel may also be cracked by sudden exposure to cold. The mouth should be kept closed on going out of a warm room into the wintry cold. If the enamel is preserved unbroken, the tooth is not likely to decay.

Human teeth loosen and drop out in advanced age. The wisdom teeth, so called because they do not appear until maturity, the "age for wisdom," are usually the first to disappear. The structure of a tooth is so hard and compact, that long after death, when the bones of the body have all crumbled to dust, the teeth remain whole. 
7. The Tongue.-This important organ consists principally of muscle, and is literally the most active muscle in the body. It is covered with mucous membrane, and highly endowed with sensibility. The nerves of the special sense of taste belong to the tongue. On its upper surface may be seen a number of little eminences, or papilla, which are freely supplied with delicate nerve-fibres from these nerves. These papillæ vary in size. Some are quite small pointed little specks. There is a row of large ones at the back part of the tongue, arranged in the form of the letter $\mathbf{V}$ inverted.

The root of the tongue is attached to the hyoid bone. The three chief functions of the tongue are: It rolls the food about in the mouth, and helps to keep it between the teeth to be crushed ; it is the seat of the sense of taste, and it takes part in the articulation of speech. In the young the tongue is bright red in color. As age advances it becomes paler, excepting at the tip and edges. This organ promptly sympathizes with the stomach when in any way deranged. By the appearance of the tongue the physician is guided, not only in ailments of the stomach, but in almost every form of disease.

8. The Saliva.-The mouth is kept moist with fluid secreted by the mucous membrane. The saliva proper is secreted by a number of glands, which are stimulated to action by the presence of food. The saliva will begin to flow before the food reaches the mouth, and sometimes the thought of food will "make the mouth to water." Mixing with the food as it is ground, the saliva assists in bringing it more quickly into a soft, pulpy mass, fit for swallowing. It is a thin, colorless fluid, which acts upon certain parts of the food chemically.

9. Salivary Glands.-The saliva is secreted by three pairs of glands, the parotid, the submaxillary and the sublingual. The parotid lies in front of the ear. It has a duct 
which carries the saliva across the cheek, and pours it into the mouth opposite the molar teeth. The submaxillary, as its name implies, lies under the lower jaw, and its ducts open into the mouth under the tongue. The sublingual is placed under the tongue, beneath the mucous membrane, and has a number of ducts opening into the mouth. A common affection in children is inflammation of the parotid gland, a disease familiarly known as mumps.

10. The Fauces.-At the back part of the mouth is the entrance to the throat. Its boundaries are the soft palate and the uvula above, the root of the tongue beneath, and on either side the pillars of the fauces, extending from the soft palate to the tongue. They consist of muscular tissue, covered with mucous membrane.

11. The Tonsils.-Between the pillars on each side is the tonsil. It is a large gland. The tonsils are often swollen from a cold or from an inflamed throat, and may become permanently enlarged, so as to interfere with the breathing. Acute inflammation of these glands is commonly called quinsy. Diphtheria usually makes its first appearance on the tonsils.

12. The Pharynx.--Immediately behind the fauces is a large space or chamber, the pliarynx. The lower portion contracts into a narrow channel, the mouth of the gullet. Opening into this cavity are the mouth and nose, in front. On each side, near the top, are the openings of two small tubes which lead to the ear. Below are the openings into the windpipe in front, and the gullet behind. Both food and air pass through the pharynx. The arrangement by which this is done is very complete. Usually the soft palate hangs like a curtain, behind which the current of air passes from the nose through the pharynx into the windpipe. When food is being swallowed this curtain is drawn up.

13. The Epiglottis.-At the root of the tongue is a spoon-shaped piece of cartilage called the epiglottis. It acts 
like the lid of a chest. Usually the epiglottis stands erect, but the moment any food passes over the tongue, it is instantly drawn down, and closes the opening into the windpipe, so that the food is carried on to the gullet. If not well closed, a little food or drink may "go the wrong way,"

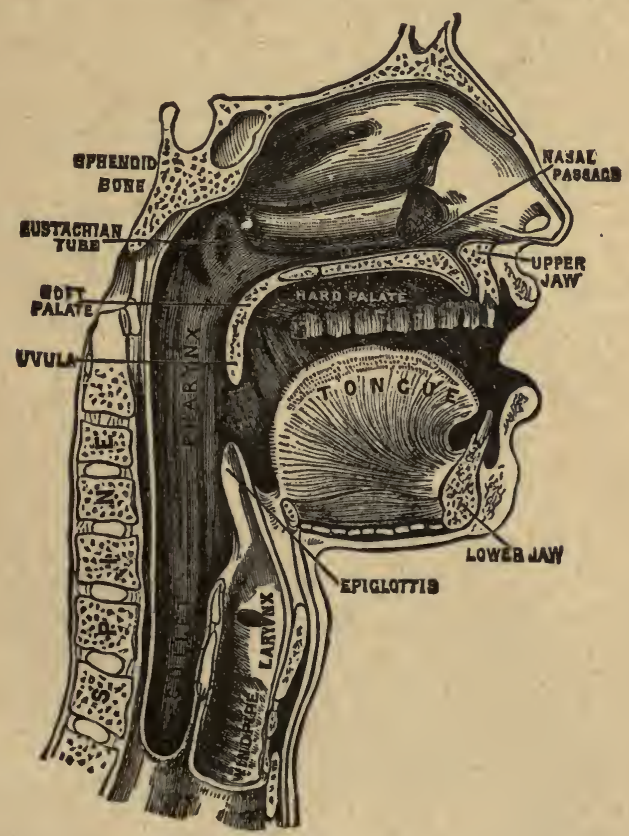

Fia. 22.-Section showing passages to the gullet and windpipe.

and cause violent coughing and choking. Boisterous laughter at table is sometimes suddenly and seriously checked in this accidental way.

The process of swallowing food is partially a voluntary and partially an involuntary action of the muscles engaged. It is by the individual's will that food or drink is carried into the 
pharynx. When it reaches a certain point the involuntary muscles, first of the pharynx, then of the gullet, begin to act, and by alternately relaxing and contracting, the food is passed on into the stomach. This motion may be seen when a horse is drinking.

14. The Esophagus.-The gullet is a tube about nine inches in length, extending from the pharynx to the stomach. This tube is made of three coats-the lining or mucous mem. brane, a middle coat of connective tissue, and the outer muscular coat, consisting of two layers. The fibres of muscle lie lengthwise in the outer layer, and in the inner layer they circle around the tube. As the muscular rings contract, one after another, they force the food towards the stomach.

15. The Stomach.-The chief organ of digestion is situated within the abdominal cavity, immediately beneath the diaphragm. It is conical in shape, something like a pear, with the small end turned a good deal to one side. It has also been compared to a bag-pipe. It is placed across the body, the large end to the left. The gullet enters the stomach near this end, on the upper surface. This is called the cardiac opening, because it is near the heart. The small end to the right is turned upward, narrowed for a little distance, and is continuous with the intestine. The opening at this end is called the pylorus, or gate guardian. The healthy stomach of the adult will contain about three pints to two quarts of liquid.

The stomach has four coats; three similar to those of the gullet, and an outside coat of smooth serous membrane, which prevents friction from the movements of the stomach. The serous membrane, after covering the stomach, passes to the inner wall of the body, and holds this organ in place. The muscular coat has two layers, one with its fibres lengthwise, the other running round the organ, and at the large end an additional layer of oblique fibres. The united action of these 
muscles produces a movement of the contents of the stomach like churning. In this way the food is thoroughly mixed with the secretions from the inner walls of the stomach. The mucous membrane, or lining of the stomach, is of a pinkish hue, changing to red during digestion. It lies in folds when the stomach is empty, but these folds disappear when it is filled. Examined closely, the lining of the stomach has a peculiar honeycomb appearance, owing to its being dotted over with small shallow pits. At the bottom of these little pits a number of ducts open. They are the openings through which the juice from the gastric glands situated in the lining reaches the food.

The stomach is freely supplied with blood-vessels, and when food is swallowed it excites the nerves of this organ, and causes the small vessels to dilate. The increased flow of blood, besides furnishing the glands with material from which to extract the juice, stimulates them to action.

The gastric juice is a thin, colorless fluid, with a distinctly acid taste. Besides this free acid, it contains a peculiar substance known as pepsin. The acid and the pepsin are both necessary to the digestion of food in the stomach. When the meal is completed the muscles begin to contract, so as to roll the food over and over, until thoroughly mixed with this juice, and reduced to a pulpy, soup-like mass. All this time the outlet to the stomach is guarded so that no food can pass until it has been properly changed. The flow of gastric juice may be too free, and interfere with healthy digestion. This increased flow may be caused by stimulating articles, such as mustard or pepper, taken with the food, or still worse, the use of ALCOHOL in any form, to stimulate the appetite. On the other hand, the flow may be too scanty. It is sometimes checked by a drink of cold water, or by swallowing a piece of ice. If food is taken when a person is much fatigued, the secretion of gastric juice is 
likely to be deficient. Strong emotions will also check the flow.

16. Absorption.-The length of time required for the digestion of food varies, some articles being more quickly digested than others. Liquid food and drinks are quickly taken up by the absorbents in the coats of the stomach. Speaking generally, after the food has been in the stomach from an hour and a half to two hours, portions of it will. have undergone the necessary changes to convert it into chyme. The pylorus relaxes sufficiently at intervals to allow this soup-like, grayish-colored fluid, which has found its way to that end of the stomach, to pass out into the intestine. In succession, portion after portion is digested and passed on, until all the food which the stomach is capable of digesting is disposed of. Then the pylorus, having retained everything as long as necessary, freely relaxes, and the indigestible balance passes into the intestine, to be further acted upon.

17. The Intestines.-The process of digestion is by no means complete when the food, changed into chyme, is poured into the intestines. Further changes here take place, and the food advances in the vitalizing process of being converted into blood.

The alimentary canal, from the stomach onward, is divided into the large and small intestines. The total length is about twenty-five feet. This tube is sn coiled and doubled upon itself as to fit snugly in the abdomen. The coats of the intestines are the same in number as those of the stomach.

The small intestine, about twenty feet in length, commences at the stomach. It is largest at the beginning, being nearly two inches in diameter. This first part is called the duodenum, because it is about the length of twelve fingers' breadth. Where the small intestine joins the large, it is little more than an inch in diameter. The large intestine is from one and a half to two and a half inches in diameter, 
beirg also largest at its commencement. At the point of union, the two tubes du not form a continuous straight passage, but the smaller one opens into the larger on its inner side, something after the manner in which a small pipe leads off from the side of a larger. The large intestine is here closed at its lowest part, forming a pouch.

A magnifying glass shows the inner surface of the small intestine to be covered with minute elevations. These are known as villi. The size of each villus is from one-fiftieth to one-thirtysecond of an inch in length. They are so thickly placed as to give the lining the appearance of the pile on velvet. It is these tiny projections that give to tripe its peculiar appearance. In each villus is a branch, sometimes double, of the lymphatic system. These branches are known as the lacteals, so called Decause, during digestion, they contain a milky fluid, the chyle, which they have sucked up from the contents of the intestine. Follow-

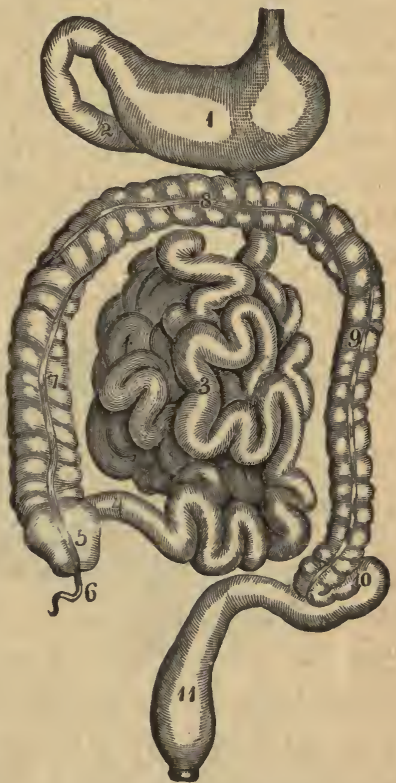

Fia. 23. - The Alimentary Canal be. low the gullet: 1 , stoinach; $2,3,4$, small intestines; 6-11, large intestine; 5 , closed pouch of large intestine. ing the chyle on through the lacteals, we find the tubes become larger, and finally pour their contents into a sac at the back of the loins, called the receptacle of the chyle. From this sac, the thoracic duct ascends through the back part of the thoracic cavity, and eventually opens into a large vein 
in the neck. It is at this point, therefore, that the nutrient parts of the food enter directly into the blood current.

The secretions which enter the intestine to be mixed with the chyme are from different sources, and differ in their action. There is the intestinal juice, from the intestinal glands, whose ducts open between the villi all over the inner surface of the intestine; the pancreatic juice, from the pancreas, and the bile, from the liver.

18. The Pancreas.-This is the sweet-bread of the lower animals. It is situated under and behind the stomach, and

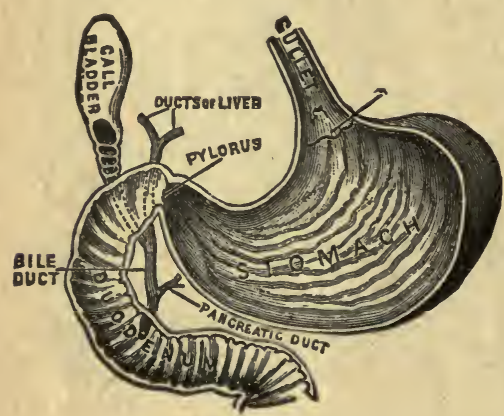

Fit. 24.-Section of Stomach. varies in length from six to eight inches. It bears some resemblance to a dog's tongue. The pancreas secretes a fluid called the pancreatic juice, which closely resembles saliva in its action on the food.

19. The Liver.-This is the largest gland in the body, and is situated immediately beneath the diaphragm, on the right side. Its weight is about four pounds. The human liver has the same general appearance as that taken from the animal. The liver is divided into a right and left lobe by a deep fissure, the right being the larger. The upper surface is smooth and rounded. In the fissure are found the bloodvessels, and a duct coming from each lobe. These ducts unite and form one channel, for carrying the bile into the intestine. At a little distance from the union of the two ducts is another, which leads off the bile when not required for digestion, and stores it up in a little pear-shaped sac, called the gall bladder. After a meal the stored-up bile finds 
its way back again into the common duct, and flows into the intestine, to be mixed with the food.

The chief function of the liver is to secrete the bile, a greenish-yellow, bitter fluid. The bile duct, as it enters the intestine, is joined by the pancreatic duct, so that these fluids reach the food at the same point, about four inches from the pylorus.

20. Kinds of Food.-Before tracing the food through these several steps in the process of digestion, and showing the action of the different secretions it meets with on its course, it will be necessary to classify the several varieties of food used by man. The almost universal habit of the human race, guided by instinct and reason, shows that a mixed diet is the best. The different kinds of teeth would even indicate this.

There are three kinds of food:

I. Nitrogenous foods, or tissue builders.

II. Carbonaceous foods, or heat producers.

III. INORganic, OR Mineral Foods.

To the first belong albumen, as the white of the egg, casein, the principal part of cheese, the fibres of lean meat, and the gluten of grain. The second class comprises the fats, starch and sugar. In the third class there are water and such mineral substances as salt, potash, sulphur, phosphoms and iron.

The elements of nutrition must have the power to combine with oxygen. The living body, like fire in a stove, must be supplied with fuel that will burn. The food, as swallowed, is not fuel. It has to undergo changes, both chemical and vital, before it is prepared to become blood and feed the system. Albumen exists in the blood, but if the white of an egg were injected into a blood-vessel, it would be worse than useless; the albumen of the blood must be the product of the digestive 
organs. Iron, also, is a constituent of the blood, but it can only become so through the digestive organs.

Any one of these kinds of food is not alone sufficient to supply the wants of the body. Nitrogenous foods have all the elements necessary for nutrition, but not all of them in sufficient quantities for ecr iomical living, while their exclusive use would, in time, overtax the digestive system. The same lack of economy and overwork of the digestive system would be evident if we confined ourselves to fats, starch, or sugar as a diet. Too much of one kind will not make up for too little of another.

21. The Digestive System a Complete Workshop. -The process of digestion is carried on in a most perfect and fully equipped workshop. It commences the moment food enters the mouth. While being made ready to swallow, the change is started by the saliva, an alkaline fluid, containing a ferment (diastase) which converts the starchy parts of food into a kind of sugar. Starch is insoluble, while sugar is freely dissolved. Eating is, therefore, not a mere grinding of the food until, with a mouthful of tea or other drink, it can be swallowed. It is the first step in digestion, and in order that the saliva may do its work properly, the food should be well ground and thoroughly moistened and softened by the saliva only. The necessity for this is more plain when we know the saliva can only act upon the starch in a mixture which is slightly alkaline, and that as soon as swallowed the food meets with a secretion in the stomach which is acid.

22. Stomach Digestion.--The work begun by the saliva is not completed until the food reaches the intestine. The gastric juice has little effect on the starchy matters. In the stomach the albumens, such as are contained in meat, eggs, cheese, bread, etc., are acted upon. Fats are not affected by the gastric juice, although the cells are dissolved and the oil set free. The free acid in the gastric juice keeps the food 
wholesome. Meat, for instance, car be kept pure for days in gastric juice. The germs which are known to be the causes of typhoid and cholera are destroyed by this acid.

The pepsin acts as a ferment, that is, it converts a substance into more simple elements, so that it is more readily dissolved and easily taken up by the system. Besides the pepsin, there is another ferment in the gastric juice, called rennet. It has the property of curdling milk, as the good housewife knows who uses the dried stomach of the calf for curdling the milk in cheese-making. Milk curdles in the stomach as a natural process of digestion, and afterwards breaks down and is dissolved.

It will be seen that the bulk of the food is changed in the stomach. What is not digested is broken down and divided, and passes on with the rest into the intestine, as a grayish, pulpy mass. It is not probable that all those portions of the food which are digested in the stomach pass into the intestine. A certain amount is immediately taken up by the absorbents in the walls of the stomach and enters the system directly. This explains why soup, beef-tea, and other liquid foods satisfy the appetite so readily.

23. Intestinal Digestion.-Here the food again enters an alkaline medium, and the final work of digestion is completed. The starch that was not acted upon by the saliva, meeting with the pancreatic juice, is converted into sugar. This juice has also the property of splitting up the oils, and rendering it possible for them, in the presence of the bile, to mix more readily with the watery fluid in the intestine, and to be sucked up by the villi. The pancreatic juice also continues the digestion of the partly changed albumens from the stomach. This juice seems, indeed, to be the most usefui of all the digestive fluids, being capable of affecting all the elements of food, and bringing them into a form fit to enter the lacteals, and thence into the blood. 
24. Action of the Ferments.-The following table will show more readily the action of the various juices on the food :-

\begin{tabular}{|c|c|c|}
\hline $\begin{array}{l}\text { Digestive } \\
\text { Juices. }\end{array}$ & $\begin{array}{c}\text { Ferments Contained } \\
\text { in them. }\end{array}$ & Action on Food. \\
\hline Saliva & Salivary diastase & Changes starch into sugar. \\
\hline Gastric juice & $\begin{array}{l}\text { (a) Pepsin : : : : } \\
\text { (b) Rennet : }\end{array}$ & $\begin{array}{l}\text { Changes albumens. } \\
\text { Curdles the casein of milk. }\end{array}$ \\
\hline $\begin{array}{l}\text { Pancreatic } \\
\text { juice }\end{array}$ & $\begin{array}{l}\text { (a) Trypsin } \\
\text { (b) Curdling ferment } \\
\text { (c) Pancreatic diastase } \\
\text { (d) Emulsive ferment }\end{array}$ & $\begin{array}{l}\text { Changes albumens. } \\
\text { Curdles the casein of milk. } \\
\text { Changes starch into sugar. } \\
\text { Fmulsities fats. }\end{array}$ \\
\hline Bile. . & Emulsive ferment & Assists in emulsifying fats. \\
\hline $\begin{array}{l}\text { Intestinal } \\
\text { juice. }\end{array}$ & Curdling ferment & Curdles the casein of milk. \\
\hline
\end{tabular}

25. The Appetite.-A desire to take food at stated intervals is a natural law common to every living creature. The selection of food in the lower animals is guided by instinct alone. In man, the choice of food depends to some extent on instinct, but more on habit and the ability to procure articles agreeable to the taste. The sense of taste, while mustly a sure guide, may be perverted, and lead to the use of food least suited to the wants of the body.

The food used should be suited to the age, the occupation, the climate, and the condition of the system. It should be taken at stated intervals. The digestive system requires rest, 
just as do all the organs of the body. Three meals a day is a common division of labor for the organs of digestion. This is in accordance with the laws of physiology, and established by ixperience. In departing from this rule we impose upon the itomach.

In infancy, milk is sufficient to supply all the necessaries of life, but as the child grows, a more varied diet is required. Now comes the temptation. The child develops tastes, and unless checked, will take to excess the food for which it has the greatest liking. Craving for candies and sweetmeats is common, and if indulged,.will injure the stomach and take away the desire for proper food. Children should be taught temperance in food, and not allowed to eat wholly of any one class because their appetites run in that direction.

The kind of food most suitable to man depends largely on the climate in which he lives. In the cold northern regions there is the strongest liking for the heat-producers, and the natives live mostly on fats. In the sunny south a diet of fruits and vegetables largely prevails. In temperate climates the diet consists of mixed foods. In his primitive state man uses food in its simplest forms. The more civilized the more he becomes addicted to the use of artificial food, and the more he suffers from digestive derangements. To the natural appetite no artificial preparations to please the taste are required. To indulge the taste for the pleasure it affords often means the taking of more food than the system requires. The cook who prepares the daintiest dishes may not always be regarded as a benefactor to his fellowman.

26. Alcoholic Stimulants and Tonics.-A tonic is a medicine given to increase the appetite, or to strengthen and invigorate the system. It is only when a person is feeling ill, or is recovering from a severe sickness, that a tonic to the stomach is desirable. To be continually dosing the system to create an appetite is unwise. It is vastly more so to try to do 
this by the use of stimulants, no matter whether the dose be in the form of some "well-known bitters," a "glass of beer," a "taste" of sherry, or a "plain" whiskey and water. Many drugs may be, and are, taken, which probably do little or no harm to the system. But this sannot be said of alcoholic stimulants. Their irritating action on any of the tissues is injurious, but more especially so on - tender part, like the lining membrane of the stomach. Derangements of digestion are sure to follow the continued use of alcohol.

27. Natural and Prepared Drinks.-Water is the universal drink. Its necessity is perfectly clear. The weight and bulk of the body are largely due to the presence of water. It is the great vehicle by which food is taken into the system, and through its agency the various functions of the body are carried on. It makes up the bulk of the blood, and is the great dissolving fluid of the system. It is not in itself a food, but it forms a part of all food taken into the mouth. It dissolves solid material, and keeps it in solution. Its use and necessity are obvious.

In milk we have a standard article of diet. It is both food and drink for the infant during many months. It will alone sustain the body at any period of life for an indefinite time. Frequently in old age it is the sole article of diet. Water and milk are the two great natural drinks. The human system needs no. other. In health any other is likely to prove injurious. It is true that tea and coffee are largely used, and, as a rule, seemingly without any injury. The taste for these, however, is not natural. It is acquired. Constant use brings the system into such a condition that it tolerates them without any apparent ill effects. If either be taken in excess, or drunk freely between meals, it will injure the stomach. But these, and kindred beverages, bear no comparison to alcohol, an agent alike destructive to the health. of the body as to the individual tissues and organs. 
When diluted with water, alcohol is readily absorbed, and carried by the blood to every part of the body. No organ or tissue is safe from it. Unless it can be shown that alcohol possesses elements of nutrition, or furnishes material for the production of heat, its presence is useless. If useless, it cannot but be harmful. Anything in the system which can serve no useful purpose must, of necessity, be in the way; and if anything is present which interferes with the functions of life, efforts will be put forth to get rid of it. Such is the case when even a small quantity of alcohol is taken. The lungs, the skin, and the kidneys are at once engaged in expelling it. It taints the breath, it exudes from the skin, it saturates the whole system with its odor. We have already said that food, in order that it may nourish the body, must be changed. Now, if alcohol escapes from the body without any change, it is clear it cannot be a food, and the question, "Is alcohol a food?" can readily be answered. The study of physiology leads to this conviction, and scientific truths cannot be ignored. As to alcohol being a factor of heat, it has been clearly demonstrated that it reduces the temperature. Experience among soldiers and seamen in high latitudes has abundantly shown that the extremes of cold are better endured without, than by the use of, spirits.

The absence of anything useful, and the burden it places on the powers of nature to cast it out, supply safe grounds upon which to declare alcohol a poison to the human system.

28. Effects of Alcohol on the Stomach.-Alcohol has a strong affinity for water, and if applied to the skin will extract its moisture, leaving it shrunken and hard. The stronger it is the greater the effect. When taken into the stomach, it will have a similar effect upon its mucous lining. When first taken, if in small quantities, such, for example, as might be called temperate drinking, it irritates the mucous coat, causing the blood-vessels to dilate. This increased flow 
of blood is really a congestion - just such a condition as we see brought about in the eye in a very few minutes if a speck of dust or a small insect chances to get into it.

Now, if this injected and distended state of the vessels be kept up by a continuous "tippling," the mucous membrane becomes inflamed, thickened and softened. The stomach shows signs of derangement. The gastric glands, which at first were stimulated to over-work and over-supply of gastric juice, are now interfered with, and the secretion is checked. The appetite for food is lost, and is often replaced by a morbid desire for more stimulants. The pepsin, so necessary to the digestion of food in the stomach, acts very imperfectly, and if the quantity of liquor taken be large, will cease to act at all. The stomach is upset, and the inebriate suffers from dyspepsia, indigestion, chronic catarrh, acidity and even neuralgia of that organ.

If this state is continued for some time, the lining membrane may ulcerate, a condition attended with considerable danger on account of the possibility of profuse bleeding from these ulcers, and the probability of some one or more of them eating through the stomach, and causing death.

Further action of the persistent use of alcohol is shown in its extension to all the coats, thickening and hardening them, until the stomach is of little use as a digestive organ. Think of the condition of the poor unfortunate drunkard; appetite gone, nausea, vomiting, intense thirst, pain in the head, red eyes, bloated face, coated and red tongue, frequent pulse, and often fever.

29. Effects of Alcohol on the Liver.-It is not alone in the stomach that the habitual drinker suffers. The small intestines are also involved. Functional derangement, and subsequent changes, such as we have described in the stomach. are likely to take place here. The pancreas, also, is affected. But it is in the liver we find the most marked changes of 
structure. The liver and the brain are the two organs which seem to receive the largest percentage of the alcohol taken into the system. Continual congestion of the liver resulting from alcoholic drinks inevitably leads to an alteration in its texture, and deranges its function. At first it is inflamed, eniarged, and soft. Afterivards it contracts and hardens, and presents an uneven surface. This is called a "hob-nail," or gin-drinker's liver. From the first, the bile secreted is unhealthy, and is not fit to perform its part in the intestinal digestion. The frequent drinker suffers from "biliousness," and other intestinal disturbances.

Sometimes the liver is very greatly enlarged by the deposit of fat in its substance. This is the disease spoken of in connection with the muscular system as -fatty degeneration. In some cases the liver reaches an enormous weight, fifteen, and even twenty to twenty-five, pounds being not uncommon.

30. The Effect of Tobacco on Digestion.-It is in stimulating and increasing the flow of saliva, which is thus lost to the system, that tobacco chiefly affects the digestive organs. The sense of taste, so necessary to the proper appreciation of food, and desire for eating it, is numbed by the use of tobacco. Hence it really checks, or in a sense satisfies, the appetite for food.

It frequently inflames the throat, and keeps up a chronic catarrh, or "smoker's sore-throat," which may extend to the stomach, and cause a feeling of general distress, with derangement of this and other organs. 


\section{CHAPTER VI. CIRCULATION.}

1. The Blood.-The blood is the life-giving liquid which permeates every part of the body, except the cuticle, hair, nails, etc. The average quantity in the body is equal to about one-thirteenth of the body-weight; therefore, a man

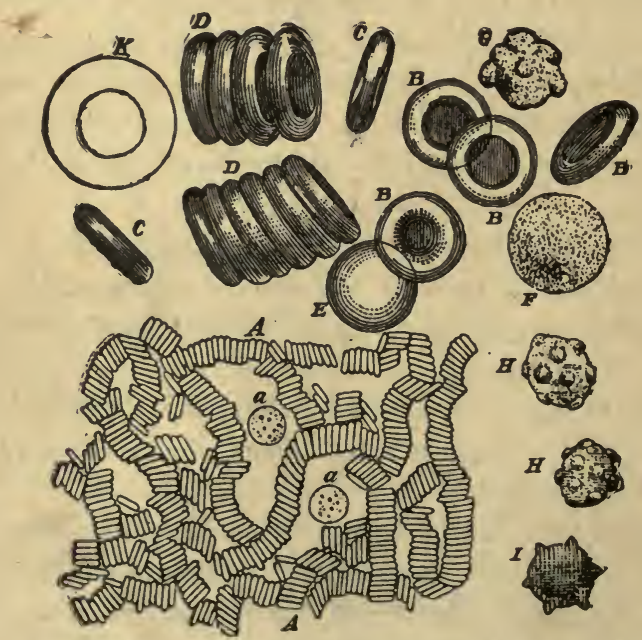

FiG. 25. - Blood Corpuscles: $A$, magnified about 400 diameters. The red corpuscles have arranged themselves in rolls. $a, a$, white corpuscles. $B$, red corpuscles more magnified; $C$, corpuscles seen edgewise; $F, G, H, I$, white corpuscles highly magnified.

weighing about one hundred and eighty-five pounds would have between fourteen and fifteen pounds of blood. As it is drawn from the body, it is a red, sticky fluid. Examined 
under the microscope, we find, in addition to a fluid, which is called plasma, there are numerous small discs, or corpuscles, floating about in the fluid.

There are two varieties of blood corpuscles, the red and the white. It is the presence of the enormous quantity of red corpuscles that gives to the blood its red color. They are little, flat, circular discs, resembling a coin, only thicker near the rim than at the centre. They have a strong tendency to run together, like a roll of ten-cent pieces - as seen in Fig. 25, where some lie separate, while others are in rolls.

The white corpuscles are not so numerous, only about one to every four hundred of the red. They are a little larger and more globular in shape, although, watched under the microscope, it will be noticed that in making their way through the minute vessels they change their shape.

2. Uses of the Blood.-These little corpuscles are really the carriers of food to the tissues. Like boats on a strean, they float along, larlen with material, which they unload into the system; then reload with the refuse, and carry it back to the lungs, to be given off into the air. They are charged with oxygen in the lungs, and carry it to where there is work to be done or repairs to be made.

The plasma is rich in mineral matter for the bones, and in albumen for the muscles.

3. Clotting of Blood.-When blood is drawn from the body it soon clots, that is, it forms into a jelly-like mass. The clot consists mainly of two substances-a network of tough, fibrous threads, called fibrin, which separates out from the plasma and the corpuscles, which are caught in this network. The cloting of the blood is an important provision of nature for arresting its flow from a wounded blood-ressel. The moment blood escapes from the vessel, the fibrin begins to form, and clogs up the cut and arrests the flow from the 
wound. It sometimes happens that little or no fibrin forms, and the slightest wound bleeds freely. In such a case it is dangerous to have even a tooth extracted.

4. The Organs of Circulation.-The circulation of the blood is carried on by the heart, arteries, capillaries and veins. The blood constitutes the food of the tissues, and in supplying these finds its way to the most remote parts of the body. The circulation of the blood never ceases while life continues. It flows from the heart, bearing the elements of growth and sustenance. It returns to the heart, carrying with it the waste products. The arteries are the channels through which the rich, bright-red blood feeds the tissues. The veins are the tube-like canals through which the dark, impure blood returns. Between the final branches of the small arteries and the small veins lies a great network of capillaries. In these capillaries the elements of the food, digested and carried into the circulation, are incorporated in the living tissue.

5. The System a Closed Sac.-The heart and the three varieties of blood-vessels form a cavity in which the blood is confined. The arteries and veins, with the capillaries, are a continuation of the heart. They form a complete circuit, so that the space within is continuous. The bloor proper cannot pass through the coats of these vessels at any point. It parts with its nutrient material while it is flowing through the capillaries, but the blood itself cannot pass through the walls, unless they are injured or cut. The prick of a pin, if deep enough, will draw blood, because it pierces one or more of these small vessels. At the same time that it imparts its nourishment to the tissues, it receives from them their worn-out products. The vitiated blood, returning to the heart through the veins, is then sent by a separate system of vessels to the lungs, where it is brought in close relation with the air we breathe. Here the vital change of 
venous into arterial blood is effected, and it flows back to the heart purified and ready for further circulation.

6. The Heart.-The great central organ of blood circulation is a powerful pump made of muscular tissue. It is placed near the middle of the chest, between the lungs, which, in fact, almost surround it, there being cnly a small triangular portion in front uncovered. At this point the action of the heart can be readily examined. It is conical in form, and is placed obliquely, with the base upward, the apex. pointing downwards and forward, toward the left side. The size of the heart varies in different persons, and according to age, but the size of the individual does not modify it. It is, however, usually

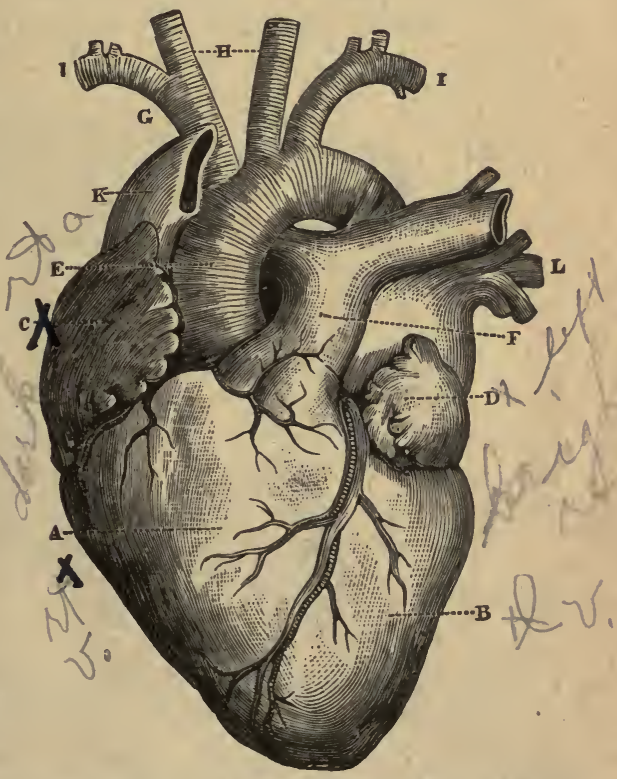

Fia. 26. -The Heart: $A$, the right ventricle; $B$, the left ventricle; $C$, the right auricle; $D$, the left auricle.

smaller in the female. The size of one's fist is said to correspond with that of the heart. -It continues to grow for some time after the full size of the body is attained, especially in the male. The average measurement in the adult is about five inches in length, three inches and a half from side to side in the broadest part, and two inches and a half from the front to the back surface. 
The heart is a hollow organ, and the cavity is divided into two separate compartments by a muscular wall running from top to bottom. Each compartment is divided into two parts, thus making four chambers. The upper chambers are called respectively the right and the left auricle. The lower are known as the right and left ventricles.

The walls of the heart are made up chiefly of muscular tissue, in which are nerves and small blood-vessels to nourish the structure. The chambers are lined with a smooth, fibrous membrane, the endocardium. The heart is surrounded by a closed sac, which is also conical in shape, called the pericardium. The base of this sac is below, while at its upper part, or the part corresponding to the base of the heart, it is folded on to that organ, and becomes its outer covering; hence the heart is really surrouncied by a closed bag, the inner layer of which is firmly attached, while the outer layer is large and loose. Between the two layers is a small amount of watery fluid to moisten the surfaces and prevent friction from the constant movements of the heart.

7. The Valves of the Heart.-The heart is a double organ, the two right chambers containing the dirk and the two left the bright red blood. The right side receives into its auricle the venous blood through tro litige velins, लme from above and the other from below, the vena cave. As the auricle contracts, the blood is forced into the right ventricle through an opening in the partition between the two chambers. The opening is guarded by a valve, made up of three triangular folds of membrane, and hence called the tricuspid valve. $\Lambda$ s soon as the ventricle begins to contract this valve closes, and the blood is sent onward into a large vessel, the pulmonary artery, and this, dividing into two, carries the blood to the lungs. 'To prevent any return of blood when the ventricle relaxes, the pulmonary 
artery is provided with half-moon-shaped folds of membrane, the semi-lunar valves.

The blood, having traversed the lungs, collects in the pulmonary veins, and is carried to the left side of the heart, where it is received into the left auricle. This circuit, from the right ventricle through the lungs and back to the left auricle, is called the short or pulmonary circulation. From the left auricle the blood is driven on through an opening in

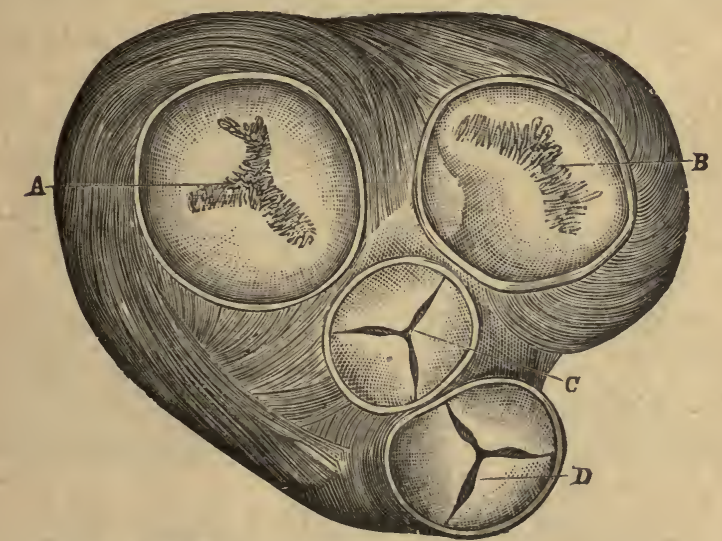

Fia. 27. - Cross section of the Ileart, showing: $A$, tricuspid valve; $B$, mitral valve; $C$, semi-lunar valves of the pulmonary artery; $D$, semi-lunar valves of the aorta.

another partition, into the left ventricle. The opening in this partition is also provided with a valve, called the mitral, because it is shaped like a bishop's mitre.

The walls of the left ventricle are nearly three times as thick as those of the right. When the left ventricle contracts, the blood is sent into the first artery, the aorta, with sufficient force to carry it to every part of the system. Its return through the various veins, to the right side of the heart, completes the long or body circulation. Semi-lunar 
valves, similar to those guarding the pulmonary artery, but much stronger, are placed at the opening of the aorta.

8. The Arteries.-The strong elastic tubes which carry the blood from the heart to all parts of the body are called arteries. We have mentioned the aorta. This is the largest artery in the body. It receives the blood from the left ventricle, carries it along, and distributes it to its numerous branches. After leaving the heart, the aorta arches backward, like the curve on a walking-stick, and passes down the back part of the thorax into the abdomen, where it divides to supply the lower extremities. Along this course it gives off such important branches as those to the arms and head, and further on, it sends branches to supply the walls of the chest and the organs in the abdomen. These are the main branches from the aorta, like the limbs of a tree from the parent trunk. Follow them on, and we find, as in a tree, the branches divide and subdivide, growing smaller and smaller as we near their termination. Ultimately they become so small and so numerous as to form a close network. This network, at its finest parts, constitutes what are called the capillaries, or hair-like tubes.

The web of the frog's foot affords a good example for seeing, under the microscope, the flow of blood through the capillaries. We can see the corpuscles wending their way in single file along these narrow passages, and occasionally swaying to and fro, stopping for a moment, but soon to be rushed on again with the ever-constant stream.

9. The Veins.-Gradually the blood in the capillaries, now dark and impure, is gathered into small tubes, called veins. As they proceed toward the heart, the veins join each other, becoming fewer in number, but-larger in size, until all those from the legs and abdomen are joined into one great vein, which opens into the right auricle at its lower part; and those from the head and arms form another large 
vein, which opens into the same auricle at its upper part. These are the vena cavæ already mentioned.

10. How the Blood is made to Flow.-The action of the heart is entirely involuntary. It contracts and dilates with great regularity. Each contraction or beat of the heart forces the blood onward into the arteries. As it again dilates it sucks the blood from the veins into the auricle. While the heart supplies the chief moving power for circulating the blood, the arteries, by virtue of their elastic walls, assist and regulate the flow. With each beat of the heart the arteries

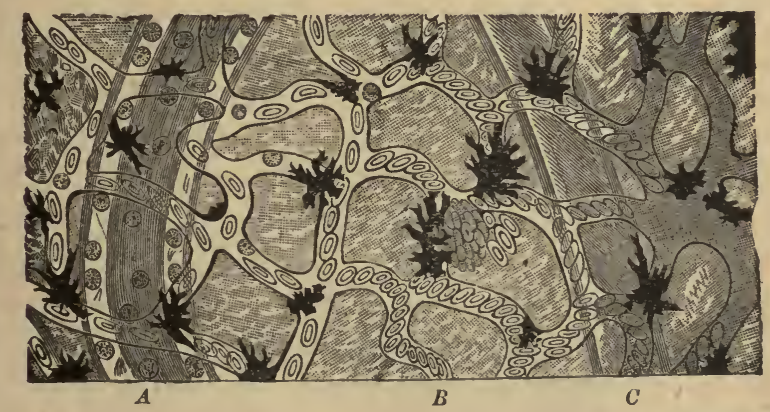

Fia. 28. - Circulation of the Blood in the Web of a Frog's Foot, highly magnified. $A$, an artery; $B$, capillaries crowded with corpuscles, owing to a rupture just above, where the corpuscles are jammed into an adjacent mesh; $C$, a deeper vein. The black spots are pigment cells.

expand, to receive the additional volume of blood. These impulses move along the arteries in waves, and can be felt in different parts of the body. They are known as the pulse. The physician usually feels the pulse at the wrist, because it is a convenient place.

The venous blood flows along in a steady, even stream. The current from behind, pressing it on toward the heart, the squeezing of the veins by the muscles of the body generally, and the suction of the heart, all tend to bring the blood back again. There is, therefore, not much actual pressure in 
the veins, and hence their walls are thinner than the arteries. They also lie nearer the surface of the body, where they are more exposed. But with little pressure there is little danger from loss of blood when injured.

11. Effects of Alcohol on the Heart.-The health and general welfare of our being depend upon the regular action of the heart, and continuous flow of the blood throughout the body. The heart is subject to a variety of derangements. These derangements may be of a temporary nature, and can usually be removed by rest and care; or they may be due to some change of structure, causing permanent impairment of the functions of the heart. The heart may be temporarily reduced in its action through fear, fright or sudden bereavement; while again, there are many emotions attended with increased action of the heart. Certain drinks and various articles of diet increase the heart-beats. General weakness may be manifested by a low or irregular pulse. Digestive disturbances may have a marked effect upon the pulse. The heart is separated from the stomach only by the diaphragm, so that the pressing upward of an over-full stomach may distress it.

Temporary disorders of the heart have generally an exciting . cause, which, if kept up, may lead to a permanent change of structure. Among the most common of these exciting causes is the persistent use of alcoholic drinks and tobacco. Alcohol invariably affects the heart's action. When first taken it increases the beats, and seems for a time to strengthen the heart. Soon, however, there will follow a weak, feeble condition of the pulse, with a feeling of depression throughout the whole system. It is then the habitual drinker will take an additional glass, another, and perhaps another, and so on day by day, until the alcohol habit has become established. Sir Benjamin Richardson, Bart., author of the Cantor Lectures, says, on this point: "A man who is very temperate, 
but who takes alcohol, feels most distinctly the effect of even a slight excess. Such a man, if he be tempted to move from the single glass of mild dinner ale a day to take a glass or two of wine, when he goes out to dinner, or to take a single glass of grog at night, is conscious of the evil influence the next day. He says, if he speaks.truly, that he was rather excited by the drink; and he says, that when the stage of depression comes, that he feels 'all-overish, depressed, rather chilly, and not up to the mark.' $\mathrm{He}$ is tired, and he thinks he should be none the worse if he took an extra glass of ale to set him right. In nine cases out of ten he does take this extra glass of ale; it does set him what he calls right, and finding how easy a thing it is to get over a slight excess, the next time he is tempted he ventures a little further. So the habit of taking too much begins in taking just a little, while being, indeed, very temperate, and while keeping in fashion with other folks. This is the beginning of woe."

In speaking of the effects of alcohol upon muscle, we pointed out that it lessens muscular power exactly in proportion to the amount taken. Now, as the heart is a muscular organ, it will, of necessity, be similarly affected. More than this, the fatty change already inentioned as due to continued use of alcohol, is more apt to take place in the muscles of the heart than elsewhere. This disease is all the more serious, in that it is likely to affect the heart. Loaded with fat, it loses its strength, becomes enlarged and flabby, while its thickened valves are no longer sufficient.

12. Effects of Alcohol on the Blood-vessels.-By the increased action of the heart more work is put upon the arteries. The pulse, for a time, is stronger from over-stimulation. As soon, however, as this stimulating effect passes off; a period of depression follows, and the pulse is reduced beiow the standard. The delicate nerves which supply the bloodvessels and keep their inuscular walls in good tone, are so 
affected by alcohol as to lose their influence, and allow the vessels to dilate. This is well marked in the capillaries, and its effect is apparent to an observer. The flushed face is an early indication of alcoholic indulgence. The coats of the capillaries relax so much that the face becomes quite reddened. What is readily seen in the skin exists elsewhere. The same degree of congestion is uniform throughout the body, and nutrition is interfered with everywhere.

This loss of power in the coats of the capillaries to contract may be temporary, but when a person becomes addicted to the use of alcohol, it will produce a permanent dilated condition of the small vessels. As a result, we see the red nose of the wine or brandy drinkers. It is the same paralyzed condition of the capillaries in the liver, brain and other internal organs which leads to diseased conditions.

Very often in chronic, though perhaps moderate, drinkers, the arteries, instead of being strong, elastic tubes, like new rubluer hose, become hardened and unyielding, and are liable to give way.

13. Effects of Tobacco on the Heart.-The use of tubacco in any form has a depressing effect on the heart. It weakens its force, and often interferes with the regularity of its action. It is more marked in its effects on the young, the weak, or on those disposed to disease. The strong and healthy may seem to escape its effects, but when we know it imposes extra labor on the heart, upsets the nerve influence which keeps up its constant and uniform action, we know enough about it to pronounce it not only useless, but harmful. It is just possible, if the truth were known, it is the direct cause of many heart failures and other cases of sudden death from heart disease. 


\section{CHAPTER VII.}

\section{RESPIRATION.}

1. Why we Breathe.-In the preceding chapter we traced the circulation of the blood, and noticed that, in passing through the capillaries, it gives to the cells of each tissue the food and fuel they require, while, at the same time, it receives from the tissues certain elements of decay. The arterial blood, freighted with oxygen, is changed into venous: blood, laden with carbonic acid and other products of chemi cal change. In the round of circulation, the venous blood is carried to the lungs. To preserve the system in health, these impurities must be got rid of, and it is the office of the respiratory system to discharge this important duty, and to give back to the blood a fresh supply of oxygen from the air. The act of breathing is necessary for life. It might even be suspended for some minutes in rare instances, but the demand for air is imperative, and if not given, life is forfeited.

2. The Organs of Respiration.-These consist of the lungs, the air passages and the pulmonary vessels, with their branches. They are situated in the chest, and with the heart and large blood-vessels, fill the thoracic cavity.

3. The Lungs.- There are two lungs, the right and the left. They are separated by the heart and large blood-vessels. Each lung is conical in shape, the apex fitting into the upper pointed cavity of the chest, immediately under the collarbone, the base resting on the diaphragm. The outer surface is rounded, to fit the curve of the ribs. The inner surface is 
concave, and has a fissure, in which are the air-tubes and vessels entering the lungs.

Each lung is divided into two lobes by a long, deep fissure. The upper lobe of the right lung is partially divided by a short fissure, so that it is said to have three lobes. The right lung is somewhat the larger, on account of the heart being placed a little to the left side.

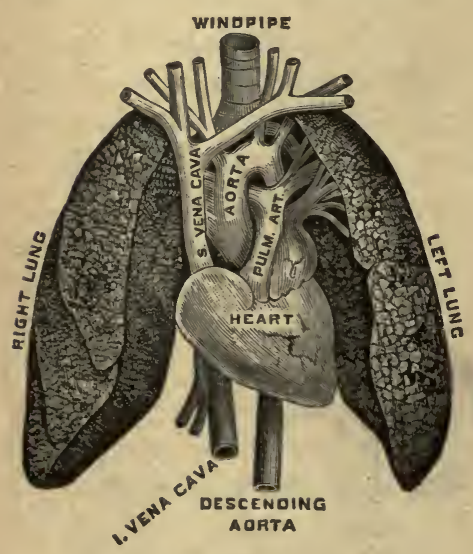

F10. 29.-The Lungs and Heart, viewed in front.

In substance the lung is of a light porous or spongy nature, and very elastic. This lightness of texture is largely due to the presence of air, which is never entirely expelled, even when we force out all we can. Examined minutely, we find the lung to consist of lobules, closely connected together, but yet quite distinct from one another. Each lobule is formed of one of the divisions of a bronchial tube, with its air-cells, and of the divisions of the pulmonary vessels. In each are also found nutritious vessels and nerves. There are a large number of air-cells to one branch of a small bronchial tube. They cluster around it like a bunch of grapes on a stem. If the stem were hollow, and each grape an empty sac communicating with it, to blow into the stem would give a fair example of how the air fills up the air-cells every time we take in a breath. Think how small these air-cells must be, when seventeen hundred of them cluster around one small tube. Yet each cell is separated from the other by a fine, thin partition. In this delicate, thin wall is a dense network 
of capillaries, and it is here the dark, impure blood, while passing through, parts with the carbonic acid, and in return receives from the air the required oxygen. As in the general system, this network collects into larger vessels, and the blood, now changed to a bright red color, passes on through the pulmonary veins into the heart.

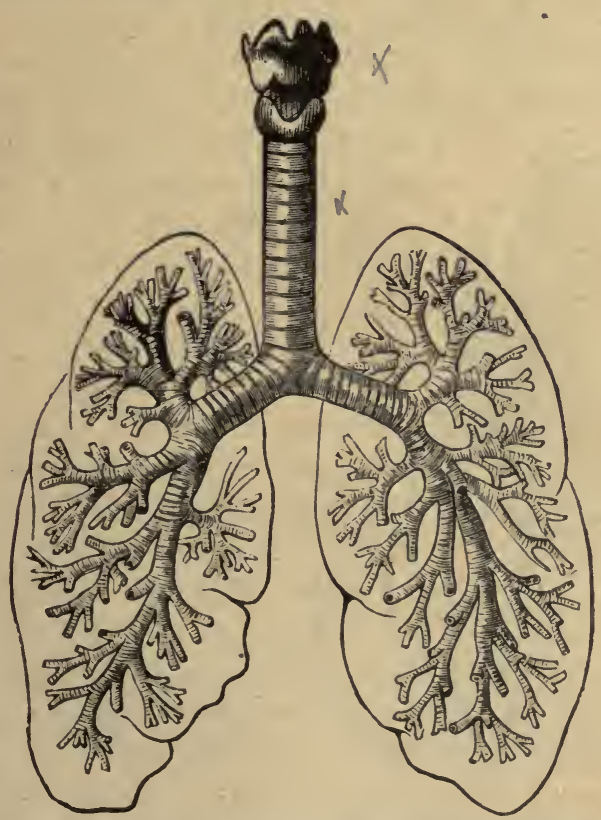

FIG. 30.-Outline of the Lungs, with the Larynx, Windpipe and Bronchial Tubes.

4. The Air Passages.-Extending from the back of the tongue to the root of the lungs are the air passages, through which the air rushes in each act of breathing. The first part, the trachea, is a single tube, which divides into two branches at the lower part of the neck, one for each lung. Each 
branch divides into a number of smaller ones, like the branches of a tree, until they terminate in the delicate aircells just described.

The windpipe is a hollow tube, about four to five inches long, made up of fibrous tissue in which are situated rings of cartilage. These rings are not quite perfect, but more like a horseshoe in shape, being incomplete at the back. They are easily felt in front. If the rings were complete at the back, the gullet could not expand so readily when we swallow food

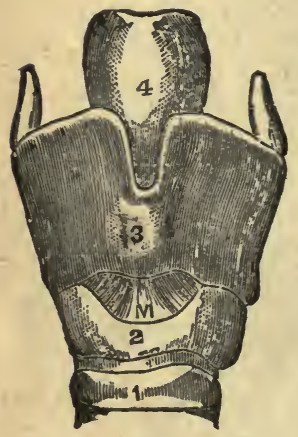

Fig. 31.-Front view of the Larynx: 1, upper ring of windpipe; 2,3 , cartilage of the larynx (figure 3 is on the Adam's apple); 4, epiglottis; $M$, membrane uniting cartilages.

The presence of cartilage in the tube prevents the sides from coming together by the suction of air. It also protects the passage from any outside pressure.

Where it enters the chest the windpipe divides into the right and left bronchial tubes. At the root of the lung each tube divides and subdivides, until it spreads throughout the entire organ.

The larynx is a triangular-shaped box of cartilage situated at the top of the windpipe. The cartilage projects forward, especially in the male, in whom it is usually quite prominent. This is commonly called "Adam's apple." The larynx has been called the voice box, because here the various sounds of the human voice are produced.

The entrance to the larynx is a triangular opening at the root of 'the tongue, called the glottis, and this entrance is guarded by the epiglottis; which was mentioned in connection with the pharynx. Within the larynx, on each side, the lining membrane forms two folds, stretching from front to back, and separated by a well-marked hollow. These are the vocal cords. The lower folds are strengthened by fibrous 
tissue placed within the fold. These are called the true vocal cords, being alone employed in the production of the voice. The upper folds are called the false vocal cords.

5. The Voice.-There is a V-shaped space or chink between the true vocal cords, through which the air passes to and from the lungs. This chink may be narrowed or widened by the action of muscles, while at the same time the cords are made tight or loose like the cords of a musical instrument. It is this power to vary the size of the chink and the tension of the cords which produces the many different sounds the human voice is capable of uttering. In quiet breathing the air makes no sound, but the moment we tune up the instrument by tightening the cords and lessening the chink, the air makes a noise. The size and length of the vocal cords are not the same in every person, and hence the variety in the pitch of the voice. A short cord on any instrument gives a high pitch, and a long cord gives forth a deep or low note. It is the same in the human voice. In women and children, the larynx being smaller,

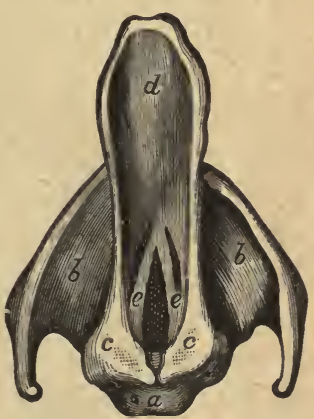

Fig. 32.-The Larynx as seen from above: $a, b, c$, cartilages of the larynx; $d$, epiglottis $e, e$, vocal cords. the cords are shorter than in men, consequently their voices have a higher pitch.

A musical sound is a prolonged vibration of the vocal cords. The number and variety of sounds produced in singing depend upon the length of the cords and their different degrees of tension.

Singing is an exceedingly useful exercise in school; it pleases the sense; it elevates the mind; it exercises the muscles of the chest; it trains and develops the vocal cords and increases the capacity of the larynx so that the child 
becomes what we may call an acquired singer; and lastly, what is also of great importance, it moderates and improves the quality of many voices which would otherwise be harsh and unpleasant.

Up to a certain period the pitch of the voice is much the same in both sexes. About the age of fourteen the larynx and vocal cords begin to grow rapidly, and the voice in the boy "cracks." Frequently the cords grow so rapidly, and become slack so suddenly, that a boy often wakens in the morning to find his voice has changed.

Voice is the sound produced by the vocal cords. Animals can produce sound, but they cannot speak. Speech is the voice modified by the mouth, tongue, teeth, lips and nose, and is a faculty of the brain which belongs only to man. Parrots and certain other birds have been taught to imitate sounds, but they do not possess the true faculty of speech. In whispering, the sounds are inade by the vibration of the lips.

6. The Pleura.-The lungs are enveloped in a closely attached serous membrane, called the pleura. Each lung has a separate covering. This membrane is reflected from the lung to the inner walls of the chest, and forms a complete lining to the thoracic cavity. It is also a closed sac like the other serous membranes of the body, and contains more or less watery fluid. The regular expansion and contraction of the chest causes a certain amount of motion between the walls and the lungs. The smooth pleura, with the contained fluid, assists the motion and prevents friction. Inflammation of the pleura is called pleurisy.

7. The Act of Breathing.-The space within the chest is increased on all sides by muscular action. One set of the oblique muscles of the sides draws the ribs upward, pressing the breast bone forward, while at the same time the diapliragm descends against the contents of the abdozaen. This enlargement of the chest esvity causes as ruah of 
air through the windpipe to fill up the lungs as they expand to occupy the increased space. We call this breathing in air or an inspiration. When this act is completed, the diaphragm at once ascends and the ribs are drawn down by another set of oblique muscles, bringing the lungs back to their ordinary size and forcing out the air. This is called breathing out or expiration. Under ordinary conditions the act of breathing is uniform and at the rate of about seventeen times to the minute, or about once to every four beats of the heart. If the heart is made to beat more rapidly by work, exercise or excitement, the breathing is also more rapid.

Breathing may be varied in other ways. In sighing, for instance, there is a prolonged inspiration followed by an expiration more or less audible. Laughing and crying are rapid, short contractions of the diaphragm. We distinguish them by the appearance of the face and the sound of the voice. In coughing and sneezing there is a sudden and forcible expulsion of the air intended to dislodge and carry out some offending substance either through the mouth or nose. Hiccough is a sudden spasm of the diaphragm, causing the air to rush against the closed glottis, producing a characteristic sound. Yawning is similar to sighing, but the air is drawn in through the mouth and the jaw lowered in a characteristic manner.

8. The Change of Elements in the Lungs.-The impurities in the venous blood brought to the lungs are carbonic acid in the form of a gas, water in the form of vapor mixed with certain organic maller, and slight traces of ammonia, also a gas. The air which reaches the lungs contains two gases, oxygen and nitrogen. The former is the life-giving element. Undiluted oxygen is so strong that if we place an animal in a jar of this gas it is exhilarated for a little while, and runs about with great animation, but it very soon dies-chemically burnt to death. Nature has 
provided against this by diluting the oxygen with nitrogen, an inert gas. These gases exist in the air in the proportion of one part of oxygen to four parts of nitrogen. There is also of necessity, since animals are constantly breathing it out, a trace of carbonic acid gas.

There exists a well-known chemical law amongst gases that when separated only by a thin moist animal membrane, they will commingle. Such an arrangement is found in the lungs - a very thin membrane or partition, on the one side of which are the gases of the air and on the other the gases in the impure blood. The process of exchange is therefore easily understood. The blood gives up its carbonic acid, its watery vapor with the organic matter dissolved in it and a trace of ammonia, while it receives in return a new supply of oxygen, which is carried to the heart and thence distributed to the tissues. The air, in parting with the required oxygen, receives from the blood its elements of impurity, and these escape with the expired air. Carbonic acid gas will not support combustion, that is, a lighted candle will go out if placed in a jar filled with this gas. The same will happen if we breathe into a jar and dip in a lighted taper, hence we know this gas is present in the breath. Watery vapor can be detected by breathing on a mirror or any highly polished substance. It collects more readily in a cool room; indeed, in very cold weather it condenses so rapidly that we can see our own breath as we walk in the open air. The organic matter that escapes by the lungs rapidly changes and becomes putrid. Breathe into a jar, close it and put it aside. In a few hours it will have a very rank smell, owing to the presence of decomposed organic matter.

19. The Effects of Impure Air.-It may be taken for granted geverally that anything the body casts off would, if retained, injure the system. Re-breathing the same air over 
and over again would soon destroy life. "The Black Hole of Calcutta" was a lungeon in which there were only two narrow windows. Here one hundred and fifty-six English soldiers were shut up, with scarcely room enough to hold them. At the end of eight hours only twenty-three remained alive. During a storm at sea, a captain ordered the hatches closed, and in six hours ninety of the passengers were dead. The high diffusive power of gases under ordinary conditions prevents such calamities. The carbonic acid gas spreads rapidly throughout the surrounding air, so that if the space in which we are breathing is not too confined, or too tightly closed up, it quickly becomes so diluted as to do no harm. To prevent its too great accumulation in the atmosphere there is a wise provision of nature by which plants and trees take in carbonic acid as we do oxygen, and give out oxygen as we do carbonic acid. In some places carbonic acid gas is found in such large quantities that it is not readily diffused or used up, and collects in great volumes. We find this at the bottoin of old wells, over fermentation vats, or in the "choke damp" of coal mines.

It is estimated that from twenty to thirty cubic inches of air enter the lungs at each breath, or from three hundred to four hundred cubic feet in twenty-four hours. By a knowledge of these facts, it may radily be letermined how much cubic space is required for school-rooms, churches, and other public buildings.

It has been observed that unbreathed air containing the same percentage of carbonic acid as the vitiated air of a close living room, is not so poisonous in its effects upon the system. It is evident, therefore, that it is important to get rid of the organic matter coming off from the lungs and the skin.

In cities and towns there are other impurities in the air which are dangerous to health. Sewer-gas, poisoned air from cess-pools and drains, the impure air from manufacturing 
places, such as chemical works, soap and bone factories, are all harmful, and often spread such diseases as cholera, typhoid fever and diphtheria. "Disease germs" float in the air, and are carried from place to place.

* Ventilation.-Of the many sources of impurity we have already given enough to show the necessity for a constant and alocindant supply of pure, fresh air in dwelling houses, schools, halls, churches, etc. The rapidity with which the oxygen in a room is taken up will depend upon the number of persons occupying the room. We must also take into consideration the amount consumed by fires, gas and lamps. Then, too, it must be remembered that each individual is giving off a quantity of impure material, which will accumulite and become foul. The drowsiness, headache and general feeling of languor and discomfort experienced in a badly-ventilated room are attributable rather to the presence of this noxious matter than to the want of oxygen. No system of ventilation is complete unless, in addition to entrances for fresh air, there are exits for foul air.

It is estimated that each individual should have for his allowance about eight hundred cubic feet of fresh air, and that this should be renewed at the rate of one cubic foot per minute. To renew this in sufficient quantity, without draught and without lowering the temperature, is the great object to be attained by ventilation. No system is perfect that does not fulfil these requirements.

In summer, little difficulty is met with where there are plenty of windows and doors. These give lots of space for the entrance and outflow of air. Besides, in warm weather it is not necessary to keep the heat confined in the room, and as the temperature of the room and the outside air are nearly alike, draughts are not very noticeable, and, if felt, are not so severe, the atmosphere being soft and mild. The winter season is the time when proper ventilation is most 
needed. Doors and windows cannot be left open with impunity. During recess, or whenever a room is unoccupied fur a short time, they should be thrown open for a few minutes, but, strictly speaking, the air should be warmed before it is brought into the room, and the foul air drawn off through openings in the walls. These openings should be large, and placed low down, so as not to carry off the newly adinitted fresh air, which, being warm, rapidly ascends.

Various systems of ventilation exist from which we may choose, but in making a selection expert advice. should be followed. In this connection it may be stated that dwellings should never be built over soil which is polluted by organic matter, such as decaying vegetable matter. Decomposition of animal and vegetable material is attended with the production of poisonous gases. When a dwelling is placed over such matter, foul gases will rise and penetrate the building. In winter, especially, the heat of the house tends to draw those gases through the lower floor, when they will ascend intc all parts of the house.

10. How the Heat of the Body is kept up.-Bodyheat is generated or produced by the oxidation or burning of certain materials in the body. The heart and lungs are not stoves for providing heat and distributing it to the body, but by their combined influence the red corpuscles of the blood are made capable of producing changes in the system which result in heat. They are the oxygen carriers and give it out to the tissues, where it unites with certain elements in the form of combustion. The mysteries of life have not so far been revealed sufficiently to show exactly in what proportion certain materials form the fuel. Not unlikely it is to some extent the worn-out material, but chiefly the refuse of nutrition. The evidences of economy shown in the human body, and in its various functions, support the belief that it is the remnants of the nutritious 
material after the cells composing the body have received what they require for their growth and development, which form a large part of the fuel of the body. The brokendown cells which have formed a part of the living structure, like a worn-out building, may be still used as fuel, but at the same time we know that when much heat is carried off from the body, as in cold climates, there is a desire for carbonaceous food.

While the lungs are not the source of heat, they are the portal by which the oxygen necessary for combustion enters the body, and if the lungs fail in their duty the supply of heat to the body is affected. See how a brisk walk in the open air, by producing a more rapid breathing, starts the flame of life into a greater glow.

11. The Need of Clothing.-The production of heat in the body, and its loss by radiation, etc., are so evenly balanced that the internal temperature in health varies but a trifle. A man may travel from the extreme north, where it is intensely cold, down to the hot climate of the Equator, and not vary one degree of heat within his body The thermometer will register close upon the normal heat, which is $98_{\frac{2}{5}}^{\circ} \mathrm{F}$. We wear clothing to help in adapting ourselves to the varying climates. In cold climates, plenty of warm woollens and furs are needed to prevent the body-heat from escaping. In hot climates, light goods open in texture are more suitable, because they help to conduct off the body-heat, while they protect the skin from the rays of the hot sun.

12. Effects of Alcohol on Respiration.-When speaking of the effects of alcohol on the skin, we noticed that it caused a dilatation of the capillaries all over the system. We are now able to understand what this means with regard to the lungs. A dilated condition of the almost endless number of capillaries surrounding the thousands upon thousands of air cells would mean the loading of the lungs with 
a large amount of extra blook, which, if frequently repeated or kept up for a length of time, would cause a congestion of those organs. How often do we hear of excessive drinkers having attacks of severe cold, pleurisy and inflammation of the lungs, which, if not immediately fatal, may lead on to that most dreaded disease - consumption.

Besides being predisposed by the use of alcohol to those diseases, the inebriate is more subject to them from the fact of his more frequent exposure to cold and damp. Often going about with his clothes wet and with an empty stomach, excepting for the whiskey it contains, it is little wonder he is ultimately overtaken with the seeds of disease which take root in one of the most vital parts.

We have seen further that alcohol decreases animal heat and lessens power to resist cold. A general chill may mean a congested condition of some of the internal organs, and most probably the lungs. If we drive the blood from one part, as, for instance, the skin, it must appear in greater quantities somewhere else.

It is not while the stimulating effect of alcohol is felt that a chill is likely to occur, but after the rapid loss of heat by radiation and inactivity of body from general depression have lowered the temperature below the normal. Reaction in these cases sets in so slowly that it is often many hours, and even days, before the man feels the same warmth and comfort of body he experienced before his debauch.

No wonder that such abuse of the system leads to derangement of function and irregularity of blood supply to the various organs. No wonder that drunkards succumb more readily to epidemic diseases than do total abstainers. It has been observed over and over again in cholera-infected districts there is always a larger percentage of deaths amongst those addicted to the use of alcoholic beverages, than amongst those who abstain from all such drinks. 
Let us follow up the effects of alcohol on the respiration of the moderate though regular tippler. The frequent engorgement of the capillaries of the lungs leads to a permanent dilated condition, with increase of surrounding tissues and thickening of the cell walls. Increase the thickness of this partition and immediately the free exchange of gases is interfered with. The blood is not properly purified, and goes back into the system already loaded with the impurities it is intended to pick up. The heart and lungs take on increased action, in order to compensate for the loss of vitality in the fluid. Breathing becomes more labored and frequent, and often wheezy. The whole system lacks endurance.

Lord Wolseley, on his Red River Expedition, did not allow spirits to his men, although they had to work hard and were sometimes wet through for days together. What was the report upon the sanitary condition and behaviour of these men? "Up early, hard at work all day, rowing or portaging from 5 a.m. to 8 p.m., with a short interval for breakfast and dinner, nothing to eat but salt pork and biscuit, nothing to drink but tea, yet they looked as healthy as possible, and when they reached Fort Francis there was not one sick man amongst them."

13. Cigarette Smoking.-Because a cigarette seems the most innocent form of using tobacco, it is often the way a boy begins its use, while at the same time it is, perhaps, the most harmful. The smoke from a cigarette is not so strong nor so irritating to the mucous lining of the mouth as that from a cigar or pipe, and, as a consequence, it is usually inhaled into the lungs. In this manner the poison fumes of tobacco, and often of other narcotics-as, for instance, opium in a Turkish cigarette - enter more directly into the system, and not only irritate the lung tissue, but vitiate the blood, and hence the whole system. 


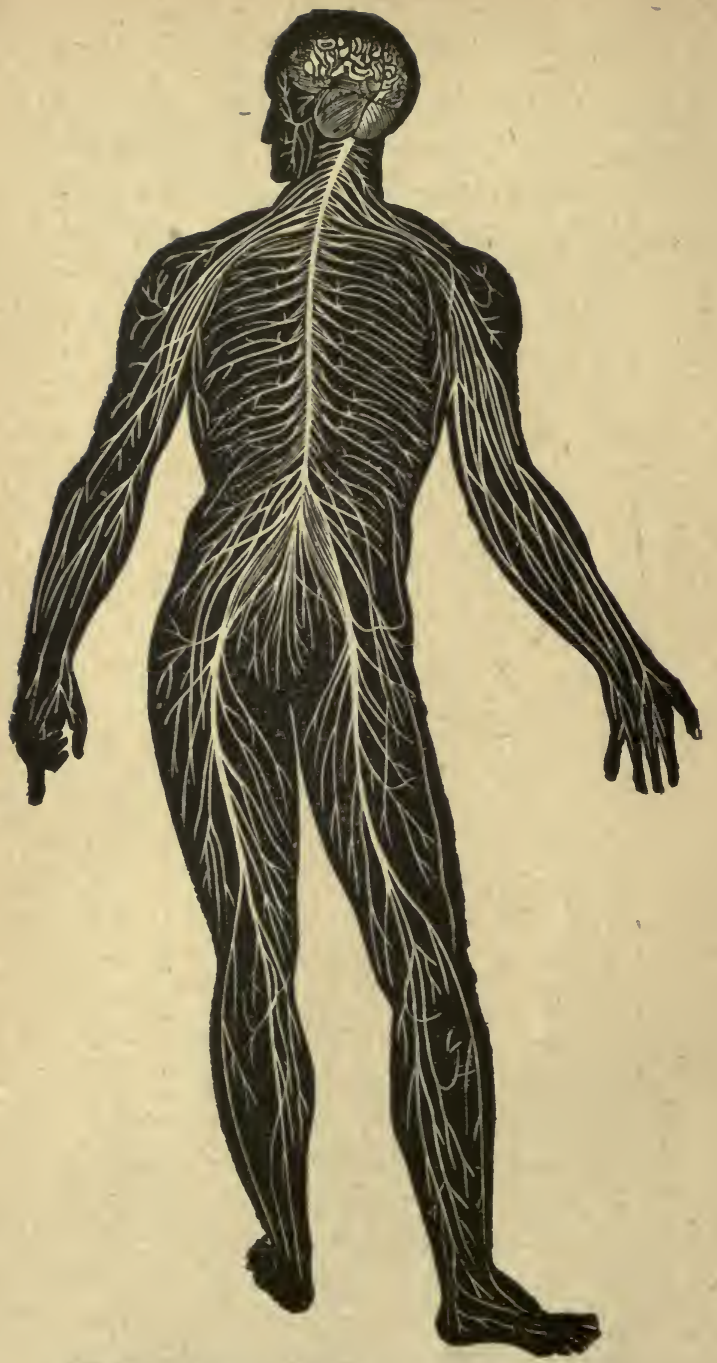

Fi6. 33.-Diagram illustrating the general arrangement of the Nervous System. 


\section{CHAPTER VIII.}

\section{THE NERVOUS SYSTEM.}

1. The Organs of the Nervous System.-In speaking of the nervous system, reference is made to the brain, spinal cord, the nerves distributed to every part of the body, and to ganglia, found in certain parts. The brain and spinal cord are continuous through the large opening at the base of the skull. They form the cerebro-spinal centre or axis. Their structure is so soft and so easily crushed, it is essential they should be well protected; they are therefore inclosed in bony cavities. They consist of two kinds of matter, a white fibrous portion and a gray vascular portion.

2. The Brain.-The brain is a mass of white fibres, overlaid with cells of gray matter, and lodged within the strong bony walls of the skull. It consists of two parts, the cerebrum, situated at the summit and in front, and the cerebellum, placed below and behind.

The weight of the brain ranges from forty to forty-seven ounces in the female, and from forty-six to fifty-three ounces in the male. The weight increases rapidly during early childhood. After the seventh year it grows less rapidly. From sixteen to twenty the increase is still more slow. Between thirty and forty the weight begins slowly to decrease. The weight of the brain in man is greater than in any of the lower animals, except the elephant and whale. As a general rule, the size of the brain indicates the intellectual capacity of the individual, but there are some striking exceptions. The size of the cerebrum is a more reliable guide in determining the mental power, but even this is not always a 
correct indication of the mental capacity. The shape of the head affords no guide to the character or mental endowments, as it may be the result of external pressure. But when the front and top parts of the head-that is, that portion in front of the ears-are deep, high and broad, it is evidence of a large cerebrum, and generally indicative of a high degree of brain power. The skull is not of the

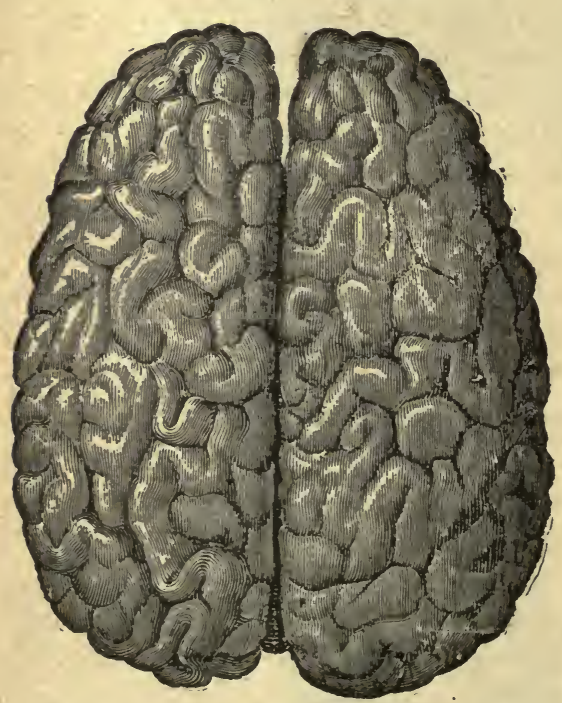

Fic. 34.-Upper surface of the Brain, showing the convolutions and its double structure. same thickness in all persons. Over the eye-brows there is a space between the two tables of bone. The extent and depth of this cavity cannot be determined by outward observation. A prominent forehead is often due to a large frontal space.

The gray matter covers the white portion, and is next to the bone; but it is not spread out on an even surface, nor does it present on its outside a uniform surface. There are a number of rounded edges, called convolutions, separated by deep furrows. These furrows are merely spaces formed by the convolutions dipping down and returning back in a sort of a fold, just as a seamstress would make a ruffle. These folds vary in depth in different parts of the brain and in different persons. The gray matter not only covers the surface of the convolutions, but dips down 
into these dividing lines, so that the two surfaces of the gray matter are in contact. The quantity of gray matter in the brain is the true measure of brain power. Not only does the depth of the folds vary in different brains, but also the thickness of the gray matter. To ascertain, therefore, the extent and amount of gray matter, it would be necessary to open out the convoluted mass and measure its thickness. In view of these facts, the value of phrenology, as practised by bump-feelers, may be duly estimated. To define a person's character and mental ability by the outward appearance of the skull is impossible. In order to arrive at a correct estimate, it would be necessary to know the thickness of the skull, the depth of the frontal space, 'he thiokness of the gray matter, and the depth to which the layer dips down between the convolutions.

3. Function of the Gray Matter of the Brain.-The gray matter of the brain is the seat of the will. Here, in a measure, is generated the nerve force. It is the seat of the intellectual faculties, the throne of reason. At this seat of power resides the authority by which the body is governed. Messages are continually arriving in the brain from every part of the body, far and near, regarding the welfare of the several parts or dependencies. At these headquarters due notice is taken of everything concerning its welfare, and orders are issued to muscles and other tissues, by which the interests of the body are looked after. The gray matter is made up of minute cells and of vascular tissue.

4. Function of the White Matter of the Brain.The white fibrous matter upon which the gray is laid receives the directions and instructions from the seat of power, and by white cords laid to every part of the frame, like telegraph wires, transmits the nervous influence to whatever part of the borly it may be necessary. By the same nerve wires, intelligence is received from every station in the body, even the 
most outlying parts. The force generated by the brain cells and thus employed is like electricity; but it is something more, which no physiologist has yet been able to define.

5. The Cerebrum.-The upper and front part of the skull contains the cerebrum. It forms about seven-eighths of the total weight of the brain. It is divided by a deep fissure into two halves, the right and left hemispheres. Each half is in itself a brain, the one half supplementing the other, as one hand or one eye does the other. Injury to the brain, with loss of brain substance on one side, does not necessarily cause loss of brain power.

6. The Cerebellum. - Immediately under the back part of the cerebrum, but separated from it by a firm membrane, lies the cerebellum, or lesser brain. It is about the size of the fist. The convolutions are not so irregular as in the cerebrum. The gray matter dips down into the white substance in parallel ridges, and is so arranged as to give its internal appearance a resemblance to a tree with branches and leaves. This is called the arbor vitce, or tree of life. The cerebellum is the nerve centre for controlling the voluntary muscles. It is also made up of two halves.

7. The Medulla Oblongata.-The medulla oblongata is the upper thickened end of the spinal cord, and forms the connecting link between it and the brain. It is about an inch and a quarter in length, and is thicker in its upper than its lower part. It also is divided into two symmetrical halves. The medulla oblongata consists of white and gray matter. The gray matter, which in the brain is on the surface, and in the spinal cord is in the interior, is continued up from the latter in the interior until it reaches the upper part of the medulla, when it begins to show on the surface.

The medulla oblongata is a very important centre, for from it pass off the nerves which control breathing, swallowing and the action of the heart. Injury here is very sudden and serious in its effects. 
8. The Coverings of the Brain.-Three membranes envelop the brain, an outer, middle and inner. The outer is closely attached to the bone, and forms the periosteum. It is a tough, strong membrane, composed of fibrous and connective tissue. Besides lining the skull, it forms a strong upright partition between the two hemispheres of the cerebrum, and also the floor upon which the back part of this portion of the

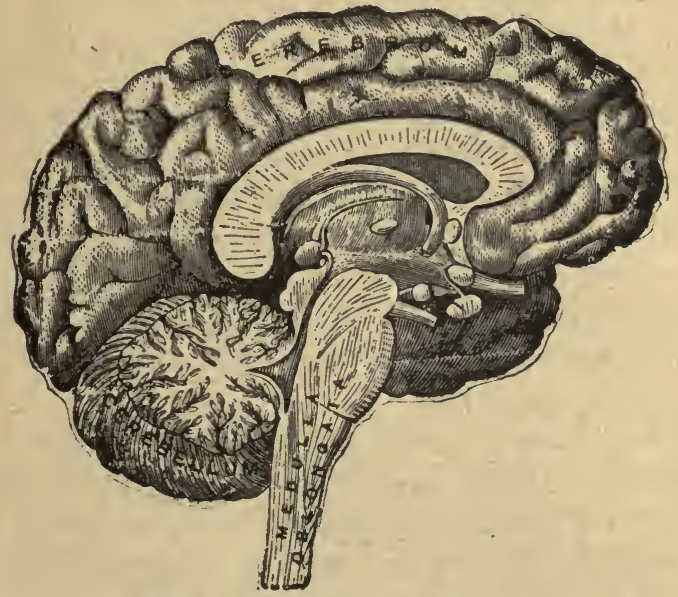

F10. 35.- Vertical section of the Brain.

brain rests. This floor for the cerebrum is the roof for the cerebellum.

The inner membrane is a thin, firm tissue, in close contact with the brain, and dipping down with it into the furrows. It is abundantly supplied with meshes of blood-vessels, and many of these extend into the brain substance to nourish it.

The miadle is a very thin membrane, so thin that it has been likened to a spider's web. It envelops the brain loosely, and is more or less separated from the other membranes by loose tissue and by Huid. The quantity of fluid varies in 
different parts of the brain, and according to the fulness of the blood-vessels.

9. Protection of the Brain. - The provision made to protect the soft yielding brain from concussion requires some notice. We have spoken of the protection afforded by the smooth, round, skull, with its two tables thickened and strengthened at the most exposed parts. Within the skull, this jelly-like mass does not lie like a lump of jelly. It is supported in several ways. - The front part rests upon a shelving of bone, the roof of the nasal cavity. The middle lobes have each a snug little cavity of their own, and the back part rests on the flooring of membrane. The upright partition prevents one hemisphere from pressing upon the other, and is a supporting column. Within the brain substance itself are a number of small cavities containing fluid, and these cavities communicate with the outer spaces. By this arrangement the pressure is equalized, and as the fluid raturally tends towards the lowest parts, the brain in reality rests upon a perfect water-bed.

Complete as this is, it is not, the whole of that all-wise arrangement by which the nerve centres are protected. The cavities of the brain communicate with the cavity of the spinal canal, so that the fluid can pass from one to the other. Hence it is called the cerebro-spinal fuid. If the blood supply in the head is from any cause excessive, some of this fluid finds its way out of the brain along the cord into the spinal canal. When the blood pressure within the brain is lessened, the fluid wells up again to occupy the space. Thus the equilibrium is constantly maintained.

10. The Spinal Cord. - Safely enclosed in the bony canal formed by the vertebræ is the second portion of the cerebro-spinal centre. It is a cylindrical cord of nerve tissue about three-quarters of an inch in diameter and seventeen inches long, tapering at its lower extremity. It does not 
nearly fill up the canal. White and gray matter make up the cord, as in the brain, but the white matter is placed outside and the gray within. It commences at the large opening at the base of the skull, the part above this being the medulla oblongata.

The spinal cord is composed of two lateral halves, formed by a fissure in front and behind. From each half nerves branch off, and dividing and sub-dividing, are distributed to the trunk and limbs of the body.

Surrounding the cord are membranes similar to those of the brain, only the outer membrane is not attached to the bone, as in the brain. Such attachment would prevent the several motions of the spine. This outer membrane of the spinal cord is a loose sheath, attached at the top and at intervals to the bony walls. Within this sheath is the cerebro-spinal fluid, so that the cord is virtually suspended in a flexible tube of fluid, and is thus protected from injury or shock.

11. The Nerves.-Running throughout the body everywhere can be found slender, white, glistening cords. These are the nerves. They look somewhat like the tendons of the muscles, only smaller. They are not so tough and strong. A nerve trunk is made up of a number of fibres running side by side, like the threads in a skein of silk. These fibres are individual nerves, which, bound for the same locality, are held together by connective tissue in a single trunk.

Besides the nerves which come off from the brain and spinal cord, there are others which have their centre in knots of nerve tissue scattered through the body, called ganglia. These are all connected together and form the sympathetic system. There are therefore three classes of nerves, spinal, cranial and sympathetic. All three classes convey impressions of a twofold kind. There are those fibres along which impressions travel to the brain, and by which it is made 
conscious of what is going on. These are called sensory nerves. Also, fibres by which impressions travel from the brain and cause muscles to contract or cells to take on increased action. These are called motor nerves.

12. Spinal Nerves.-Thirty-one pairs of nerves are given off by the spinal cord. The openings in the bones of the spine on each side allow them to pass out. Each nerve has two roots, one in front and one behind. The anterior root consists of motor fibres, the posterior of sensory fibres. The two roots unite or are bound together in one sheath. If the anterior root were cut or destroyed by disease, the person

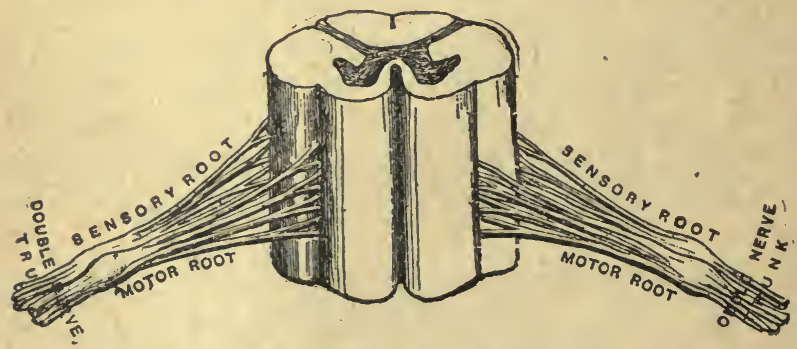

Fi๘. 36.-Section of Spinal Cord, with roots of spinal nerves. Front view.

would lose the power of motion in the part supplied by that nerve, that is, that part would be paralyzed. If the posterior root were divided, the power of feeling would be lost. The spinal nerves, after leaving the spinal column, are formed into several groups, where they join together and then branch off to different parts. This collection of nerves is called a plexus.

13. Cranial Nerves. - Arising from the base of the brain, the medulla oblongata, and one pair from the upper part of the spinal cord, are the twelve pairs of cranial nerves. They all emerge from the skull, through small channels in the bone. Nearly all of these nerves have their' 
deep origin in the medulla oblongata, although! the superficial origin of some of them is some distance off.

THE FIRST PAIR are known as the olfactory, or nerves of smell. They pass out through the roof of the nose, and are distributed to the lining of the nostrils.

THE SECOND PaIR, or optic nerves, are distributed to the eye-balls, and are the nerves of vision. These nerves do not pass directly forward, one to each eye, but cross fibres with each other before they leave the skull, making a close union between the eyes.

The third PaIR, THE FOURTH PAIR ANd THE SIXTH PAIR supply the various muscles by which the eyes are moved. These are called the motores oculi.

THE FIFTH PAIR are called the trifacial, on account of each dividing into three branches. These are the largest nerves given off from the brain, and supply the skin of the face and some of the deeper parts, such as the teeth, roof of mouth, soft palate, tongue, etc. One branch supplies the sense of taste. It is usually some of the branches of these nerves that are affected in people who suffer from neuralgia of the face and tooth-ache.

The SEventh PaIR, or facial, are the moving nerves of all the muscles of expression in the face. They usually work in perfect unison and cause the muscles to draw evenly, as in laughing, singing, whistling, etc. When one of these nerves is paralyzed it gives a very odd expression to the face.

THE EIGHTH PAIR, or auditory, pass to the inner ears, and are the nerves of hearing.

The Ninth PAIR, or glosso-pharyngeal, are distributed to the mucous membrane of the pharynx and neighboring parts.

The TENTH PAIR, or pneumo-gastric, are the most widely distributed of all the cranial nerves. They send branches to the windpipe, lungs, gullet, stomach, heart, etc. 
The eleventh PAIR are called the accessory, because they join the tenth pair. They also supply the organs of voice.

The TWELFTH PAIR are called the hypo-glossal, or regulators of the tongue.

14. The Sympathetic System.-In this system we have the nerves of organic life. It is a double chain of ganglia, with nerves connecting them. They are situated on each side of the backbone, from the head to the lower extremity of the spine, with extensions into the chest and abdomen. They consist of soft, gray matter, and supply the organs on which life depends, as the stomach, lungs, heart, etc. They control the blood-vessels, and have frequent connections with the cranial and spinal nerves. Blushing is a sympathetic act, allowing the blood-vessels of the face to enlarge and fill with blood. Fear, on the other hand, blanches the face, by the sympathetic nerves contracting the blood-vessels and driving out the blood.

This intimate relationship of all the nerves of the body, keeping every part in free communication and in close sympathy with every other part, explains the designation, "sympathetic system." By the sympathetic system, the brain has free intercourse with every part of the human frame, and by this link exercises control over all the important functions and vital operations of the body.

15. Growth and Development of the Brain.-As we have seen, the growth of the brain in early childhood is very rapid. As years advance, the increase in general bulk is not so marked. There is usually, however, a continuous growth, but it is largely confined to the gray matter. As in other structures of the body, so in the brain, proper exercise is necessary. The amount of gray matter, with the corresponding amount of intellectual strength, depends largely on a due exercise of the faculties of the mind. The amount and kind of exercise should be regulated by those properly trained and 
educated to discharge so important a duty. While aiding in the development of the mind, let us remember it is necessary to keep the body in a sound state. The various organs must be in a sound condition to perform their proper functions. The body itself must be supplied with the requisite food. The blood must be duly purified by the constant supply of pure air. The muscles must be daily exercised. The skin must be kept clean. In a word, none of the functions of life must be wanting in a healthy performance of their respective duties. To exercise the brain, and pay no regard to the body generally, is sure to result in unhealthy development. This is particularly the case in early childhood.

All children are not born with the same power for brain development. Some are born without the germs for much future brain power or active intelligence. Others are born with the elements which produce very fertile minds. The careful teacher will discriminate between these two classes, and he will rate the varying grades of capacity in the young under his control. He will be guided by this consideration in directing the mental exercises allotted to each. A bright. active mind requires no urging, and often should be held in restraint; while the sluggish brain must be stirred by encouragement and stimulated by example.

Overwork of a too active brain is sometimes the direct cause of acute disease of that organ, with a fatal termination. In other instances, too much brain-work leads to degeneration of the over-grown gray matter, and the promising child becomes sluggish in mind or deficient in intellect, and even in some cases an idiot. It must never be forgotten that physical exercise is just as important to the growing child as brain-work, and in many cases more so. When a quick, clever child becomes indifferent to play, and prefers to sit in dreamy idleness, his brain is not in a hcalthy condition, and 
requires careful attention. No child or youth should be allowed to isolate himself.

The same uniformity of exercise in brain and body generally must be observed all through the active years of life. If the ardent student, in preparing himself for an examination, fails to take physical exercise and give his brain an opportunity to rest, the chances are he will not only fail in his examination, but permanently impair his mental strength by the over-work of the brain.

16. Rest and Sleep.-The necessity for rest at stated periods is most imperative. Brain work will be better done when due attention is paid to regular rest. It is the same as in the use of muscles. The skilled workman can continue his employment only for a certain time. The laborer does more and better work when he takes an occasional rest. Besides this voluntary rest of the brain, nature has provided a rest which must be taken by everyone. In sound sleep the brain gets complete and perfect rest. Any attempt to shorten the hours of unconscious repose is a violation of the laws of health. Nature will not be cheated of its "sweet restorer, balmy sleep."

But sleep is also essential for body rest and for repair of the whole system. During those restful hours in bed, the circulation is lowered and the heart-beats are fewer. Just as it is less tiring for us to walk than to run, so is it much easier for the heart to beat at the rate of fifty or sixty times a minute, as it does in sleep, than at seventy or eighty when we are moving about. And again, while we are asleep nature is busily at work building up and repairing the tissues, and restoring the energy we have exhausted during the day.

The amount of sleep demanded by nature is not the same in all persons. More sleep is necessary for the young than for the old, and for those whose employment is arduous than 
for the idle. Sleep is the natural rest of all organs. The more all the organs are used the more rest they need. The organs of the child are particularly busy. They have to sustain their proper functions and also assist in the general building up of its body, and hence a child needs lots of sleep. From six to eight, and in the young, ten hours of sleep out of the twenty-four, is not too much. Girls need more sleep than boys. It is always an injury to be awakened out of a sound sleep, and it is particularly so with the infant. It is extremely doubtful if at any time anyone can take too much sleep.

17. The Abuse of Narcotics. - Sleeplessness may be due to a variety of causes. Whatever the cause, it should be attended to and removed as early as possible. A serious cause of inability to sleep is over-work of the brain and mental worry. In such a case a person should give up all brain work at once, and rest long enough to allow the brain tissues to recover their tone. In addition to absolute rest, change of scene and diversion of the mind are most desirable. In no case should opiates or ether narcotics be used to enforce sleep. To tamper with such drugs is unsafe. They are injurious to anybody, but particularly so to infants and young children. All the "soothing syrups," * cordials" and "drops" contain opium, and should never be allowed a place in the family medicine chest. Sleeping draughts paralyze the nerve centres and impair digestion, and worse than all, there is always the risk of an over-dose, which usually results in death. It is very unwise to use any medicine, especially any of the narcotics, such as opium, morphine, chloral, bromide, etc., unless ur.der the guidance of a physician.

18. Effects of Alcohol on the Brain and Nervous System. - When alcohol is taken, its direct effect is upon the brain and the nervous system generally. It is primarily through the nervous system that it exerts its evil influence 
on the different organs and tissues of the body. The effects of alcohol are conveniently divided into four stages.

The First Stage. - The first effect upon ths nervous system is to weaken the capillary nerves, and thus allow the small blood-vessels in all parts of the body to dilate. This produces, as we have already said, a general redness of the skin, most noticeable in the hands and face. But the same condition of the small blood-vessels exists inwardly as is found on the surface of the body. There is increased circulation in the tiny blood-vessels throughout the gray matter and anongst the white fibres, wnich causes an exaltation of the mental faculties and a general exhilaration. This constitutes the first stage.

If its use is now discontinued the poisonous effects pass off, the blood-vessels regain their natural size, and the normal condition of the system is restored. But even this temporary stimulation is followed by reaction, and the individual feels a corresponding depression or prostration, while the aching head shows that the brain tissue has been exposed to the ravages of an injurious agent. If addicted to the use of alcohol for some time, though only to the extent of this first stage, serious results may follow. The coats of the small blood-vessels become weakened and diseased. The increased force of the heart may burst the weakened coat and allow the blood to escape into the brain substance, and. by pressure render the victim unconscious. He has, in fact, been seized with an apoplectic fit, and if the escaped blood is sufficiently large in amount, death will be the issue, or if life be spared he will almost certainly lose much of his mental power.

The Second Stage.-If the individual continue to imbibe alcohol, the condition of the first stage gradually changes and other symptoms appear. The voluntary muscles become affected. They are no longer under the complete control of 
the mind. The effect upon the brain is such that the person feels "jolly." But he loses his mental balance and says and does things he would not say or do if in his sober senses. The heart's action is quickened, and the blood, charged with alcohol, is pumped into the brain with increased force.

If even now he fortunately ceases to drink, the system will struggle back to a natural state. Sturdy efforts will be made to carry the poison out of the system. Corresponding reaction again sets in. The headache becomes a pain, the organs supplied by the cranial nerves are disordered. $\mathrm{He}$ has a sick stomach, feels generally out-of-sorts, and very likely ashamed of his intemperance. The dangers mentioned in connection with the first stage attend the second stage in a greater degree.

The Third Stage.-Continuing to drink after the second stage has been reached will, in due time, produce intoxication, a condition in which the individual ceases to be a rational being. The nervous system no longer controls the vital organs of the body. They are all filled with blood, and are incapable of performing their functions. The mind is obscured, and only the animal part of man remains in action. When thus intoxicated, the person may be silly and full of ridiculous talk, or shout or laugh immoderately. Perhaps he will boast about himself in a most untruthful manner, or he may bewail imaginary griefs and shed tears of supposed sorrow. On the other hand, he may become passionate, cruel and quarrelsome, so as to do serious acts or commit crimes altogether contrary to his nature when sober. If he stands or attempts to walk he has no control over the muscles, and reels or staggers on his way, or falls helpless to the ground.

$\mathrm{He}$ has now lost all the elements of manhood, and is "beastly drunk," and yet is it not a libel on the beast of the field, whose only drink is that provided by the Creator, to have a man, thus degraded, compared to him? In this 
condition the whole of the vital organs are in a state of disease. The heart's action is feeble and unsteady. The heat of the body, which in previous stages was slightly increased, at least on the surface, is now reduced below the natural temperature. The blood-vessels are over-loaded, from want of proper circulation; a state of lethargy sets in, and he becomes entirely unconscious. The poor unfortunate is now "dead drunk," and the fourth stage is reached.

The Fourth Stage.-A person "dead drunk" may be said to be at the portal of death itself. Everything that characterizes the man is dead. The senses are all dead. The voluntary muscles are the same as dead. Raise the arm, and it will fall helpless, like that of a dead person. Place your hand on the surface of his body, and it feels as cold as death. Excepting for the heavy, labored breathing and rattling in the throat, he might be considered actually dead. But there remains just enough vitality in the nervous system to act upon the respiratory centre and keep the heart in action in a feeble, uncertain way. All the other powers of life are entirely in abeyance. A person in such a state is liable to die at any moment. The dose of alcohol he has taken may be sufficient to extirguish what little life remains, and thus close the fourth stage. His utter helplessness also exposes him to death by accident. Lying out in the bitter cold, he readily perishes. If he falls into water, he has no power to save himself, and drowning ends the scene. Completely dazed, he stumbles about and, perhaps, falls in the middle of the road or on a railway track, and there he lies, unconscious of the approaching vehicle or train which will crush out what life remains.

Sir Benjamin Richardson, in classifying the effects of alcohol into four, stages, says, when referring to the fourth: "The last stage of all, the stage just short of death, the fourth stage of the action of alcohol, is clearly not only un- 
natural, but a stage of dreadful disorder and of danger. It is clear, surely, to the simplest mind, to the mind of the youngest child who can read this book, that a person who is lying down, unable to move naturally, unable to hear plainly, unable to see correctly, unable to speak distinctly, and unable to do anything more than breathe and live-it is clear, I repeat, to the simplest mind, that a person so placed must be in a state of danger and disease as bad as any that could be caused by those accidents we all shrink from, accidents that wound and stun and kill.

"If we look at the whole course of the action of alcohol from the first stage to the last, we can see no good whatever that is supplied by it. Every step that seems harmless is, at best, nonsensical ; and every step that seems to be hurtful, is hurtful beyond anything that I can explain."

19. Results of the Use of Alcohol.-It will be observed that the four consecutive stages gradually merge from one into the other. There is no distinct line to mark the close of the one and the beginning of the next, and there is no uniformity amongst those who drink. There are many who daily use alcoholic drinks who do not experience the several stages described, and there are some who never take enough to pass beyond the first stage, but in any of these there is always the danger of overstepping the limits each has prescribed for himself. The taste for such drinks, when once established, is with difficulty, in many cases, overcome. With many others the desire to take more and more is irresistible. There are not a few who never take enough to cause intoxication, but are more or less under the influence of alcohol every day. They have acquired the habit-in other words, the brain has undergone certain subtle changes which constitute a disease. Such persons are afflicted with what is known as alcoholism.

This disease may be acquired in the way mentioned, or it 
may be inherited. The symptoms are not always the same. While some keep the system saturated daily by oft-repeated doses, others will only periodically give way to the morbid impulse. This insatiable desire for intoxicating liquors at stated intervals is called dipsomania, and in many cases it is so strong that a man's whole mental power and moral nature are subjected to its evil influence. Recovery from this disease is possible, but, sad to say, it is not common. The best and surest treatment is of a moral character, aided by suitable nerve tonics.

Alcoholism is a brain disease, and is most common among brain-workers, who, being engaged perhaps in ambitious or exacting pursuits, and passing through hours of -worry, risk the temporary relief which a stimulant gives. It' is obvious that such cases should, if possible, find some occupation in which there would not be the same strain on the nervous system. A prolonged rest would be better still. A complete change of place and surrounding influences should be made.

It would be easy to point out other forms of disease arising from the use of alcohol, but the picture already presented should be sufficient to satisfy anyone of the terrible evils it brings to those who indulge in its use.

20. Tobacco. - The action of tobacco on the nervous system is that of a narcotic poison. Its active principle is nicotine, a very strong and rapidly fatal poison. A single drop given to a rabbit will produce death in a few minutes. The habitual smoker does not as a rule experience any alarming effects from the nicotine he absorbs, because his system has become used to it. Ask the same smoker how he felt after his first smoke. He will tell you, for he remembers it well, that he turned sick; the skin became pale, and a cold, clammy perspiration stood out on his forehead; his muscles weakened, he trembled all over, and his brain reeled so that he could not stand. The depression was alarming; he was 
completely prostrated. It was only after repeated trials, and when he had got the system accustomed to it, that he could take his smoke with comfort.

While it is possible to train the system to tolerate the poison to such an extent as not to cause any immediate prostration, there is hardly a smoker who does not feel at times a certain amount of nervous depression. It may be a slight trembling of the muscles, causing the hands to be unsteady, or it may be a weak, trembling action of the heart, with a very rapid pulse, sometimes irregular. This action of tobacco on the heart has become so noticeable as to be known by the medical profession as "the tobacco heart." Then again he may suffer from a form of nervous dyspepsia, with nausea and loss of appetite, or a general irritability of the nervous system, with headaches, weakened memory, impaired vitality, and loss of flesh.

It makes little difference in what form tobacco is taken; whether in smoking a pipe, cigar or cigarette, taking it in the form of snuff, or chewing tobacco, the nicotine is absorbed, and it is only a question of the amount in each case. It is true some forms are more cleanly and less offensive to our friends than others, but in any form it is injurious, and is at best a selfish and a filthy habit.

\section{Evil Effects of Tobacco on the Young.-Tobacco} has a more profound effect upon the nerves of a young lad than on a grown person, because his nervous system is more sensitive and more easily impressed. It is a hundredfold more injurious in youth. It weakens the system and tends to impair muscular and mental activity. The whole body is saturated with a poison, and cannot grow and develop as it should. The use of tobacco in any form by young persons should be sererely condemned. Self-preservation is the first law of nature. Let us protect ourselves against this enemy by shunning it altogether. 


\section{CHAPTER IX.}

\section{THE SPECIAL SENSES.}

1. The Five Special Senses.-In addition to the common supply of nerves of ordinary sensation stationed everywhere, like sentinels, to guard the body and keep us informed of the condition of all its members and organs, there are special nerves for acquainting us with what exists outside of ourselves. These nerves go to supply certain organs which are specially adapted to receive impressions from the outer world. There are five special senses-taste, smell, sight,

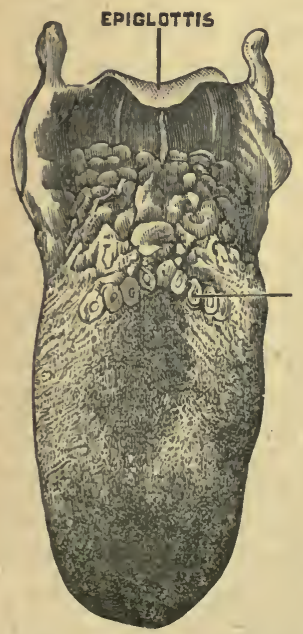

Fia. 37.-Upper surface of the Tongue, showing the papillø. hearing and touch.

\section{The Sense of Taste.-}

The tongue is the organ of the special sense of taste. If we examine the tongue carefully, we can see on its surface a number of small projections. These vary in size. At the back they are quite large. On the sides and at the tip they appear as small red points, while on the surface generally they are very minute and thickly set. These little papillæ are the taste points, and into them can be traced the tiny endings of the nerve of taste. In the act of tasting, 
the papillæ start up, giving the coat of the tongue a velvety appearance.

In order to taste any substance it must be in solution. We cannot taste the sweetness of sugar until some part of it melts on the tongue. Anything that will not dissolve is tasteless. The different tastes seem to be limited to certain parts of the tongue. For instance, salty and bitter substances are best tasted at the back part, while the tip takes notice of sweet substances and the edges best appreciate acids. We have natural tastes and we have acquired tastes. In his original state, man is guided almost solely by the natural sense of taste in selecting his food. Amongst civilized people there are many acquired tastes. While the sense of taste is intended to distinguish between what is suitable and what is not suitable to enter the stomach, we often violate this sense and take what is not good because we have acquired the taste. No one will say, not even the toper, that liquor is agreeable to the taste, even from the very starting of the habit. The hot, fiery liquor is never agreeable, but it is forced upon the delicate taste bulbs, and their judgment is ignored, until this sense becomes depraved. It is possible, also, to train the taste to tolerate, and even to like, certain articles of food which at first are not palatable.

The appearance of the tongue varies in different persons. In some it has a smooth, soft, even surface. In others it is mapped out in sections by deep lines, which intersect each other. In a healthy state of the system it is reddish in color, but is readily affected by disorders of the stomach, and covers over with a whitish or brownish coating.

In some animals the surface of the tongue is very rough. The papillæ are long, and stand out firm and stiff. The cat, for instance, has a rough tongue, while some beasts of prey can strip the flesh from the bones of their victims with the tongue alone. 
3. The Sense of Smell. - The outward shape of the most conspicuous feature of the face needs no description. The frame-work of the nose consists of bone and cartilage. Fourteen bones enter into the formation of this organ. Four plates of bone are so placed as to form a strong arch, the bridge of the nose, capable of resisting considerable outside force. Joined to the plates of bone, on either side, are plates of cartilage to form the nostrils. The chamber thus formed

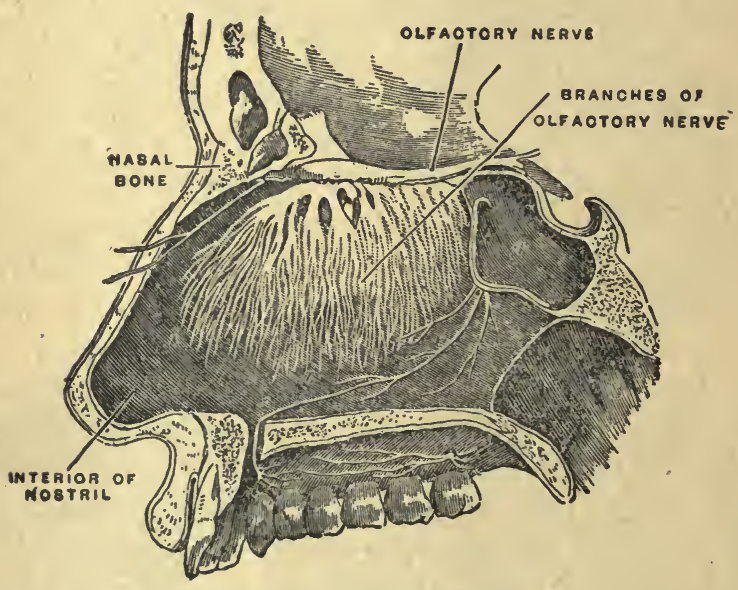

FIG. 38. - Sectional view of the Nose.

is large and is divided by a vertical wall into two halves. The floor of the nasal cavity constitutes the roof of the mouth. At the back part of the roof of the nose is a very thin plate of bone, on which rests a portion of the brain. This bone is pierced by numerous little holes, giving it the appearance of a sieve. The olfactory nerve, or nerve of smell, lies on this bone, and gives off, from its bulb-like end, quantities of little filaments, which reach the nasal cavity through these holes and spread out on the mucous membrane. 
In each half of the cavity are three small and very spongy bones, curved so as to form nearly parallel ridges, and making three distinct passages in each nasal cavity. (Fig. 22, p. 65.) The filaments of the olfactory nerve are spread out on the two upper ridges, but not on the lower. It will be seen from this that the sense of smell resides chiefly in the upper part of the cavity, and hence the necessity for taking an extra sniff when we want to detect a very faint odor. This extra sniff sends some of the air through the higher passages.

The mucous membrane of the nose lines all its passages, and is continuous with the lining of the pharynx and windpipe. This is the most natural and healthy course for the air in breathing, because the several passages or warming chambers in the nose temper the air as it is drawn in, while at the entrance to the nostrils small hairs grow to strain out dust and other impurities from the air.

4. Functions of the Nose.-The sense of smell acts in conjunction with that of taste. In fact, it precedes taste in recognizing the properties of any food about to be taken into the stomach. It acts a most important part in guarding the portal through which the body receives its nourishment. Taste seems to depend a good deal upon smell. If our sense of smell is not keen, the taste is also defective. Every mother knows this when she holds the nose to administer a nauseous draught to her child. Sight also assists taste. In fact, without the aid of sight and smell it would often be impossible to distinguish substances put into the mouth.

As stated, the lower portion of the nose takes no part in detecting odors. The nerves supplied to this part are not from the olfactory, but they do efficient and useful work. If the air about to pass inward contains any irritating substance, these nerves detect it; sneezing is induced and the offending matter is forcibly expelled. The sense of smell contributes largely to man's comfort and pleasure. It is ever 
on the alert and ready to warn him of anything disagreeable, offensive or injurious. By it he knows the appetizing qualities of many foods. By it he enjoys the fragrance of the flower and of choice perfume.

It is not always necessary to bring the substance close to the nose to detect its odor. Some smells can be recognized at a great distance from their source. Invisible particles float in the air and fall upon the sensitive membrane of the nose. Some persons have not as acute a sense of smell as others. Like all other faculties, it can be educated. Certain tribes af Indians, who rely in a great measure upon this organ, have an extraordinary sense of smell. The lower animals, also, differ in the acuteness of this organ. The dog, especially the hound, has a wonderful faculty for smelling. He will follow on the trail of a fox for miles guided only by the scent.

5. Other Uses. - The cavity of the nose has other functions than those mentioned. It is the outlet for the secretions from the cavities in the cheek bones. Also, the cavity between the plates of bone in the forehead opens into the nose and is relieved of its secretions. Likewise, when the secretion of water in the eyes is excessive, but not sufficient to overflow in the form of tears, it is carried from the inner corner of the eye by a small canal into the nose.

6. The Sense of Sight.-The organ of sight is lodged in a cavity made up of thin plates of bone joined together. At the bottom of this cavity, or socket, as it is called, is a small opening through which the optic nerve passes from the brain to the eye. The eye-ball, fitly so called, is about an inch in diameter. It is composed of the crystalline lens; a jelly-like substance, called the vitreous humor, situated behind she lens; the aqueous humor in front, and the iris which acts as a curtain, through the centre of which is an opening, 
the pupil. The eye-ball, or globe, rests upon a soft cushion of fat. This gives it an easy support and allows it to move about with the utmost freedom.

7. The Coats of the Eye. - The eye has three coats. The back part of the outer covering, the "white of the eye," is called the sclerotic coat. It is a dense, firm membrane, and preserves the shape of the eye. In front, the outer coat

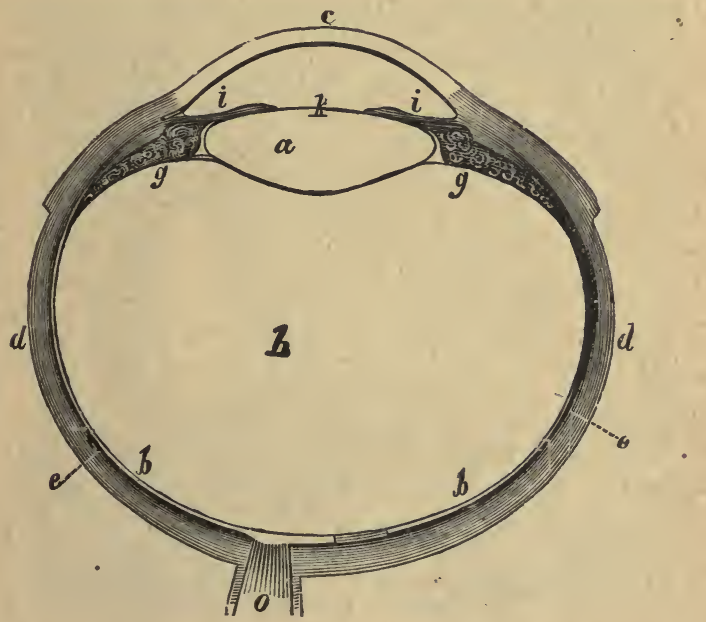

Fia. 39.-The Eye: $a$, crystalline lens; $b$, the retina; $c$, the cornea; $d$, the sclerotic; $e$, the choroid; $g$, capsule of lens; $h$, vitreous humor; $i$, iris; $k$, pupil; 0 , optic nerve.

is thin and transparent, and is called the cornea. It is the window through which light is admitted.

The second coat, the choroid, lines the outer coat at the back. It is a layer of black substance intended to absorb the surplus light in order that objects may be clearly seen. The third is the retina, a delicate membrane in which are distributed the branches of the optic nerve. It is the innermost coat and lies on the choroid. 
8. The Crystalline Lens.-As may be seen in a section of the eye-ball, the lens is placed in the front part of the globe. It is a flattened, double-curved body, with the flatter side in front, resembling two watch crystals of different curves placed back to back. It consists of layer upon layer of a soft jelly-like substance, the inner layers being more dense than the outer. It is surrounded by a delicate covering, which fixes it to the inside of the eye all round. Both the lens and its covering are transparent.

The lens not only allows the rays of light to pass through, but it draws them nearer together, that when they reach the retina they may be brought to a point, or focus. In this way all the rays of light coming from the different parts of an object, or all the objects in the field of our observation when we look out, are brought to a focus on different parts of the retina, and clearly picture there a miniature of all that is before the eye. The optic nerve carries this impression to the brain and we see.

9. The Vitreous Humor. - The greater part of the interior of the eye-ball is fllled with the vitreous humor. It is a thin, jelly-like substance, made up mainly of water, with a small quantity, of albumen and salts. - This liquid is contained in compartments formed by the walls of a delicate membrane. (Fig. 40.)

10. The Aqueous Humor. - The space between the cornea and the lens is filled with the aqueous humor. This space is partly divided into two compartments by the iris. The aqueous humor is more watery than the vitreous.

11. The Iris. - Floating in the aqueous humor is a circular curtain or disc, called the iris, from its resembling a rainbow in its many colors. It has an opening in its centre, the pupil. The iris is made up chiefly of muscular fibres, and has a background of coloring matter. The muscular fibres are arranged in two layers. In one the fibres 
circle round the iris. When these contract they narrow the pupil. In the other layer the fibres run from the outer border of the iris to the free margin of the pupil. When these act they pull back the curtain and dilate the pupil. No light can enter the eye excepting through the pupil, so that the amount of light admitted is regulated by the iris.

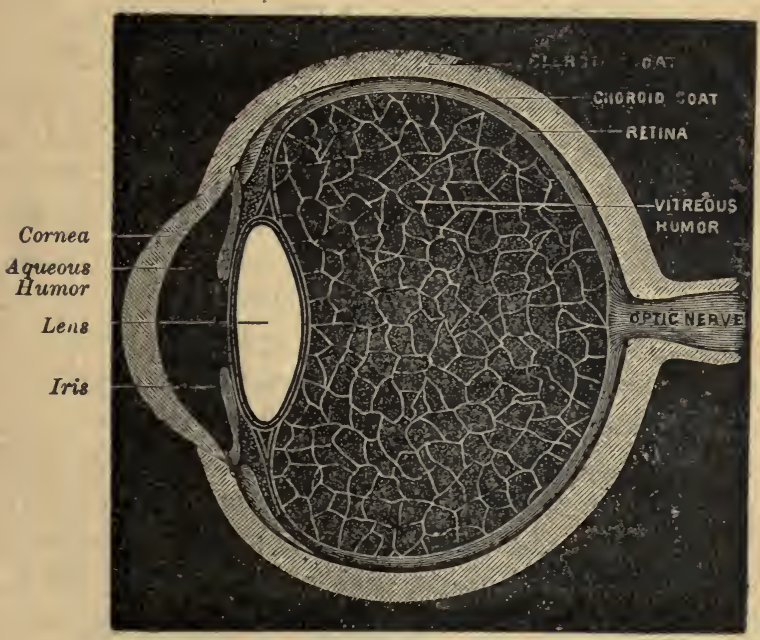

Fra. 40.-Section of Eye-ball.

If the light is very bright, the pupil becomes small : if it is dim, it enlarges.

This ring-like curtain, which is drawn and withdrawn according to the intensity of the light, varies in color in different persons. The color of one's eye is the color of the iris. Blue, gray, black or brown, with the varying shades between, are all due to the color of the iris, except that in some persons the pupil is always large and gives the axs 2 . dark appearance. 
12. The Eye-lids. - In order that the eyes may serve the body, it is necessary they should be placed in a prominent position, consequently their front parts are more or less exposed. To afford protection to the eyes, and at the same time to shut out the light when too intense, we have the eye-lids. They are folds of skin, to which are attached delicate muscles for moving them up and down. To give firmness to the lids, there is a plate of cartilage in the fold. At the edge of the lids the skin turns in to join the lining membrane. This membrane is called the conjunctiva, because after it has lined the eye-lids for a considerable distance back, it folds on to the eye-ball. It covers the surface of the eye from this point forward. On the cornea it is extremely delicate and transparent.

The upper eye-lid is larger than the lower, and much more movable. The nerve influence to the eye-lids is wonderful. Their movements are partly voluntary and partly involuntary. We wink continuously while awake. This act, intended to keep the eye moist and free from dust, is involuntary. We can open and shut the eye by a voluntary act when we will, but the flash-like closing of the eye when suddenly threatened is involuntary. The extreme sensitiveness of the exposed parts of the eye is also a protection. Small particles getting into the eye are not allowed to remain there without causing a good deal of pain and irritation.

The upper and lower lids come together at their two extremities, forming the outer and inner angles of the eye. The space between the two angles varies in different persons, and has the effect of making one's eyes appear large or small.

The eye-lashes are short, curved hairs, arranged in one, two or more rows along the border of the lids. They shade the eye and protect it from tiny insects, dust and other particles of matter floating in the air. Small oil-glands in the margins 
of the lids keep the edges smooth and prevent them sticking to each other.

The eye-brows are also shades for the eyes, and help to protect them from the fierce rays of the sun. These fringes of hair incline outwards so as to divert the perspiration from the forehead off to the sides and thus prevent it trickling down into the eyes.

13. The Tears.-While we are awake, the eye-ball is in almost constant motion. With every movement the eye rubs against the lids, and in order that there may be no friction, the surface is moistened by a watery fluid which when it overflows forms tears. This fluid is secreted by a gland about the size of an ordinary bean, situated in a hollow in the upper and outer part of the socket. This teargland has several small ducts, which open at the outer corner of the

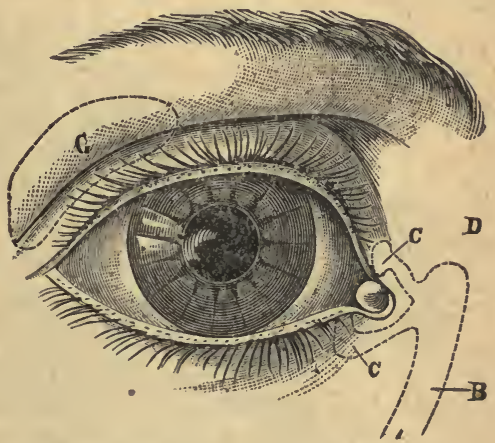

Fia. 41. -The Eye-lashes and the Tear Glands: $B$, tear duct; $C, C$, tear canals; $D$, tear sac; $G$, tear gland.

eye beneath the upper eye-lid. The motion of the eye and the winking of the lids spread the fluid over the exposed surface. The same movements carry the fluid to the inner angle of the eye, where it collects in a small hollow between the two lids, and is drained off by small canals, one in the upper and one in the lower lid. These canals run inward to a sac in the corner of the nose, and from this sac the fluid descends into the nose. Any local irritation of the eye or mental emotion, such as weeping or crying, causes more fluid to form than can be carried off by the canals. It overflows and runs down the cheeks in tears. 
14. Motion of the Eye-ball--It is the duty of the eye to watch objects from every point-right or left, up or down. Its ability to do this depends upon the action of the muscles supplied to it. The rapid glance of the eye here, there and everywhere is produced by the contraction of one or more muscles.

Six muscles move the eye, and are attached to the outside of the ball. Four of these are straight muscular bands for.

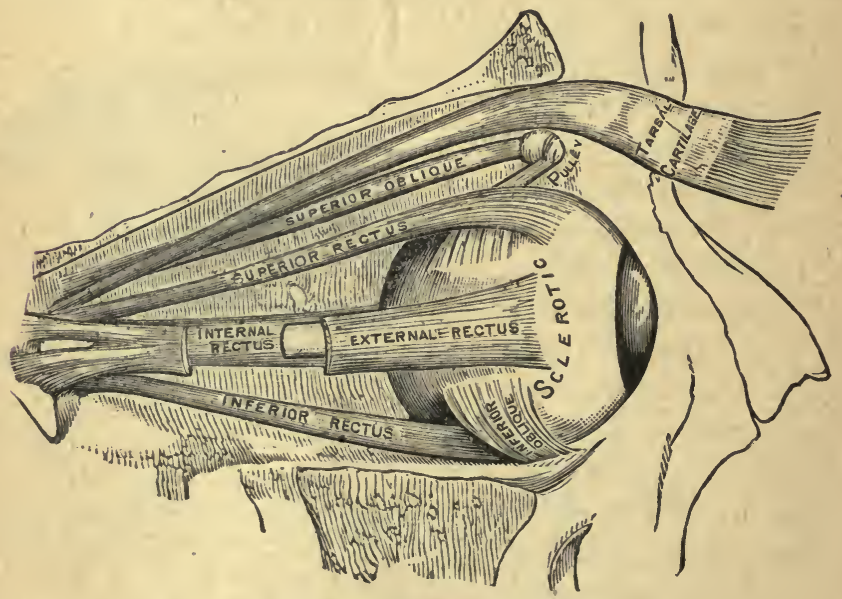

Fia. 42.-Muscles of the Eye-ball.

moving the eye to the right or left, and up or down. They all arise from the back part of the socket, near where the optic nerve passes in from the brain. These muscles are arranged in pairs, and are evenly balanced. The fifth and sixth are oblique muscles. The fifth also arises from the back part of the socket, and passing forward along the upper surface of the eye-ball, its tendon runs through a ring of cartilage at the upper and inner border, like a rope through a pulley. It then turns and is attached to the eye-ball. 
The sixth is the opponent of the fifth. It is a short muscle arising from the socket near the tear sac, and, passing beneath the eye-ball, is attached to its outer side. The oblique muscles rotate the eye as the head is turned, in order that objects may be pictured on the same part of the retina. When acting with the straight muscles, they move the eye in oblique positions. For instance, the eye can be turned outward and obliquely upward.

Through the combined action of these six muscles the various movements of the eye are performed. The wonder of this exquisite mechanism is greatly increased when it is remembered that the two eyes act together and are moved in the same direction at the same moment. This harmony in the action of the muscles of both eyes is maintained by the close connection between the nerves supplying these muscles. If from want of proper nerve supply, or from weakness or disease, any one of the muscles acts imperfectly, the effect is at once noticeable in the nature of a "cast," or "squint."

15. How we See.-To have a thorough understanding of the eye as an optical instrument, it would be necessary to have a clear knowledge of the properties of light. It must here suffice to say that the light, in the form of undulating rays, passes through the transparent cornea, then through the pupil in quantity according to its size, and falling upon the lens, converges to a point at the retina.

The rays of light strike the convex cornea from different directions. Those which are straight for its centre pass through without any deviation. Of those which come from the different angles, some are too near the outer border of the cornea and are reflected back, while others pass in, and are more or less refracted, or brought nearer together. The humors of the eye also bring the rays nearer, but the lens is the chief instrument of refraction. By reference to Fig. 
43 , the direction of the rays from the several points on their way to the retina will be clearly seen.

There is a delicate little muscle in the interior of the eyeball, attached to the membrane, which encloses and holds the lens in place. Its use is important. It finds the focus for varying distances, just as a boy pulls his spy-glass in or out to get a correct focus according to the distance. Our eyes are arranged naturally for seeing distant objects. When we look at near objects, this little muscle is brought into action. It draws upon the membrane and slackens it, allowing the lens to become more rounded. The lens is rapidly adjusted

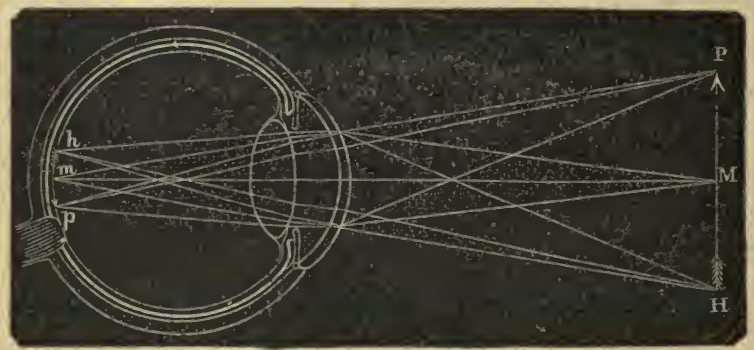

Fra. 43.-Diagram showing how the image of an object is formed upon the retina.

in this way for varying distanees, and brings the rays of light to a focus exactly on the retina. If the lens be too flat, the rays will not come to a focus before reaching the retina. If it be too rounded, the rays come to a focus in front of the retina. In either case the eyesight is defective. In the one case the person will be far-sighted, and in the other nearsighted. The far-sighted person finds relief in convex glasses, the near-sighted person in concave glasses.

It may not be the fault of the lens that the rays are not brought to a focus on the retina. The eye-ball itself may 
be too shallow or too deep, that is, the retina may be too near or too far away from the lens.

16. Hygiene of the Eye--After middle life, and as age advances, most persons find their eyesight defective. This is commonly due to a loss of power in the little muscle, and the lens can no longer adapt itself to varying distances. This condition should not be neglected. The extra effort to see distinctly will make matters worse. Suitable glasses should be used without delay. As the years advance, stronger ones will be necessary. This long-sightedness is not uncommon in childhood, and may be seen sometimes in several members of the same family, on account of their having the same formation of eye. It would be well for teachers, as well as parents, to be on the look-out for such cases, and have the defect remedied by having the child wear suitable glasses, at least during, study hours. If not attended to, the evil will likely increase and may lead to squinting. Short-sightedness is also not uncommon, and is said to be on the increase. Prolonged.application to study may bring about this condition of sight, or constantly holding the book too near the eyes. The use of glasses is here also a necessity. Shortsighted children at school are 'apt to lean forward over the desk. Note the habit and search for the cause. Fine print should never be used in schools, nor the eye taxed for any length of time in any way.

Reading as we lie on a couch or on a bed, the prevailing custom of reading on the railway train, reading fine type in twilight, or in a dim light, are all habits which should be strongly condemned.

Constitutional diseases, especially scarlet fever, are often followed by weakness of sight. After a severe illness the eyes should be used with great caution. If reading, or other use of the eyes, causes them to ache, or brings on a pain in the forehead, it should be discontinued at once. 
17. Color-Blindness.-Color-blindness is an inability to distinguish colors. It has been ascertained that about four persons out of every hundred are thus affected. The colors which usually give the most difficulty are red and green, and as these are the colors most frequently used in connection with the signal lights of railroads and steamboats, it becomes a serious matter.

Color-blindness, in its true sense, is usually an inherited defect in sight, but, as a matter of fact, children and others often fail to recognize colors because they have not been trained to do so. The faculty of distinguishing colors should be cultivated from childhood onward.

18. The Sense of Hearing.-The organ of hearing is divided into the outer, middle and inner ear. The outer ear comprises that part which stands out prominently on eitherside of the head, and the small tube or canal leading into the bone, called the auditory canal. The peculiarly shaped outer part, commonly called "the ear," is so constructed to collect sound and transmit it through the auditory canal. It consists of plates of cartilage covered with skin on both sides. The auditory canal is about an inch long, and is lined by a continuation of the skin of the ear. Glands are found in this lining which secrete ear-wax, to moisten and protect the parts. Fine hairs grow at the outer part of the canal, to prevent insects and foreign matter from getting into the ear.

At the bottom of the canal, stretched across it, is a thin membrane, the drum. It is this thin membrane that receives the sound-waves in the ear.

19. The Middle Ear.-Beyond the drum is a small cavity, the middle ear. Hanging across this chamber, from the drum inward, is a chain of three very small bones, which, from their shape, have been named the hammer, the anvil, and the stirrup. These bones, though so small, are complete 
in their construction and articulate with perfectly formed joints, one of which is a ball-and-socket joint. At the bottom of the cavity is a small tube, leading from the middle ear to the upper and back part of the pharynx. This passage keeps up a supply of air to the middle ear. By holding the nose and keeping the mouth closed, we can force air up this passage. It enters the ear with a sudden click.

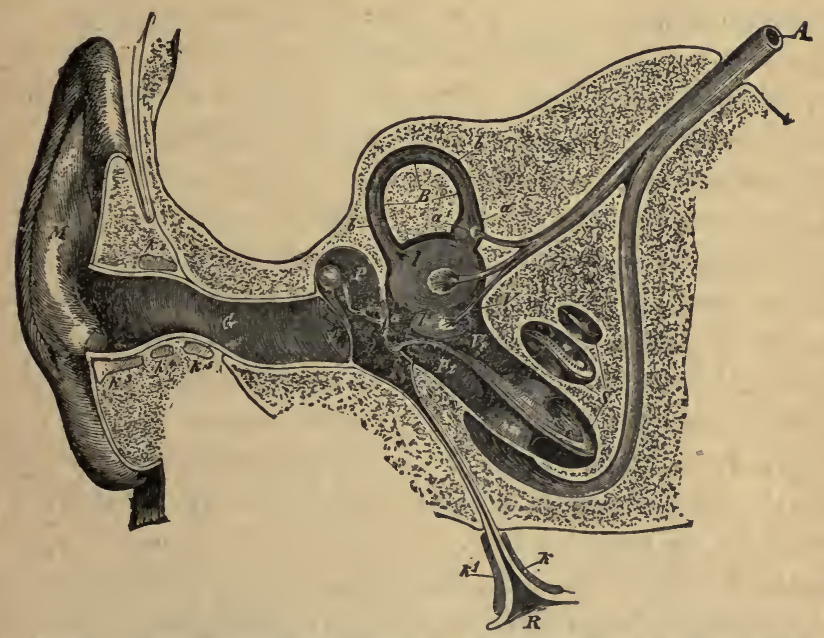

Fic. 44.-Section through the Right Eàr: $\boldsymbol{M}$, outer ear; $\boldsymbol{G}$, auditory canal; $T$, the drum; $P$, middle ear; $O$, bones of the ear; $R$, pharyngeal opening of Eustachian tube; $V$, vestibule; $B$, a semicircular canal; $S$, the cochlea; $A$, auditory nerve.

20. The Inner Ear.-This chamber is somewhat complex, and is sometimes called the labyrinth. It is situated in a solid bone at the base of the skull, hollowed out for the purpose, and consists of three portions - the vestibule, or antechamber, the semicircular canals, and the cochlea, or snail shell. The vestibule, situated on the inner side of the drum, is not larger than a grain of wheat. Above and behind are three bony semicircular canals, which communicate with the 
vestibule at each end. The cochlea, which has been compared to a winding-stair or a snail shell, is in front of the vestibule. In the cochlea are minute fibres, or tendrils, regularly arranged from bottom to top, which may be likened to the key-board of a piano. The cochlea is filled with fluid, and in it floats a delicate sac containing hair-like bristles, some fine sand, and two ear-stones. In this wonderfully constructed chamber are the endings of the nerve of hearing, spread out on the walls of the cochlea.

21. How we Hear.-When one throws a stone in the water, from the point where the stone strikes are seen a series of circular wavelets. In like manner, when two substances strike together, waves of air are produced. These waves, caught by the outer ear, pass through the auditory canal and strike upon the drum. The impulse is conveyed through the chain of bones into the vestibule, and on to the cochlea. This sets the bristles, stones and sand in motion in the liquid, more or less, according to the intensity of the air wave. The effect of the impulse upon the nerve by agitation of the contents of the cochlea is conveyed to the brain, and we hear.

A knowledge of the principles of sound would be necessary to understand how the various noises and musical sounds are created. The loudness of a sound depends upon the force of the air waves. Other variations depend upon the length, frequency and regularity of the waves.

Although sound is mostly carried by the air waves, as described, it may reach the cochlea through the bones of the head. A watch can be distinctly heard when placed on the top of the head, or if we hold it between the teeth the sound is carried to the nerves of hearing. Deaf persons by this means may be made to hear, unless the nerve itself is destroyed. The ability to recognize distance in sound, and the direction from which it comes, is largely due to experience and to education of the sense of hearing. 
Unlike the eyes, each ear is independent of the other, and can receive different impressions at the same time.

In some of the lower animals the outer ear is movable. This enables them to turn it in the direction of the sound, a valuable means of protection to wild animals who prey upon each other.

22. Hygiene of the Ear.-The essential part of the ear being deeply seated and away from outward influence, this organ is not subject to injuries and derangements to the same extent as the eyes. Still, the ear may become affected, and the hearing impaired, or even destroyed. Deafness in one ear is by no means uncommon. Temporary deafness may result from the closing of the canal by a collection of wax. In attempting to remove this with a pin or a hard-pointed substance of any kind, there is danger of injury to the drum. The safest way is to drop in a few drops of warm sweet oil, and afterwards gently syringe out with warm water. An insect sometimes gets into the canal, caúsing a good deal of pain. It can generally be drowned with warm water, or killed with a few drops of oil, and then washed out. Cold water should not be allowed to run into the ear, and a cold wind blowing against the ear may affect the sensitive nerve, causing "ear-ache." A closing up of the tube leading into the throat, from a cold or other inflamed condition of the throat, may produce temporary deafness.

23. The Sense of Touch. - The sense of touch is distributed all over the body. The skin everywhere is endowed with sensibility. But in certain parts, as the tip of the tongue and fingers, the sense of feeling or touch is developed to a high degree. Touch is, to a large extent, an educated sense. It begins to develop in infancy. There is no special nerve of touch, but in the fingers the little papillæe mentioned in coinnection with the skin have each a speciai nerve ending, a sort of touch corpuscle. 
The sense of touch informs the mind not only as to the nature of an object and its relative position, but as well the degree of temperature of the air and of substances. By this sense the body feels the comfort of a suitable amount of heat, and learns the danger from extreme cold. The common sense of the skin acts in conjunction with the muscular sense. It also frequently acts in harmony with the other special senses.

\section{Special Senses closely related.-The several spe-} cial senses have a close relationship. They not only often act together and in harmony, but one will become a substitute for another in case one is weakened or destroyed. Instances of this are very common. Indeed, wherever one of the special senses is lost, another will, by development, assume the duties in serving the system as a whole. A blind person hears more acutely, and knows more by the sense of touch. The law of substitution in the human system is constantly in operation, and nowhere so remarkably as in connection with the nerves of special sense.

\section{Effects of Alcohol and Tobacco on the Special} Senses.-The nerves of special sense, like those of the hody generally, are injured by the constant use of alcohol or tobacco. We have noticed in its effects upon the nervous system, that more alcohol goes to the brain than to any other organ. This being the case, the special nerves centred in the brain will naturally be disturbed. We find this to be true. A little liquor interferes with a person's sight and hearing. It is more than probable his taste and smell are deficient. An acute observer will notice a man has had liquor by the appearance of the eyes, even when it is only a glass or two, and in that wild state of the brain, "delirium tremens," the special senses are sometimes completely depraved. A man sees on the walls of his chamber all sorts of moving creatures, hears strange but fancied noises, and has most erratic and imaginative scnsations of taste and smell. 
But far short of this pitiable condition, the eye and ear of the chronic drunkard may become impaired. Dimness of vision and a lack of acuteness in sight are recognized affections of the eye, which may be produced both by alcohol and tobacco, especially by the latter. One physician reports the case of a man who persisted in using a strong " navy plug" tobacco until it led to "nearly total blindness." Another physician says a refined lady who had learned to smoke "to keep her husband company," found her sight rapidly failing from its use.

A general hardening of the walls of the arteries all over the body, alluded to in the chapter on Circulation, with weakness of their coats from alcoholic liquors, may have its outcome in rupture of a blood-vessel anywhere. This may happen to a small blood-vessel in the retina, with bleeding into the eye, and consequent loss of sight. The same hardenfd condition of the coats of the arteries may affect the hearing, producing spells of "giddiness," and sometimes a "buzzing" in the ears. Deafness from a "dry catarrh" of the middle ear, and many other affections of this organ, are agravated by the use of alcohol and tobacco.

Color-blindness is sometimes produced by alcohol, and is more common among heavy drinkers than among total abstainers. It is, therefore, doubly important for engineers on railway trains, and others on whom many lives depend, to avoid all intoxicating liquors.

The two senses, taste and smell, so closely allied and partly dependent upon each other for efficiency, are both more or less depraved by the smoking and drinking 'habits. A man whose calling requires of him an acute sense of taste and smell, a professional "tea-taster," for example, knows he cannot use either tobacco or alcohol in any form and retain those faculties with any degree of accuracy. 


\section{CHAPTER X.}

\section{'FIRST AIDS TO THE SICK AND INJURED."}

1. The Protection of Life.-We have endeavored to show, in the preceding chapters, how our bodies are built up and sustained. We have pointed out the various systerns, how they are constructed, the useful purposes for which they are intended, and the close sympathy which exists between them. We have shown that one member of the body cannot suffer without all suffering, and that we cannot violate the laws of nature, or do an injustice to one part, without being called upon to pay the penalty.

Life is uncertain, and our bodies are not intended at best to last much beyond the "threescore years and ten." Yet, when we look into the arrangement and construction of the many parts of ourselves, we wonder what life is, and how the spark is kept constantly aglow.

We cannot wholly understand the secret of life; but we can in part, when we notice the many wise provisions the Creator has made for its protection and its continuance from day to day. The God who created us and cares for us is a Master Workman, and does nothing but what is perfect. He has also placed within us the instinct and the desire to protect ourselves and to save ourselves, as far as possible, from sickness, disease and injury. But accidents are likely to happen and sickness may overtake us at any time, hence the knowledge gleaned from the pages already studied, if practically applied, will become very useful in an emergency, when skilled help is not at hand.

2. Bandages, Splints, etc.-In order that we may be of 
service in cases of accident, it is necessary to know what appliances are needed, and how to use them.

Bandages are usually made of unbleached cotton or calico. They may also be made of flannel, muslin, gauze, india rubber, etc., according to their intended use. There are many kinds of bandages, but the most useful and most convenient ones are the roller bandage and the triangular bandage. The latter is the one likely to be near at hand, for every boy and girl has usually a pocket handkerchief, which, when folded diagonally, makes a double triangular bandage. As its name implies, it is a three-cornered bandage, made by taking a piece of cotton about forty inches square, and cutting it diagonally into two halves. We will describe this bandage as having two ends and a point, and the longest side as the base. Three forms of bandage are made from it:

The UNFOLDED BANDAGE, as in a wide sling, where the ends are tied behind the neck. The forearm resting in the sling, the point is brought around the elbow, and pinned in front.

THE BROAD BANDAGE, where the point is first brought to the base, and the whole folded once.

The NARROW BANDAGE, where the point is also brought to the base, and the whole folded twice.

We cannot go fully into the application of this bandage, but one or two examples will show there is no part of the body that cannot be properly bandaged with it. It is also well suited for keeping poultices, etc., in place, and for bandaging splints to broken limbs. For the upper or lower limb the bandage is folded narrow or broad, and is applied by placing its middle over the dressing on the wound, carrying it round the limb and back again, and tying at the starting point. For the body, it is generally unfolded. For instance, it is applied to the right chest by placing the middle of the bandage on that chest, with the point over the right shoulder, carrying the two ends round the body, under the 
arms, and knot behind. Next draw the point over the shoulder downwards, and tie it to one of the ends. To apply the bandage to the head, fold the lower border lengthways, to form a plait like a hem, one and a half inches wide; place the middle of the bandage on the head, so that the plait lies crossways on the forehead, the point hanging downwards over the back of the neck. Carry the two ends backwards over the ears, cross at the back of the head, enclosing the point, bring forward, and tie on the forehead. Then stretch the point downwards and turn it up over the back of the head, and fasten it on the top with a pin.

The roller bandage is made by tearing the cotton into strips of different widths, varying from three-quarters of an inch to six inches, and from one and a half to ten yards in length, according to the part of the body to be bandaged. For the fingers, an inch by a yard and a half; for the arm, two inches by five yards; for the leg, three inches by six to eight yards; and for the body, four to six inches by ten yards are the most suitable sizes. These bandages should always be tightly and evenly rolled. The great secret in doing this is to start very close and firm. In applying this bandage, begin at the extremity of the limb, and roll it evenly round and round, overlapping a little each time, so that it is smooth and snug. Continue it up until you have reached the wound and secured the dressing.

A splint is an appliance for holding a limb steady. Anything we can pick up, a shingle, a picket from the fence, an umbrella, a bat, a broom handle, would make a good temporary splint. A picket bandaged to a broken leg by three triangular bandages, one at the ankle, one at the knee, and one well up the thigh, will hold it firmly enough to be moved with safety. If possible, pad the splint with wool, strips of cotton, grass, or anything soft and pliable.

The most convenient dressing for a wound is a piece of 
cotton folded into four or five thicknesses, or a clean handkerchief similarly folded, wrung out of cold water, laid smoothly on the wound, and secured by a triangular bandage, as directed.

A poultice makes a softer dressing, but it is not so readily at hand, nor so useful, as the water dressing for fresh cuts or bruises. It is usually made from ground flax-seed, or what is called linseed meal. Put sufficient boiling water into a bowl, stir in the meal gradually, as in making porridge, until it is the thickness of thin dough. Then spread upon cotton, and put on a facing of thin muslin. The chief feature about a poultice is its faculty for retaining heat. It must be applied hot, and changed as soon as it gets cold.

A mustard plaster is made by mixing mustard with water or vinegar and the white of an egg, and should be of the same consistence as a poultice. Spread it on thick gray paper, and use a facing of muslin. It should be applied not longer than five minutes at a time.

Fomentations are flannels wrung out of hot water, or hot water and turpentine-a tablespoonful to every quart of water. Lift the flannel from the boiling water, and wring it as much as heat will permit; then throw it into a jack towel, wring well, and carry to the patient still enclosed in the towel. Unfold and apply. Change every few minutes.

In tying a knot, always make a "reef" or "sailor" knot, which is a double loop, with both ends coming out, on one side under, on the other over, the loop; not one end on either side of the loop, as in the "granny" knot.

3. Hæmorrhage.-Bleeding may be from an artery, a vein, or from the capillaries. If an artery is cut, the blood spurts out in' jets with great force, and is of a bright red color. Coming directly from the heart, the loss of blood is rapid and the danger is in proportion to the size of the artery cut. When a large vein is cut, considerable blood 
may be lost, but as the current is towards the heart it has not so much force. It flows evenly and is of a dark purple color. If the capillaries only are cut, the blood oozes gently from the wound.

4. Bleeding from an Artery.-The arteries are found in nearly every part of the body. Wherever it is possible, they are situated deep down in the tissues. The larger trunks usually occupy the most protected situations, and generally run in a very straight course. They are therefore, fortunately, not so frequently cut or injured as the veins, which run near the surface and are more tortuous and more exposed. When an artery is cut, it calls for prompt action, and requires some presence of mind. If the artery is large, there is no time to be lost. Let us remember two things to be done, even if we forget everything else. Put firm pressure directly on the bleeding part, and also on the artery somewhere above the wound, that is, between it and the heart. To apply pressure on the wound, take a pad made of some firm substance, such as a flat cork, a smooth, flat stone, a roll of paper, a penny, or whatever is within reach, and tie it firmly with a handkerchief or a triangular bandage folded narrow.

To apply pressure on the artery above the wound, we must

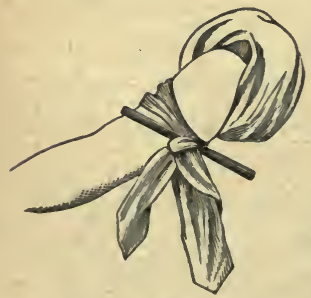

Fig. 45.-Showing how a triangular bandage and a stick may be applied to the arm to stop bleeding. know the most suitable places. Generally speaking, we can arrest bleeding from any part of the arm by pressing upon the artery in the arm-pit, and from any part of the leg by pressing upon the artery in the groin. The pressure is best applied by taking the narrow folded bandage, or handkerchief, tying a knot in its centre, placing this knot over the line of the artery, and tying it loosely but with 
a firm knot around the limb. Now introduce a piece of stick under the bandage and twis it round and round until it is tight enough to stop all bleeding. In the upper part of the arm, the artery lies along the inner edge of the swell of the biceps. From this point the artery takes a straight course to the middle of the bend of the elbow. Here the knot should be placed about the middle, and either use the stick, as before, or bend and fasten the elbow firmly over the knot. In the thigh; the artery lies almost in a straight line from the inner part of the groin to the inmer and under side of the knee. The twisted bandage is applied high up on the thigh, the knot being placed on the line of the artery. For bleeding below the knee, the twisted bandage should be adjusted immediately above the knee, or the knee can be bent over the knot or pad and fastened firmly.

For bleeding from the head or neck, naturally we cannot put the twisted bandage round the neck. We must pad and bandage firmly over the wound, if it is on the head, and in the neck press our fingers into the wound itself, and directly above and below the wound.

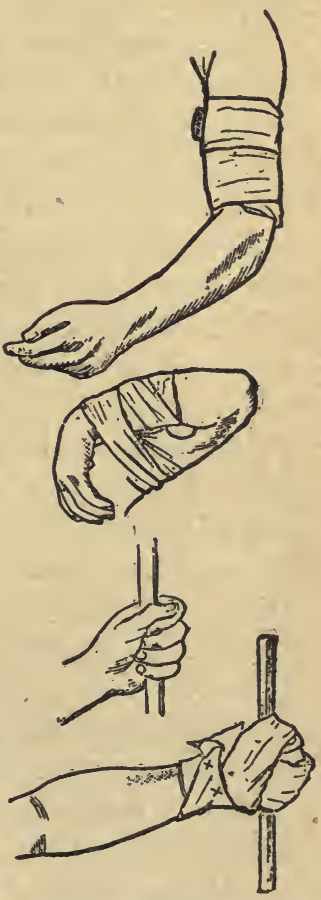

FIG. 46.-Showing how a bandage may be used to stop bleeding from an artery in the arm.

The twisted bandage is so important that children should be frequently practised in its use.

5. Bleeding from the Veins. - First place the person in a lying-down position and raise the bleeding part; then 
examine the wound and wash it well with very cold or with hot water. If the bleeding is too profuse to be stopped in this manner, tie a pad firmly over the wound and free the clothing above so that the blood can pass on readily towards the body.

6. Bleeding from the Capillaries.-The simple oozing of blood from a wound is easily controlled. Cleanse the wound well by a good washing with cold water. Lay on it the cold water dressing, or the same dressing dipped in alum water, and secure it firmly with a triangular bandage. ,

7. Bleeding from the Lungs or Stomach.-Keep the person quiet and as composed as possible, and put him in a reclining position with the shoulders well raised. Apply ice or very cold cloths to the chest or pit of the stomach, and give him plenty of ice to chew and swallow in little pieces.

8. Bleeding from the Nose.-This is a very common occurrence in children and growing people, and is not often alarming. Placing the patient in a chair, or allowing him to stand, get him to raise both arms high above the head, well extended, and keep them there for some time. Pinch the nose near the end between the finger and thumb, and press backwards or press upward upon the upper lip, or both. You will compress a small blood-vessel in either case. Put a piece of ice or a cold key to the back of the neck. The sudden, cold shock causes the small blood-vessels to shrink. The ice or cold water may also be applied to the forehead and nose. Do not forget to undo the collar and free the circulation at the neck.

Any one of these simple means may suffice to stop the bleeding, but if all fail, roll a small piece of cotton wool on a long, fine pen-handle, dip it into a bottle of tincture of iron and run it into the nose, keeping the pen-handle level and allowing it to gn straight, back for about one and a half to 
two inches. Leave this in for a minute or two, then withdraw and roll on a fresh piece, dip and return.

9. Cuts, Wounds, etc. - Having arrested all bleeding according to the methods described, the next thing to do is to dress the wound. When an artery is cut, the bandages must not be disturbed until a physician is called. In all other cases, after cleansing the wound well with cold water, or, better still, with cold water and borax (four tablespoonfuls of the latter to a pint of water), bring the edges together closely and evenly. If the wound is a clean-cut one, use small strips of sticking-plaster to keep the edges in close contact. These strips should be only from a quarter to half an inch wide, and from two to four inches long. In applying them, leave intervals between. Next lay on the water dressing, using the borax water in preference to plain water. Fasten this in place with a triangular bandage. If there is much pain or inflammation, keep the dressing constantly wet with the cold borax water. When a wound is badly torn or bruised, do not use the sticking-plaster, but, having arranged the edges as evenly as possible, apply the dressing as above. Lastly, place the patient in an easy position, and do not allow any straining on the wounded part.

10. Bites of Animals.-Tie a thick cord tightly around the limb on the side nearest the heart. Suck the wound well, spitting out the poison. Encourage bleeding by bathing the wound freely with luke-warm water. If positive the bite is from a mad ${ }^{\circ} \mathrm{dog}$, or other rabid animal, burn out the poison at once with pure carbolic acid, or a red-hot iron.

11. Burns and Scalds.-A burn is caused by dry heat, and produces pain, with redness of the skin, blistering, and, if intense, destruction of the deeper tissues. A scald is caused by hot or boiling liquids falling on the skin; the epidermis is raised, large blisters form, and the true skin is reddened and inflamed. The chief objects in the treatment 
are to ease the pain and to prevent unsightly scars. The best dressings are Carron oil (a mixture of equal parts of linseed oil and lime water), castor oil and olive oil. Apply the oil freely, wrap the part up in cotton wool, and bandage loosely. As healing goes on, keep the parts in their natural position, so that when the scars form and oontract, as they have a tendency to do, they cannot draw and bind the limb in a false position.

12. Clothes on Fire.-Prompt action is necessary when a child's clothes accidentally catch fire. In a very few minutes it will be enveloped in flames, and so severely burnt as to render recovery doubtful or impossible. Place the child flat on the ground at once. Flames naturally ascend, and will rapidly encircle the body in the upright position, but when lying down they ascend into the air; smother the flames with your coat, a shawl, rug, table-cloth, or anything at hand. If on fire yourself, do not run for help, but get flat down, pull. something over you and smother out the flames, or roll round and round on the floor. Crawl to the bell and ring it, or to the door, and call for help. Girls and women are more apt. to get seriously burnt in this way than boys or men, on account of their mode of dress.

13. Frost-bite.-The nose, ears, fingers and toes are occasionally frost-bitten. Rub the parts affected with snow, or other cold application, in a room without a fire. If a person is severely frost-bitten, give hot drinks, such as beef tea or hot ginger tea, and in the after treatment deal with the wound as you would with a burn. Poultices may be needed later on, to remove the parts destroyed by the frost.

14. Broken Bones.-A simple break is one in which the bone only is divided. A compound break is one where the bone pierces the skin, making an external wound. The usual symptoms of a broken bone are: The limb is helpless and painful; it is very likely altered in shape, and there is an 
unusual looseness at the seat of fracture. Any movement causes a scraping together of the broken ends of the bone, which can be felt, and sometimes heard. Often the limb is shortened, and there is an unevenness along the surface at the broken place.

Do not move the person until you have made the limb safe from further harm by putting on splints. By careless handling, or by attempting to use the limb, we may sometimes convert a simple break into a compound one, by forcing the fractured bone through the skin.
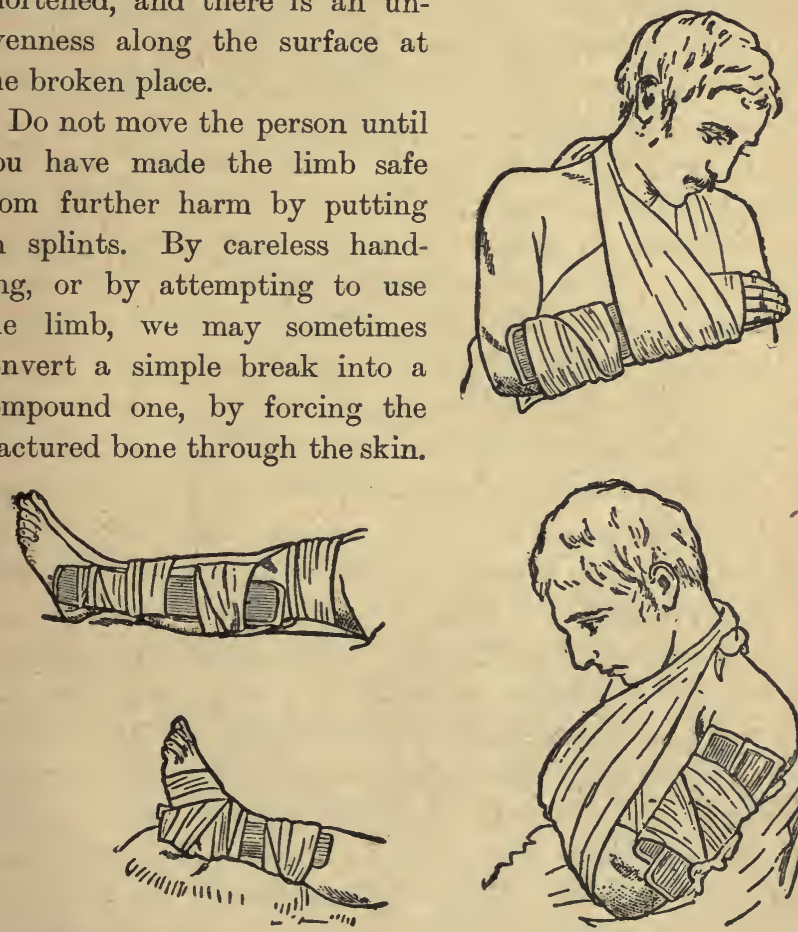

Fia. 47.-Showing how a temporary splint may be put on a broken leg.

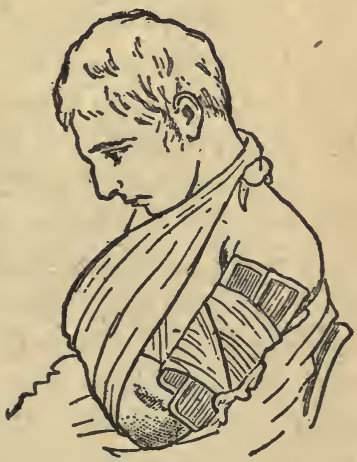

Fra. 48.-Showing how a temporary splint and a sling may be put on a broken arm.

It then becomes a much more formidable injury. Seizing the hand or foot, as the case may be, pull steadily, but firmly and in a straight line, until you bring the limb into as natural a position as possible, and secure with splints and bandages. If it is the arm, it should then be put in a sling; but if the 
leg, it is always safer to tie both legs together, securing them at the knee and ankle and carry the patient home on a door, shutter, or other improvised stretcher.

15. Dislocations. - When a bone is thrown out of the joint, there is always a good deal of pain. The part will have a deformed look, and the limb will be helpless and fixed.

Apply cold-water cloths, to relieve the pain and prevent swelling, until the doctor comes. If the person must be moved, carry him on a stretcher.

16. Sprains.-A sprain is a wrench of the joint, tearing some of the ligaments and tendons which bind it. The joints least liable to dislocation are most liable to sprain. Those most commonly sprained are the ankle, wrist and knee.

Apply ice-cold water at once and continuously, for two or three days, keeping the joint well elevated. If not attended to in this way at once, and considerable swelling has occurred, then hot fomentations are better than the cold. It is also a good plan to put on a roller bandage, evenly and firmly, and keep it well soaked with water.

17. Insensible Conditions. - Insensibility is brought about by some interference with the proper action of the heart, or by some disturbance to the natural condition of the brain. If from any cause the heart's action becomes suddenly weak, and does not send a proper supply of blood to the brain, the patient is pale, and may become gradually unconscious. On the other hand, too much blood to the brain causes a delirium, which may pass into insensibility. An injury to the brain may cause insensibility; so also poisoning. Opium may put the brain to sleep. Alcohol may deaden the brain centres. Anything which stops the breathing also checks the heart, and soon produces insensibility.

The most common forms of insensibility met with are : fits, concussion and compression of the brain, sun-stroke, intoxication, drewning, suffocation by gas, strangling, poisoning, etc. 
18. General Hints.-Note the surroundings and glance around for probable cause. Place the person on his back, with a pillow or folded coat under his head. Straighten him out, and examine carefully. Undo his clothes at the neck, chest and waist. Feel the pulse at the wrist, and listen to his breathing. Examine his pockets for a bottle of spirits or poison. Smell his breath, to detect liquor. Notice the face, whether pale, as in fainting, or flushed, as in intoxication. Do not attempt to make an insensible person swallow anything. If the person is affected with violent spasms or convulsions, do not hold him too firmly, but restrain him sufficiently to prevent self-injury, and place something hard between his teeth, to prevent the tongue from being bitten.

19. Fits.-Ordinary fainting fits are produced by being in a too close, warm room, by mental shock, by loss of blood, or by a weak heart. Lay the patient down, with the head very low, and bathe the face and head with cold water. Give plenty of fresh air, and, if at hand, use smelling salts.

Apoplexy is caused by the breaking of an artery in the head, with bleeding into the brain. Although placed in the lying position, the head and shoulders should be kept well up, to keep the blood away from the brain as much as possible. Use cold water and ice to the head, and heat to the arms and legs. Hot stove-lids, hot bricks, hot-water bottles, or mustard plasters can all be used to draw the blood into the legs and arms.

Epilepsy is a convulsive fit, which some people are subject to at intervals. When the spasms are on, treat as already directed, and when consciousness returns give some nourishment, such as beef tea, and advise rest and sleep.

20. Concussion of the Brain.-A shaking up of the brain by a fall or blow on the head is called concussion. If the blow is severe enough to break in both tables of the skull and cause pressure on the brain, it is called compression, and 
is more serious than concussion. In either case the patient should be immediately taken into a quiet, dark room, and put to bed, with a large pillow under his head. Apply warm blankets to the body and hot applications to his hands and feet.

21. Sun-stroke, or Heat-stroke.-When over-heated, we feel faint and exhausted. We are overcome with the excessive heat, but it is not sun-stroke. Lying down in a cool, shady place, and sponging the face and hands with cold water, will quickly relieve. A drink of hot tea or coffee or beef tea will stimulate the flagging heart. A sun-stroke is more serious, and insensibility soon follows. The conditions are: too much blood in the head and brain, the face red, the head hot, the breathing slow and labored, and the pulse full, but weak. Perhaps the first symptom the patient will notice is intense pain at the back of the head. It is not necessary to be exposed to the sun's rays to get sun-stroke. Intense heat of any kind may produce it. Remove the patient to a cool room, and place him on a couch with his head high. Apply ice-cold cloths, or, better still, the ice-bag, to the head, back of the neck and spine, and warmth to the legs and feet.

22. Intoxication.-Excess in drinking brings about intoxication. In this condition the individual is usually not perfectly insensible, and can generally be roused by pinching or shaking. This is a good time to give an emetic of salt or mustard, a tablespoonful of either to a tumbler of water. Give him plenty of it. Many, however, are beyond this stage. They are "dead drunk," and require the utmost care. In dealing with such a case, get him to bed in a comfortable room. Raise his head a little, and apply cloths frequently wrung out in cold water. Roll him in warm blankets, and put hot-water bottles to his feet and hands. When he rouses, give him a little beef tea or hot milk. 
23. Drowning.-The great object is to restore the breathing. Lose no time. The moment the body has been removed from the water make all efforts to save life. Do not lose valuable time in order to procure shelter, warmth, etc. Instantly remove all tight clothing from the neck, chest and waist,

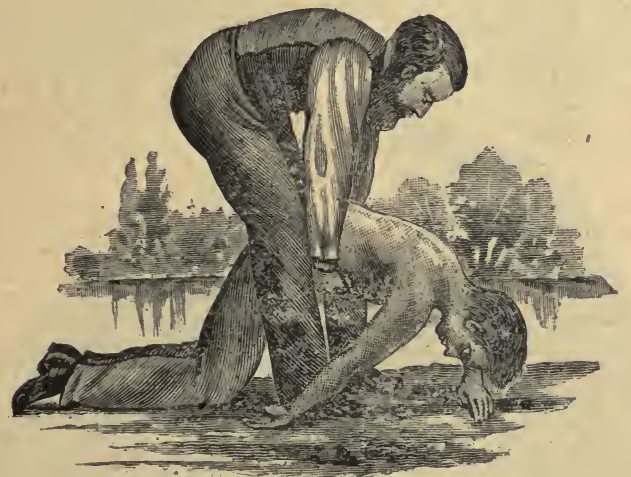

Fig. 49.-First Position: to remove water and mucus from the throat and windpipe.

Turn the patient on his face, and getting astride him at the hips (Fig. 49) with your face towards his head, lock your hands under his body and raise him as high as you can without lifting the forehead off the ground. Give the body two or three smart jerks to remove all water, slime or mucus from the mouth, throat and windpipe.

Next place the patient on his back in a lying position, with a pillow or coat rolled up underneath the shoulderblades, and with the head hanging back slightly. Sweep the forefinger, covered with a handkerchief or towel, round the inside of the mouth, to free it from sand, mud, froth or mucus. If you have anyone to help, get the assistant to draw forward the tongue. It generally tends to fall back in the throat and close the air-passage. The assistant can hold 
the tongue better by using a dry handkerchief or towel. If you have no help, draw forward the tongue and secure it by a string, a rubber band or a strip of handkerchief fastened round the lower jaw.

24. Artificial Respiration.-These preliminary efforts should be the work of but a few moments. Now you are ready for the main part of the treatment-to keep up artificial respiration until the natural breathing comes.

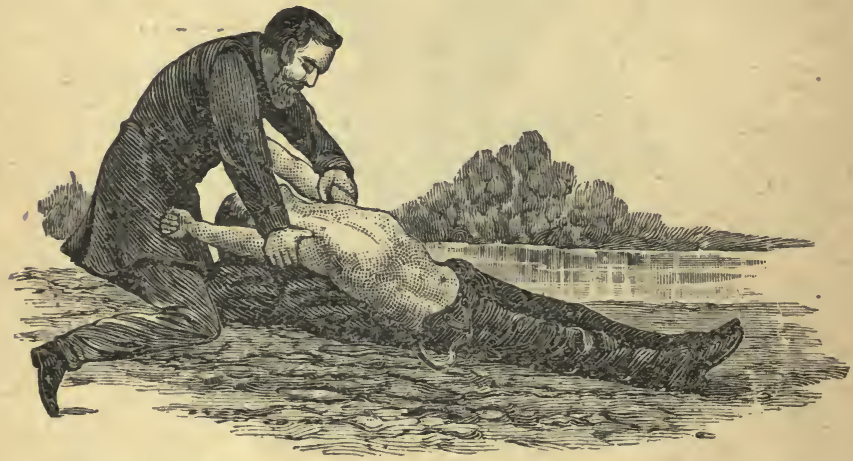

Fia. 50.-Second Position: for the purpose of drawing air into the lungs.

Stand or partly kneel at his head, and grasping the arms near the elbows, draw them up over the head until they meet, extending them upward with a good pull (Fig. 50), and hold them there for a couple of seconds. This increases the cavity of the chest, expands the lungs, and the air is drawn in to fill the space.

Now draw down the arms and press them firmly against the sides of the chest. (Fig. 51.) This tends to force air out of the lungs, and thus you complete the act of respiration by artificial means.

Repeat this process steadily at the rate of about fifteen times in a minute until he begins to breathe. Do not get 
discouraged too quickly, even if there seems to be no life in the body. Artificial respiration should, if necessary, be kept up for at least two hours. Life has been restored even after four hours.

As soon as the patient begins to breathe, wrap him in dry, warm blankets, and rub the limbs under the blankets vigorously towards the heart, so as to assist the circulation in the superficial veins. Put heated flannels, hot-water bottles, or hot bricks to the feet, legs, armpits and pit of the

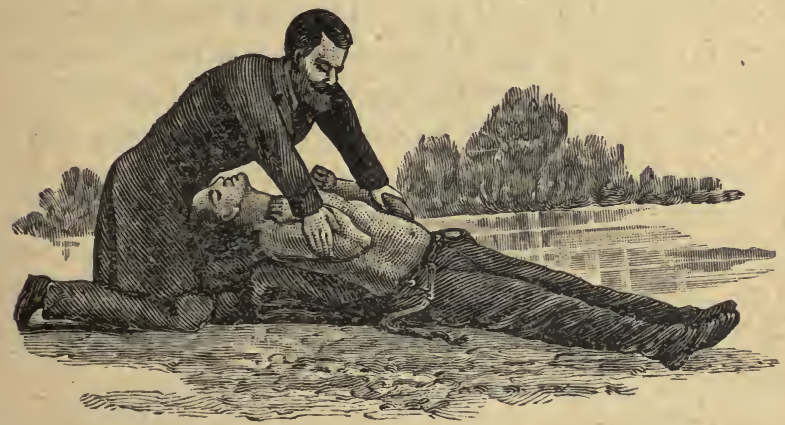

Fia. 51.-Third Position: for the purpose of expelling air from the lungs.

stomach. When able to swallow, give him small quantities of hot milk, beef tea or coffee. Keep the patient in bed and let him sleep if possible. If his breathing is not free and easy, put a mustard plaster to the chest for a few minutes, and repeat again in an hour if necessary.

25. Suffocation by Gas, Smoke, etc.-The chief dangers from suffocation by noxious gases come from burning coal in badly constructed furnaces, stoves or ranges, from "blowing out" gas in bed-rooms, instead of turning it out, or from foul air in old wells or in mines.

Remove the patient at once to fresh air. Undo all clothing about the neck, bare the chest and dash on cold water, 
If breathing is not immediately restored by these efforts, lose no time but seit to work to perform artificial respiration, as in drowning, using the same precautions, the same energy, and keep it up as faithfully.

26. Foreign Bodies in the Eye, Ear, etc-Although the organs of special sense are well protected, yet foreign substances will, by aecident or by the wilfulness of children, sometimes get lodged in them and cause trouble and annoyance. Cinders and particles of dust often get into the eye, and cause a good deal of pain. Do not irritate and inflame the eye by rubbing it. Open the eye-lids and perhaps the overflow of tears will wash out the offending substance, or draw down the upper lid well over the under one, and the lashes may remove it. If it can be seen, get a friend to use a fine, clean handkerchief to dislodge it. Lime in the eye may cause serious mischief, unless attended to at once. Mop the eye with a camel's hair brush or fine feather, dipped in a solution of vinegar and water, one tablespoonful to a small teacupful of water.

Small insects may crawl into the ear and cause great pain. Put in a few drops of warm sweet oil, and then syringe out the ear with warm water. A pea or bean getting into the ear will soon swell out from the warmth and moisture, and is very difficult to remove. Do not wait for it to swell, but go to a physician and have it taken out.

A child may shove a pea, bean, or button, ete., up the nose until it is beyond reach. If the child can be got to blow the nose, he may dislodge it; or it may be removed by holding, his mouth closed, and blowing up the other nostril with a tube. The air passes around and may force out the obstruction.

Bits of food, a thimble, a copper, or other substance, may lodge in the throat and endanger the life of a shild from shoking. A quick, smart slap between the shoulders may 
force it out, or turn the child on his head and give him one or two vigorous shakes. If there is still no relief, try to grasp the object with your finger and thumb, or if too far down for this, run your finger down and shove it on into the gullet, so as to free the windpipe.

27. Poisons.-Whenever it is necessary to have a poison- . ous drug about the house, it should be carefully labelled "POISON," and put in a safe place. There should be only one place for all such articles, and that place should be a locked cupboard or chest. Do not keep any medicine or drug that has lost its label. Throw it out at once, instead of taking a dose to find out what it is. "An ounce of prevention is worth a pound of cure."

If you believe a poison has been swallowed, but do not know what it is, the best you can do is to encourage voruiting and get the stomach to reject all it can. The best and most convenient emetics are large draughts of warm water and mustard or salt.

If you now discover what poisonous substance has been swallowed, you must try and recall to your mind the best remedy you can use or have at hand for counteracting it. Charge your memory with the antidotes or drugs given to counteract the effects of the poisons most commonly met with. It is a wise precaution to have the antidote for each poison kept in the house, and it is safer still, where practicable, to label and place each antidote with the poison it will counteract.

Mineral acids and alkalies neutralize each other, and therefore one is an antidote for the other.

If a strong mineral acid, such as oil of vitriol, aqua fortis, or spirits of salt, be swallowed, give large drinks of soda, magnesia or lime-water, chalk, soap-suds or plaster from the wall. When hartshorn, caustic soda, lime or strong lye are taken, give vinegar and water or lemonade. Carbolic acid 
has become somewhat common in households, and is a dangerous poison. Alkalies do not neutralize this acid. The best you can do is to give large quantities of sweet oil and milk.

Rat poisons contain either phosphorus, mercury, arsenic or strychnia. For any of these, first give an emetic. Phosphorus is also in common use in the manufacture of matches. It is best counteracted by large draughts of warm water and magnesia. No oils. For arsenic, give new milk, raw eggs, linseed tea, and a full dose of castor oil. For mercury, give the same antidotes as in arsenic. In a case of strychnia poisoning, after encouraging vomiting by an emetic or by tickling the throat with a feather, give animal charcoal mixed with water; use cold applications to the body, and, if necessary, resort to artificial respiration.

Narcotics, such as opium, morphine, laudanum, paregoric, etc., in large doses, produce a deep sleep or stupor. After using a brisk emetic, keep the patient roused by walking him about, slapping the face and body with cold, wet towels, and give strong coffee.

28. Alcohol in First Aids.-It is, unfortunately, too common a practice when a person' is taken suddenly ill or meets with an accident, to give brandy or whiskey. Not, knowing what to do, we are apt to do the wrong thing. In all the different emergencies and ailments we have been dealing with in this chapter, not only is alcohol unnecessary, but in many cases it would be positively harmful. When the patient can swallow at all, a drink of hot beef tea, hot milk, or hot ginger tea will answer every purpose.

\section{Alcohol and Tobacco Irritant Narcotics.-The} irritant poisons, such as mineral acids, arsenic, etc., can be and are used as medicines in properly regulated doses. With the same care, narcotics are sometimes given to relieve pain or soothe the wearied brain to sleep. In like manner, the 
irritant narcotics, such as brandy and all spirituous liquors, tobacco and nicotine, may be taken in small doses, without producing any marked signs of poisoning; but just as surely. as an overdose of any of the other poisons will produce serious results, so sure is an overdose of alcohol or nicotine to endanger life or even prove fatal. Many a child, and many older persons, for that matter, have lost their lives by taking a large dose of alcohol, either by mistake, or by having it forced upon them, or in a wager.

Intoxication is in reality a poisoned condition of the system. The name itself implies this. Alcohol, when taken almost pure and in sufficient quantity, may produce death in a few minutes or in a few hours; and even when taken in small quantities, while it does not produce symptoms of poisoning, it tends to shorten life, and is often the primary eause of many of the every-day examples of ill-health, sickness and squalor, since it weakens the constitution, undermines morality, and is the great fountain of pauperism, thereby rendering thousands of homes unhappy.

If alcohol and tobacco were irritants only, they would be as little used as any of the irritant poisons, but they are narcotics as well, and while they soothe, they also irritate and destroy; while they stimulate, they also depress; while they exhilarate, they also weaken; -while they charm the senses for a time, they fascinate until they conquer; while they drown sorrow, the respite is brief, for it soon returns with greater weight. Instead of elevating, they debase; instead of strengthening the moral system, they undermine it; instead of improving the mental and intellectual faculties, they numb the very nerve centres; and instead of nourishing and invigorating the system, they interfere with its various functions, and render it more susceptible to injury and decay. 


\section{CHAPTER XI.}

\section{HOW TO PREVENT DISEASE.}

1. Preventable Diseases.-During recent years much progress has been made along the lines of acquiring more accurate knowledge of the causes of the various diseases, their modes of spreading, and of more effective measures for preventing and restricting them. It is a nobler aim for the physician to prevent disease than to cure it. The name of Sir W. Jenner will ever be known, not so much because he was a celebrated physician, but because by the introduction of vaccination he established a method of preventing the virulence of small-pox. Scurvy, which a few years ago was a very common disease on board ships long out at sea without vegetables, or amongst soldiers in war time where the diet was not sufficiently varied, is now a rare disease, owing to the discovery of the cause, and the use of lime-juice and lemonjuice when fresh vegetables cannot be obtained. Leprosy was a well-known disease in ancient days, and up to a few hundred years ago it. was common in Great Britain. By a continued and careful isolation of cases it has now become a rare disease. The much dreaded cholera has been pretty effectually held in check by the watchfulness of the Public Health Officers at the various seaports. And of other preventable diseases, such as typhoid fever, measles, scarlet fever, diphtheria, erysipelas, etc., better means of arresting local epidemics have been used recently than in former years.

But while much has.already been done in the way of preventing disease, more remains to be done. The seeds of disease have been widely sown in the human race by inatten- 
tion to the laws of health, and will continue to germinate and grow if not arrested by the strictest compliance with those laws, not only of individuals, but of communities as well. In view of the fact that by the observance of sanitary laws disease may be prevented, it is obvious that education on this subject should be widely diffused. It should begin in childhood with the parent, by precept and example. It should be continued in the school-room, from the lowest grades upward, and the wise and prudent man will be a student of hygiene all his life.

2. Infectious and Contagious Diseases.-The terms infectious and contagious have a separate and distinct meaning, although they are commonly used synonymously. The distinction is important in so far as each term indicates the means whereby the poison which invades the system is developed.

The poison of an infectious disease is developed external to the human body, and is introduced to the system irrespective of a pre-existing case. Typhoid fever and cholera are types of this class. In a contagious disease the germs of the poison are received directly or indirectly from a person having the disease. The germs, having been received into the system, undergo a process of development and multiplication. There is always a period, longer or shorter, between catching the disease and its actual appearance. It is a period of incubation or hatching. Familiar types of this class are scarlet fever, measles and small-pox.

Some diseases are more distinctly contagious than others, as scarlet fever and small-pox; some, as diphtheria, seem to be both infectious and contagious, while cholera is .believed by some to be contagious as well as infectious.

The poisor of infection, developed external to the body, requires suitable soil in which the germs may take root and grow. This soil consists of dead matter which has formed a 
part of a living being or a vegetable growth. It is not merely dead matter, it is matter undergoing decomposition; not alone decomposing, but putrefying. It does not require much of this putrefying matter to form a breeding-ground for the disease germs, and, unfortunately, such breeding-grounds abound on every hand. They are the outcome of every-day civilized life. They are found in the waste material which comes from every dwelling-house, from many factories, stables, storehouses, butcher stalls, etc. They exist in the form of garbage thrown from the kitchen or lying in the cellar, in the slops of the kitchen, in the dust on the floor, or lodged on the furniture. In a word, a breeding spot for disease will be found in every hole and corner of an untidy house-on the walls, in the clothing, everywhere.

\section{Means of Invading the Human System.-The} manner in which these disease-producing germs find their way into the body is varied. They are often, when floating in the air as dust, inhaled with the breath. They may be mixed with the food or drink, and swallowed. When these germs gain admission to the system, they enter into a contest with the elements of the body. Having found a soil suitable for their development, they, in taking root, take nourishment from the cellular structures of that particular part. They encroach upon the living cells, and a struggle for life ensues between the cells of the part and the invading cells. Sometimes the seat of conflict is in one part of the body, sometimes in another. In typhoid fever the battle-ground is in one portion of the intestine, in cholera it is in another portion. In diphtheria it is in the mucous membrane of the throat. It is here also in whooping-cough. In erysipelas it is in any part of the surface where there is a wound or broken integument.

In this struggle for life the more numerous and more powerful the invading force, the more decided the victory. But sometimes the invaders fail to conquer. Not everyone 
exposed to infection or contagion takes the particular disease, not because the germs do not enter the system, but because they were too weak, or because the powers of life enabled the cells attacked to successfully resist the enemy, to destroy him and cast him out. Polluted germs sometimes enter the body, and instead of attacking a particular part, contaminate the whole system. This is seen in intermittent fever and low fevers, caused by living in malarial districts.

The lesson these facts afford is easily learned. The force of the maxim, "Prevention is better than cure," is to be applied to every-day life. High authority has declared that cleanliness is next to godliness. But the matter of cleanliness must be applied, not only to the person, but to his surroundings as well. If this rule be observed, no soil for impure germs to grow in will exist about the dwelling, the office, the work-shop, or especially the kitchen.

The most efficient means of dealing with all refuse material is always at hand. All refuse organic matter that can be burned, should be thus destroyed. Filth in fluid form may be burned by mixing sawdust with it. If not burned, the material should be far removed from every place of habitation or be properly disinfected. Pure air and sunlight are valuable disinfectants, and should be let into every hole and corner of the house and premises. Beside air and sunlight, nature has provided another disinfectant in common earth, which will absorb fluids, and by chemical action convert offensive material into soil.

4. Antiseptics and Disinfectants.-An antiseptic is an agent which restrains or absolutely prevents decomposition; a disinfectant oxidizes the dead matter as it decomposes, but the best disinfectants are those that destroy the germs of disease. The use of an antiseptic, as common salt in curing meat, prevents the necessity of using disinfectants, and the timely use of a disinfectant destroys the soil in which germs 
would develop. The butcher, finding his meat a little tainted, can restore it by the timely use of a disinfectant, and hence he washes it with Condy's fluid, or, better still, a solution of the acid from willow bark. One of the best and cheapest antiseptics is boiling water. It has no equal in the universality of its use and in its cleansing and wholesome properties. In the kitchen, in the scullery, in the laundry, in the dairy, it is the perfect antiseptic. The housewife knows its antiseptic properties when she scalds the milk cans before "setting" the milk, in order to keep it pure and sweet.

Many of the best disinfectant drugs are powerful poisons, and, therefore, cannot be recommended for general use. Strong-smelling drugs are not necessarily good disinfectants. They may be good deodorizers, but cannot be relied upon for killing germs. Carbolic acid, for instance, will only disinfect where it touches, and although much vaunted and much used, is not a good general disinfectant. The following is a better general disinfectant, and is one which cannot be too strongly recommended, not only for its effectiveness, but because it is cheap, free from smell, practically non-poisonous in the strength it is used, and will not stain or injure linen, clothes, etc. Dissolve half a.drachm (nearly half a small teaspoonful) of nitrate of lead in a pint of boiling water. Then dissolve two drachms (two teaspoonfuls) of common salt in eight quarts of water. Pour the two mixtures together. After the sediment has settled, the liquid is a saturated solution of chloride of lead.

A cloth dipped in it and hung up in a room will purify a fetid atmosphere. It may be used to be poured down a sink, drain, or other foul opening.

5. The Sick Room.-The proper management of a case of contagious disease, to prevent it from spreading, should be understood by everyone. From this case the germs may find their way to other members of the family. They may pass 
directly from the one affected to another by inhaling the breath or the exhalations from the body, or they may be carried by a third person from the first to the second, or by means of a book or other inanimate object. Again, the germs may lie dormant for an indefinite period, perhaps in clothing or on the walls of a room, like wheat in a granary stored away, ready to grow when sown on a suitable soil. Instances are not uncommon where a contagious disease appeared, when it was impossible to ascertain its source. It is known that these diseases do not arise spontaneously. As well expect to have a crop of corn without planting corn, as to have scarlet fever, for instance, without having had the germs of that disease planted in the system. Doubtless, in the instances referred to the germs had been lying undisturbed upon some object.or in some article of clothing for a time past recollection; or, as has often Kappened, a family has moved into a dwelling where a case had existed, and proper disinfection had not been made.

Certain contagious diseases are only contracted once in life, as measles and scarlet fever, with some few exceptions. Sometimes a person may be exposed to a contagious disease without catching it, and when again exposed is not so fortunate. This is due either to the existence of a more powerful poison at the last exposure, or to what is called a predisposition on the part of the individual. He may be at this time in less robust health, and the vital powers are unable to cope with the germs successfully. It is to be remembered that no one in poor health should expose himself as attendant upon the patient. The more contagious the disease, as in scarlet feveror small-pox, the greater the care to be observed. While the welfare of the patient is duly attended to, the welfare of others should not be neglected. There need be no conflict between the two necessities.

The first thing to be done when a case of contagious disease 
becomes known, is to isolate the person. It is preferable to have the sick room at the top of the house. The germ-tainted air is more likely to ascend than descend, and in ventilating, the foul air of the chamber will escape above the heads of the occupants, and be soon lost in the atmosphere.

The sick room should be large, bright and airy, but should contain only such articles of furniture as are absolutely required for the comfort of the patient and nurse. The room should be stripped of carpets, curtains, pictures and table covers, unless they are subsequently to be burned. Also books, papers, ornaments, and in fact everything that can be easily removed. The less there is in the room the less surface there is on which the disease germs can collect. There should be no superfluous bedclothes, and the nurse must be satisfied with a cushionless chair. She must not go about the house or among the family. She must take her meals by herself, and sleep either in the sick room or in a room similarly prepared, and used only by herself. Only the nurse and doctor should enter the room, and nothing should be taken back and forth to and from the sick room. All the excretions of the body must be disinfected at once. In a case of diphtheria, the discharges from the throat should be collected on pieces of old cotton, and promptly put in the fire. Any food or drink left by the patient should be either burned or disinfected.

Besides avoiding the sick room, the other members of the family should, as far as possible, withdraw for the time from society generally, and especially should the attendance of any of the children at school be discontinued.

Proper ventilation is necessary night and day. The old idea that night air is dangerous has mainly lost its hold upon the intelligent mind. But admitting that night air is objectionable, it is far better for the patient than the close, tainted air of the room. When the room remains altogether closed for a time and then opened, the rush of foul air outward may 
cause a current which might be a source of danger to the patient. The form of ventilation must be directed by the doctor, and his instructions in this and all other respects should be implicitly followed.

When the patient has recovered, he should, after a bath, be put in clean clothing brought into the bath room, and should not re-enter the sick chamber. The room and contents must be thoroughly disinfected. Throw the windows widely open. Soiled articles, with the wood-work of the room, should be thoroughly washed and scrubbed with hot water and soap, and then with the solution of chloride of lead. Articles of little value should be burned, also articles that will not stand washing. Fabrics must be subjected to continued boiling, and then dipped in disinfecting fluid. The wall paper had better be removed and burned. All these precautions must be observed, especially in the more contagious diseases. When it is a prolonged case of sickness which is not contagious, the room need not be so thoroughly dismantled, and more attention will be necessary in making the room cheerful and attractive.

6. Stimulants in the Sick Room.-The free use of alcoholic stimulants in the sick room is now strongly deprecated by those. who have carefully watched their effects. Heart tonics and diffusable stimulants, such as ammonia, etc., are more serviceable than alcohol in the majority of cases. They have not the depressing after-effects, nor do they clog the system and interfere with nature's struggles towards the restoration of health.

In the course of acute fevers, and in epidemics of virulent diseases, few physicians now resort to the routine treatment of alcoholic stimulants; indeed, it is a well-known fact that spirit drinkers are the first victims in cholera and other epidemics. 


\section{CHAPTER XII.}

\section{PHYSICAL EXERCISE.}

1. The Benefits of Exercise.-The study of physi ology, however brief, will impart such a knowledge of the construction of the human frame and the functions of its various organs as will enable us to interpret the many wants of the system, to appreciate the difference between that which is wholesome and that which is unnecessary or useless, to know what is required of us in aiding in that growth of body and mind which will attain to perfect manhood, and to avoid the use of anything that tends to injure the health or undermine the constitution. Both mind and body are more susceptible to external influences in youth than in mature age. Early attention is necessary to the formation of correct habits, not only in eating and drinking, but in every action and movement of the body. Excess in anything should be avoided. We have seen that excessive action of any part is sure to be followed by a corresponding reaction or loss of function in that part for a time. The heart may be induced by stimulants to act too fast, but there comes a time when it will act too slowly. The mind may be overexerted for a while, but reaction will set in and the brain become sluggish. The muscular system may be over-taxed by hard labor or violent exercise, but weariness and prostration are the result.

While we can injure our systems by excesses, we can also do so by inattention or neglect. Untrained minds have not a large amount of brain energy. Sluggish circulations and enfeebled digestions frequently follow in people who live 
in-door, inactive lives. Want of strength, loss of growth, and lack of symmetry in form may all result from a careless disregard of the necessity for daily exercise. Physical_exercise stimulates the whole system, puts new life into every part, and gives increased energy and force to every organ of the body. It develops the various muscles, gives strength and form to the limb, and courage and ambition to the mind. The child grows proud, not only of his attainment of muscular strength, but of its effects. His body becomes better set up, the chest expanded, the shoulders well back and the head erect. The movements of the limbs are done with precision and ease. The step is elastic and the gait free and smooth.

Physical exercise should be taken regularly and at stated times. It is not the impulsive exercise of a day that will improve the system. It is the taking of a certain amount of muscular action every day. Too much exercise in one day or at one time is fatiguing, and will exhaust the strength rather than build it up. The amount of exercise must be regulated by the strength, and can be gradually increased as the system becomes used to it.

2. Kind of Exercise. - That kind of exercise which calls into action the greatest number of muscles is always the best. It is well to exercise as many of the muscles as possible at the same time, and as no one form of exercise or employment brings into use all the muscles, the necessity for some variety is at once apparent. There is quite a variety of natural forms of exercise apart from the many occupations of life. Walking, riding on horseback or bicycle, rowing, swimming, skating, snow-shoeing, lawn tennis, football, and out-door games generally are all valuable modes of natural exercise. They have also the great advantage of taking persons out into the open air and sunshine, where the lungs are better supplied with pure air, and the blood enriched 
with larger quantities of oxygen. Walking is one of the best exercises we can get, because it involves the use of a great many muscles. The legs, arms and body are all in motion, which means muscular action. Swimming is another form of exercise which is especially useful, inasmuch as it requires the active employment of a very large number of the muscles. A healthy, strong person in. water of a moderate degree of warmth, so that too much heat of the body is not carried off, will, after a little practice, not only secure all the benefits of a bath, but also the good effects of the most perfect natural exercise. The feeling of comfort and general toning of the system after a good swim can hardly be obtained in any other way.

But useful as are these natural forms of exercise, and each commendable for some special feature, yet no single one of them calls into action all the voluntary muscles; hence, in addition to these, it is advisable, especially during the period of growth and development, to devote a certain time daily to artificial training of the muscles.

3. Regulation of Exercise.-The kind of exercise most beneficial depends upon the age, the condition of health, and to a certain extent the sex and the occupation. Exercise in health may with advantage be carried to slight weariness, but not so as to cause a feeling of prostration.

The employment of some affords ample exercise for the well-being of the body. The occupation of others is such that only a portion of the muscular system is engaged. In these the idle muscles should be exercised in other ways. The brain-worker needs exercise of the whole muscular system, and, when practicable, it should be varied from day to day.

Exercise should be taken in the open air. As we have said, it is not the muscles alone that are benefited. The various organs are made to do more work. The action of 
the heart is increased, the breathing is deeper and more rapid, and there is greater activity of the circulation. Pure, fresh air improves the quality of the blood thus sent more rapidly coursing through the system. The tissues of the body are supplied with better material for building it up. The waste products are given off more freely, and the skin, kidneys and lungs have to do more work in getting rid of these used-up particles.

A daily walk of four or five miles, or its equivalent in any out-door exercise, not only strengthens the voluntary muscles, invigorating the whole system, but it also stimulates the muscles which eontrol the organs of digestion, improves the appetite, and supplies the body with new material and new resources.

4. Time for Exercise. - As a general rule, exercise should not be taken while fasting, $n c r$ very soon after taking a meal. Experience has shown that in the one case prostration often follows, with loss of appetite, and in the other digestion of the food is delayed, and sometimes stopped for a time. While the stomach is most actively engaged, say, for two hours after a meal, the body should have its leisure time. Let the occupation be as light and the exercise as gentle as possible for at least the first hour after taking food.

Our longest period of fasting is during sleep. On first rising in the morning the system is relaxed, and the body is the weakest. This is plainly not the time for exercise which is at all violent or prolonged. Some food, if only a morsel, should be taken before going out to work or to study before breakfast. The evening is not so good a time for exercise as the earlier parts of the day. After the many hours of work the energies are nearly spent, and the body is tired.

It is just as important to regulate the form and amount of exercise to the time of life as to the time of day. The little child is not likely to take too much exercise. It will drop to 
sleep when tired. A plucky lad may outdo his strength, and bring on illness, in his ambition to excel at some muscular feat, or overeome his fellow in some game or sport. The satisfaction of defeating an opponent at lawn tennis, or the desire to carry off some trophy, may goad a young girl or an ambitious youth to physical harm. The imprudent efforts of

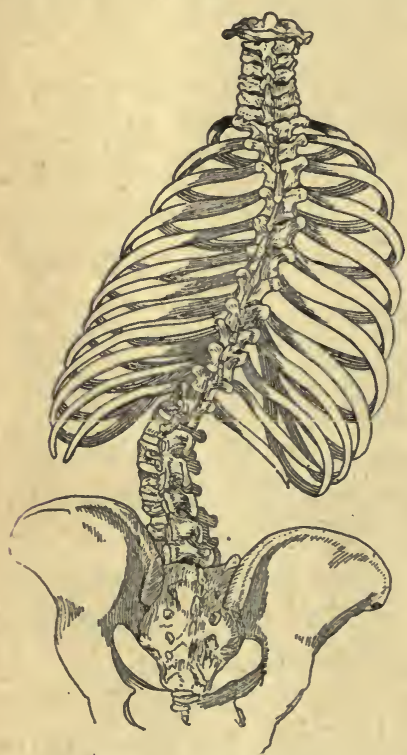

Fia. 52.-Curvature of Spine. people of middle and advanced age to appear young, to run to "catch" the train or street car; or show their agility in other youthful ways, have often caused sudden and serious results.

\section{Necessity for Exercise.} -Children when deprived of sufficient out-door exercise are generally pale, puny and delicate. Nothing weakens the young body like an in-door, inactive life. It makes a child tender and susceptible to the slightest change of weather. Colds, coughs and headaches are quite common. Children of the working-classes are usually strong and healthy. They may not be well clad, perhaps they are often dirty, but they have the freedom of the lanes, the fields and the streets, and spend the greater part of the day in the open air.

The development of the child's body from day to day calls for close attention to its many requirements. Proper nourishment must be supplied and suitable clothing provided. The child must be taken out into the fresh air, and directed and eneouraged in those efforts of physical exertion which tend to strengthen the system and hasten its growth. 
The bones and ligaments of the young are soft and pliable. They readily grow into false positions by constant habits of stooping or bending to one side. The spinal column is kept in position by a well-balanced action of the muscles supplied to it, and if these are unevenly exercised they become stronger on one side than the other, and draw the spine to that side, producing a lateral curve (Fig. 52), which, if allowed to exist for some time, may cause a permanent deformity. Children whose constitutions are naturally weak are more apt to grow into false positions than the healthy and robust, and hence require more careful attention. Fig. 53 is an illustration of how curvature of the spine is brought about, and shows the marked contrast between this position, which is productive of so much deformity, and the natural position, as shown in Fig. 54.

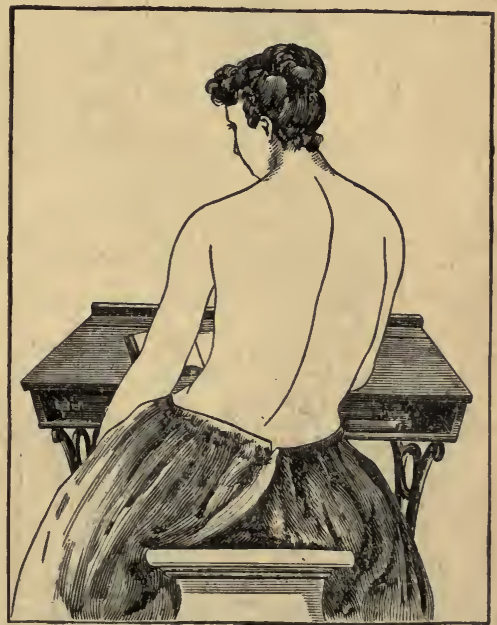

FIG. 53. - A school-girl at her desk in a position often resulting in curvature of the spine.

But there is another element which enters largely into the child's life. The training of the mind is as important as the training of the body. The child must be sent to school, and remain more or less inactive for several hours a day. As it grows older, tasks will be given that involve close application to books at home as well as during school-hours, and so it becomes necessary for the teacher, in regulating the various 
exercises, to provide as carefully for the needs of the body as of the mind.

6. Gymnastic Training.-The importance of physical as well as mental training is being recognized at the present time by the introduction into schools and colleges of systematic drill, calisthenics, and various other forms of gymnastic

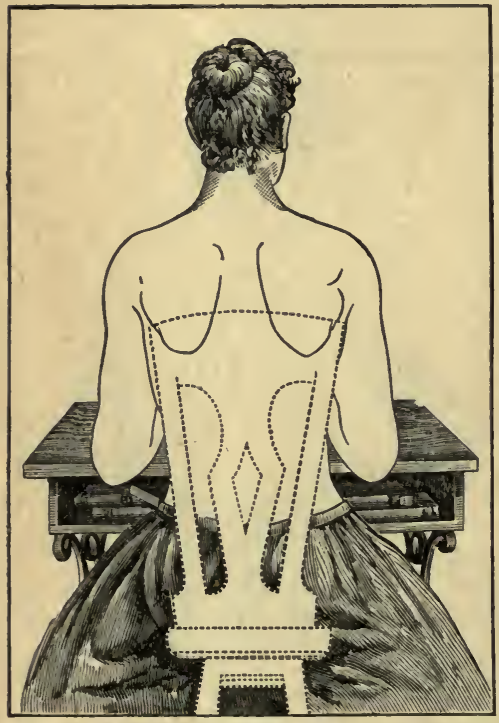

FIG. 54.-A correct position at the school-desk, with no undue strain on the spine.

duced into the schools of Ontario. The scope of this work does not allow a full description of any system. It may be stated, however, that they not only secure physical training, but as well a species of light mental exercise. The mind is engaged as well as the body. The object is to make the mind act quickly in conjunction with prompt motion. At the word of command, a whole class performs certain move- 
ments together. This united action leads to a desire on the part of each to excel, or at least to do as well as others, and eventually every member of the class has developed in him a desire to remedy his defects, to carry himself erect, be graceful in figure, and move with ease and facility.

Very little apparatus is necessary. Motions and movements of the body may be made without anything in the way 'of appliances. Wooden dumb-bells are as good as metal ones. The muscles of the arm can be exercised just as well without the actual weight in the fist. By effort the same tension can be put upon the muscles of the arm to raise a pen-handle as to raise a ten-pound dumb-bell. The weight of a body is measured by the amount of muscular force it is necessary to use in order to lift it. If we use the same muscular force to raise the pen-handle as the ten-pound weight, the muscles have done the same amount of work. But these various movements should not be made at any great expense of muscular force. They may be carried to the extent of slight fatigue, but not beyond. An exercise of fifteen minutes is quite long enough at any one time, and if during the practice it produces a feeling of dizziness or discomfort, it should be at once discontinued.

Physical culture in schools is intended not so much to promote growth as to correct false positions and habits of sitting, standing or walking, and thus guard against deformities of the body and lack of symmetry in its development. Keeping these objects in view, that form of physical training which is necessary in any particular case can be selected from the following exercises, compiled and rearranged from Lucy B. Hunt's "Handbook of Light Gymnastics," by Dr. A. F. Blaisdell, for his estimable little work, "Our Bodies and How We Live": 


\section{EXERCISES.}

\section{FREE GYMNASTICS.}

Position.-Stand with heels together, hips and shoulders back, hands firmly closed and well back upon the chest.

Directions.-Each number fills a strain of music, except when otherwise specified.

Keep the heels together and hips back, unless the exercise otherwise directs. The arms overhead should always be with elbows unbent.

These exercises should be taken slowly and with caution at first. As the strength increases, greater rapidity and force should be employed.

Music for the free gymnastics should either be in galop or polka time.

\section{Exercise 1.}

1. Thrust right hand down twice, left twice, alternately twice, together twice.

2. Repeat No. 1, only thrust hands out at sides instead of down.

3. Repeat No. 1, thrusting hands directly up.

4. Repeat No. 1, thrusting hands from shoulders directly forward.

\section{Exercise 2.}

5. Right hand down once, left once, then clap hands through rest of strain.

6. Same exercise, out at sides.

7. Same exercise, directly up.

8. Same exercise, out in front.

\section{EXERCISE 3.}

9. Hands on the hips, step with right foot forward, then diagonally forward, directly at side, diagonally back, directly 
back, cross back of left, cross again still farther back; lastly, cross in front of left foot, returning to position after each step.

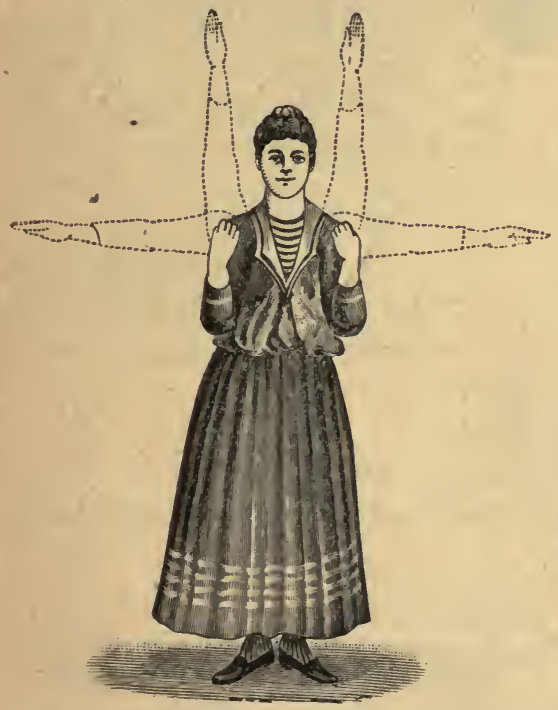

Fra. 55.

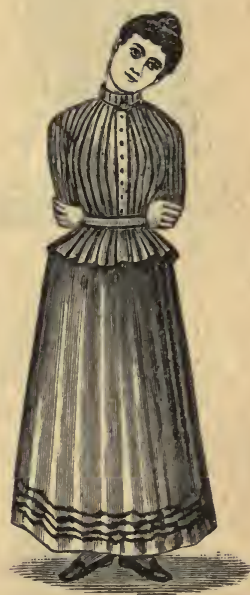

F1G. 56.

10. Repeat No. 9, with left foot.

EXERCISE 4.

11. Stamp with right foot forward three times, advancing each time, then left three times. Stamp three times back with right foot, same with left.

12. Repeat No. 11.

\section{EXERCISE 5.}

13. Hands still on hips, twist body alternately to right and feft, twice each ; four beats of music.

14. Bend body alternately to right and left, four beats of music finishing the strain. 


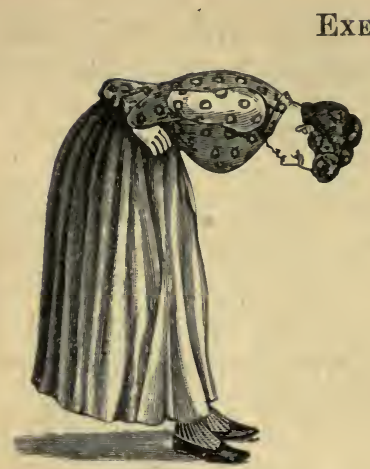

Fig. 57.

15. Bend body alternately. forward and back, twice each.

16. Bend body first right, then back, left, front; re verse, left, back, right, front, finishing the strain.

17. Same as No. 13, only twist the head.

18. Same as No. 14, only bend the head instead of the body.

\section{Exercise 7.}

19. Same as No. 15, with head only.

20. Like No. 16, bend head instead of body, right, back, left, front, then reverse.

\section{Exercise 8.}

21. Arms extended in front, bring them forcibly back to chest eight times.

22. Arms again extended, raise right hand twice without bending the elbow, then left twice, alternately twice, together twice.

\section{EXERCISE 9.}

23. Hands closed on chest, thrust down, out, up, and in front, twisting the arms each thrust; repeat.

24. Thrust hands from chest toward floor without bending the knees, stop on chest, then over head, rising on toes, and opening hands at each thrust, continue in half time through the strain.

25. Cross left foot over right, at same time touching fingers over head; then right foot over left, alternately in half time through the strain. 


\section{Exercise 10.}

26. Stamp left foot, then right, charge diagonally forward with right foot, bend and straighten right knee, at the same time carrying arms back from horizontal in front. When the arms are extended in front, the hands should be the width of the shoulders apart.

27. Repeat this exercise on the left side.

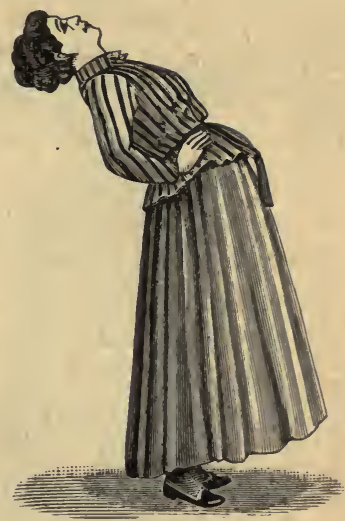

FIG. 58.

\section{EXERCISES WITH DUMB-BELLS.}

Position.-Heels together, hips and shoulders back, bells down at sides. One-half of each strain of music is given to the exercise, the other half to what is called "the attitude." In taking these attitudes the bells are brought first to the chest; then, unless otherwise specified, placed upon the hips.

Directions.-Step carefully but quickly to all the attitudes.

Rest oftener than in the other exercises.

Use too light, rather than too heavy, dumb-bells. Oldfashioned waltzes are best for these exercises. Scotch airs and airs from popular operas, in this time, can easily be adapted by a skilful musician.

\section{Exercise 11.}

28. Hands down at sides, palms in front, turn bells four times, bringing them to chest on fourth accented beat. 
Attitude: Step diagonally forward with right foot, carrying hands to hips, looking over right shoulder.

29. Elbows at sides, turn bells just half-way round four times.

Attitude: Step diagonally forward with left foot, looking over left shoulder.

30. Arms extended at sides, turn bell four times.

Attitude: Step diagonally back with right foot, looking. over right shoulder.

31. Arms extended over head, palms in front, turn bells four times.

Attitude: Step diagonally back with left foot, looking over left shoulder.

\section{Exercise 12.}

32. Bells far back on chest, thrust both down, out at sides, up, and out in front.

Attitude: Turn to the right, throw arms up at side without bending the knees. The bells in this attitude should be exactly horizontal and parallel.

33. Repeat No. 32, turning to the left and throwing the arms up on left side.

Attitude: Repeat attitude No. 32.

\section{EXERCISE 13.}

34. Drop bells at sides, right hand up to armpit once, left once, together twice.

Attitude: Drop to sitting position, bells touching the floor, rest through the remainder of the, strain.

\section{Exercise 14:}

35. Bells on shoulders, thrust each up once, both together twice.

Attitude : Rise on toes, palms forward, bells parallel.

36. Arms extended in front, turn four times. 
Attitude: Step diagonally forward with right foot, right hand on hip, looking back at left bell, which is extended in left hand.

\section{EXERCISE 15.}

37. Arms extended sideways at an angle of forty-five degrees, turn bells four times.

Attitude: Step forward with left foot, left hand on hip, looking back at right bell,

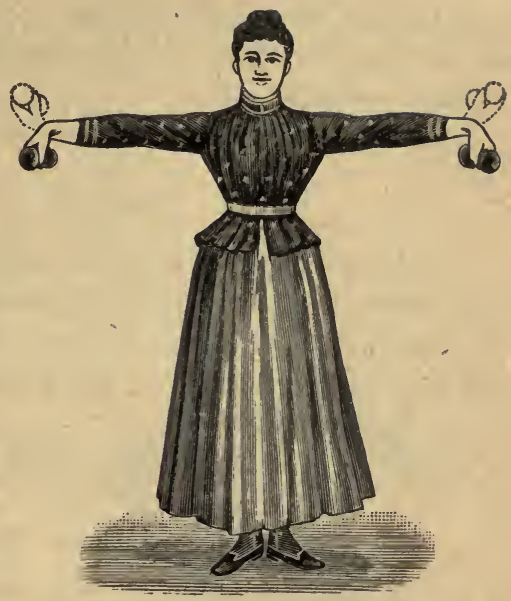

Fig. 59. which is extended in right hand.

EXerCISE 16.

38. Bells on chest, right hand down, then up, left hand the same.

Attitude: Turn body to the right, thrust right hand obliquely up, palm up; left hand obliquely down, palm down.

\section{Exercise 17.}

39. Bells on chest, right hand up, left down; reverse, then both down, both up.

Attitude: Turn to left, thrust hands up and down, as in INo. 38 .

\section{EXERCISE 18.}

40. Arms extended in front, palms opposite, right hand up once, left the same, both together up twice.

This should be done without bending the elbows. 
Attitude: Step diagonally forward with right foot, the body and head thrown forward, and arms thrown wide apart.

41. Repeat No. 40.

Attitude: Repeat attitude No. 40, on the left side.

\section{EXERCISE 19.}

42. Arms extended at sides, right arm up once, left-once, both twice, without bending the knees.

Attitude: Step diagonally back with right foot, right hand up, with bell perpendicular, left hand on hip.

43. Repeat No. 42.

Attitude: Repeat attitude on left side.

ExERCISE 20.

44. Arms extended, with bells parallel in front, bring the bells back forcibly upon the chest four times.

Attitude: Fold the arms with bells closely pressed against the chest, and bend back slowly from the waist.

\section{EXERCISE WITH WANDS.}

Directions.-Always select a wand just long enough to reach the armpit when placed on the floor at one's side. All exercises from behind the head or back should be taken with caution, and avoided altogether by those with weak backs.

Position.-Heels together, hips and shoulders well back. The wand is held in front of the right shoulder, till first signal from piano, which consists of three chords struck with both hands, the first being the length of the other two; then drop it horizontally in front of the body. At second signal raise the wand till the arms are extended in horizontal position in front of body, place the hands so as to divide the 
wand into three equal parts. At third signal, carry the wand back to second position down in front.

The simplest of Strauss's waltzes must be used, or those of other composers similar in style.

\section{Exercise 21.}

45. Raise the wand to chin four times, keeping elbows high, last time carry it above the head, then bring down under chin four times.

46. Carry wand from above the head nearly to floor, four times, without bending knees or elbows, then down back of the neck four times.

47. Carry wand from above the head to chin,

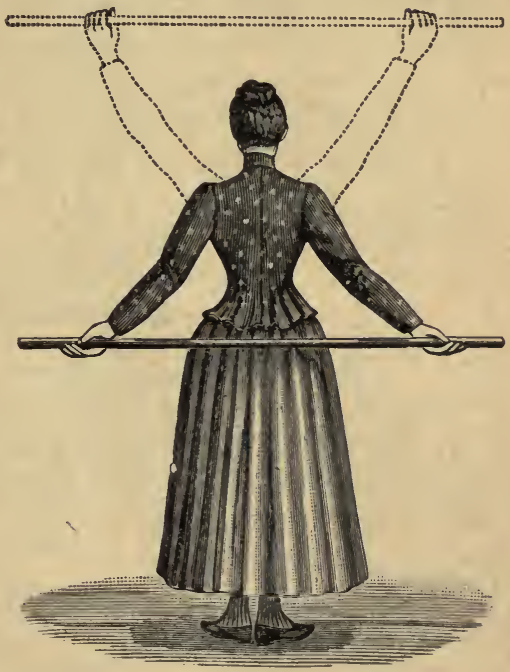

Fro. 60. and then back of neck, alternately four times each.

Exercise 22.

48. Wand over head. On first beat, carry right hand to right end of wand; on second beat, left hand to left end, then carry hand back of head to hips, six times, keeping elbows stiff.

49. Carry wand back from above head down nearly to floor; and then back to hips, four times, alternately four times each.

50. Carry wand from above the head to right and left sides alternately eight times, keeping elbows stiff, and stopping exactly over head each time. 


\section{EXERCISE 23.}

51. On first beat, let go wand with left hand, place end of wand on floor between feet. On second beat, place wand on floor at arm's length, diagonally forward on right side. Step with right foot to wand through rest of strain, keeping right arm, left knee, and wand perfectly straight.

52. Repeat No. 51 on left side.

53. Repeat No. 51, keeping the foot stationary, the knee bending with each accented beat.

54. Repeat No. 53 on left side.

\section{Exercise 24.}

55. Arms horizontal in front, wand held perpendicularly, bring wand back to chest eight times, keeping elbows high.

56. Wand and arms in same position, bring wand to right and left shoulders alternately four times each. In passing the wand from one side to the other, raise the arms straight to a horizontal position in front.

\section{Exercise 25.}

57. Hands in front of chest, point wand diagonally forward at an angle of forty-five degrees, first to the right, then to the left, alternately through strain, making the change of hands just in front of chin.

58. With wand pointing in the same direction as in

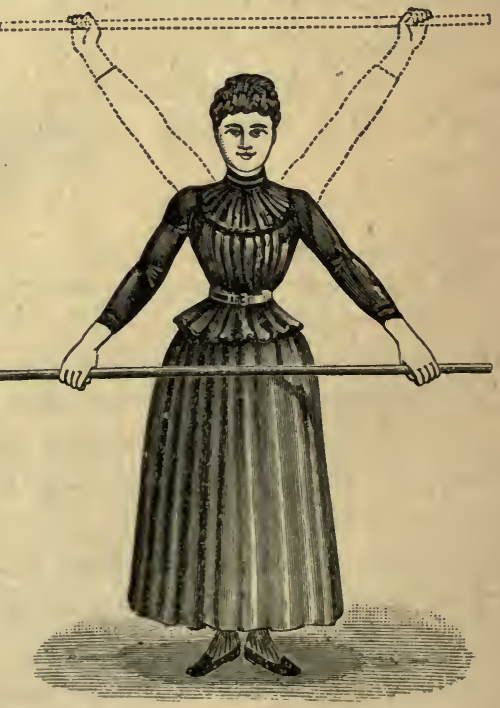

F10. 61. 
last exercise, step diagonally forward with right and left foot alternately through strain.

59. Repeat No. 58, only step back instead of forward, leading with left foot instead of right, keeping wand pointing forward.

EXERCISE 26.

60. Wand horizontal over head, right hand in front, reverse position, bringing left hand in front, on half time through the strain.

61. Same position, right face, bend forward, bringing wand to perpendicular on right side, four times.

62. Repeat No. 61 , on left side.

\section{ExERCISE 27.}

63. On first beat, put left end of wand on floor in front of feet; on second beat, carry wand at arm's length in front, charge right foot to wand twice, left four times, changing hands and feet at same time.

64. Right foot back four times, right hand on wand, same with left hand and foot.

65. Right foot forward and back four times, left the same, holding wand in same position as last exercise.

66. Both hands on wand in front, right foot forward left back at the same time, reverse and repeat.

\section{EXERCISES WITH RINGS.}

Directions.-These exercises are performed in couples, partners facing each other about three feet apart; the one standing on right of teacher on platform, holding both rings.

Schottische time is the best, but slow marches and quicksteps can be used.

In all exercises, turning back to back, be careful and not 
pull suddenly, and never let go the ring before the word is given.

Always stand at such a distance from next couple that there can be no hitting of rings.

The rings should always be strongly made, and about six inches in diameter.

\section{ExerCise 28.}

67. On first beat of music, the ring in right hand is ex tended, and grasped by partner's right hand. Second beat, right feet together, toes touching; on third beat, left feet back at right angles with right feet, with left hands upon hips. Turn the ring over half-way and then back to place through rest of strain, keeping perfect time.

68. Repeat No. 67 , only use left hand and left foot, instead of right.

69. Repeat No. 67 , only first join both hands, on second beat, right feet together, third beat, step back, as ,before, turn rings through strain.

70. Repeat No. 69, with both hands joined and left feet touching, right feet back, turn rings through strain.

\section{EXERCISE 29.}

71. On first beat, turn back to back, on second beat, left feet together, charge directly forward with right feet; head and shoulders well thrown back, pull evenly with partner, and turn the rings through strain.

72. Repeat No. 71, with right feet together, left out in front, turn rings through strain.

\section{EXERCISE 30.}

73. On first beat, turn face to face, on second beat, raise arms above head, then lower rings without bending knees, 
looking alternately to right and left of partner through strain.

74. First beat, lift arms towards platform, high up at side, the others low down at the opposite side, carry them alternately up and down through half the strain, then both together, half a strain.

\section{Exercise 31.}

75. First beat, turn back to back, charge diagonally forward with right and left feet alternately through strain.

76. First beat, turn face to face, place left foot inside partner's left, short step back with right foot at right angles with the left. Rings over head held firmly, arms perfectly straight, sway alternately through the strain.

77. Repeat No. 76, with right feet together, instead of left.

\section{EXERCISE 32.}

78. First beat, turn back to back, charge up and down the hall alternately twice each; charge with right feet at same time, then left feet at same time alternately through rest of strain.

79. First beat, turn face to face, repeat No. 78 . 


\section{APPENDIX I.}

\section{REGULATIONS OF THE EDUCATION DEPART-} MENT RESPECTING THE STUDY OF PHYSIOLOGY AND TEMPERANCE.

By the regulations of the Education Department, at least one hour per week shall be devoted to familiar conversations with the whole school on the effect of alcoholic stimulants and of narcotics upon the human system. Attention should aiso be called to the degrading tendencies of their habitual use, and their injury to the individual and to society generally. These conversations are in addition to the course of study prescribed for the fourth and fifth forms.

The chapters upon digestion, respiration, the circulation of the blood, and the nervous system shall be studied in the Fourth Form, and the examination for entrance to the High School shall be based upon the pupil's knowledge of these chapters. The maximum marks awarded is seventy-five, onethird being required for pass.

In the Fifth Form, the course in the Fourth Form is continued, including also the other subjects of the text-book. In the case of candidates who fail to pass the Leaving Examination, twenty-five per cent. of the maximum marks will be required for Entrance, 


\section{APPENDIX II.}

\section{QUOTATIONS FROM THE LICENSE ACT WITH} RESPECT TO MINORS.

"Any licensed person who allows to be supplied in his licensed premises, by purchase or otherwise, any description whatever of liquor to any person apparently under the age of eighteen years, of either sex, not being a resident on the premises, or a bona fide guest or lodger, shall, as well as the person who actually gives or supplies the liquor, be liable to pay a penalty of not less than $\$ 10$, and not exceeding $\$ 20$, for every such offence.

"Any licensed person who allows to be supplied in his licensed premises, by sale or otherwise, any description whatever of liquor to any person under the age of twenty-one years (hereinafter called the minor), in respect of whom a notice in writing has been given to any such licensed person, signed by the father, mother, guardian or master of such minor, correctly stating the age of such minor, and forbidding such licensed person to sell or supply such minor with liquor, the said minor not being resident on the premises, or a bona fide guest or lodger, shall, as well as the person who actually gives or supplies the liquor, be liable to pay a penalty of not less than $\$ 10$, and not exceeding $\$ 20$, besides costs for every such offence." 


\section{APPENDIX III. \\ AN ACT RESPECTING THE USE OF TOBACCO BY MINORS.}

[ASSENTED TO 14TI APRIL, 1892.]

Her Majesty, by and with the advice and consent of the Legislative Assembly, enacts as follows:

1. Any person who either directly or indirectly sells or gives, or furnishes to a minor under eighteen years of age, Cigarettes, Cigars, or Tobacco in any form, shall, on summary conviction thereof before a Justice of the Peace, be subject to a penalty of not less than $\$ 10$, or more than $\$ 50$, with or without costs of prosecution, or to imprisonment, with or without hard labor, for any term not exceeding thirty days, or to both fine with or without costs and imprisonment to the said amount and for the said term, in the discretion of the convicting magistrate.

And in case of a fine, or a fine and costs being awarded, and of the same not being, upon conviction, forthwith paid, the Justice may commit the offender to the Common Gaol, there to be imprisoned for any term not exceeding thirty days, unless the fine and costs are sooner paid.

2. This Act shall not apply to a sale to the minor for his parent or guardian, under a written request or order of the parent or guardian.

3. A person who shall appear to the Magistrate to be under eighteen years of age, shall be presumed to be under that age unless it is shown by evidence that he is in fact over that age.

4. This Act shall go into effect on the 1st day of July, 1892. 


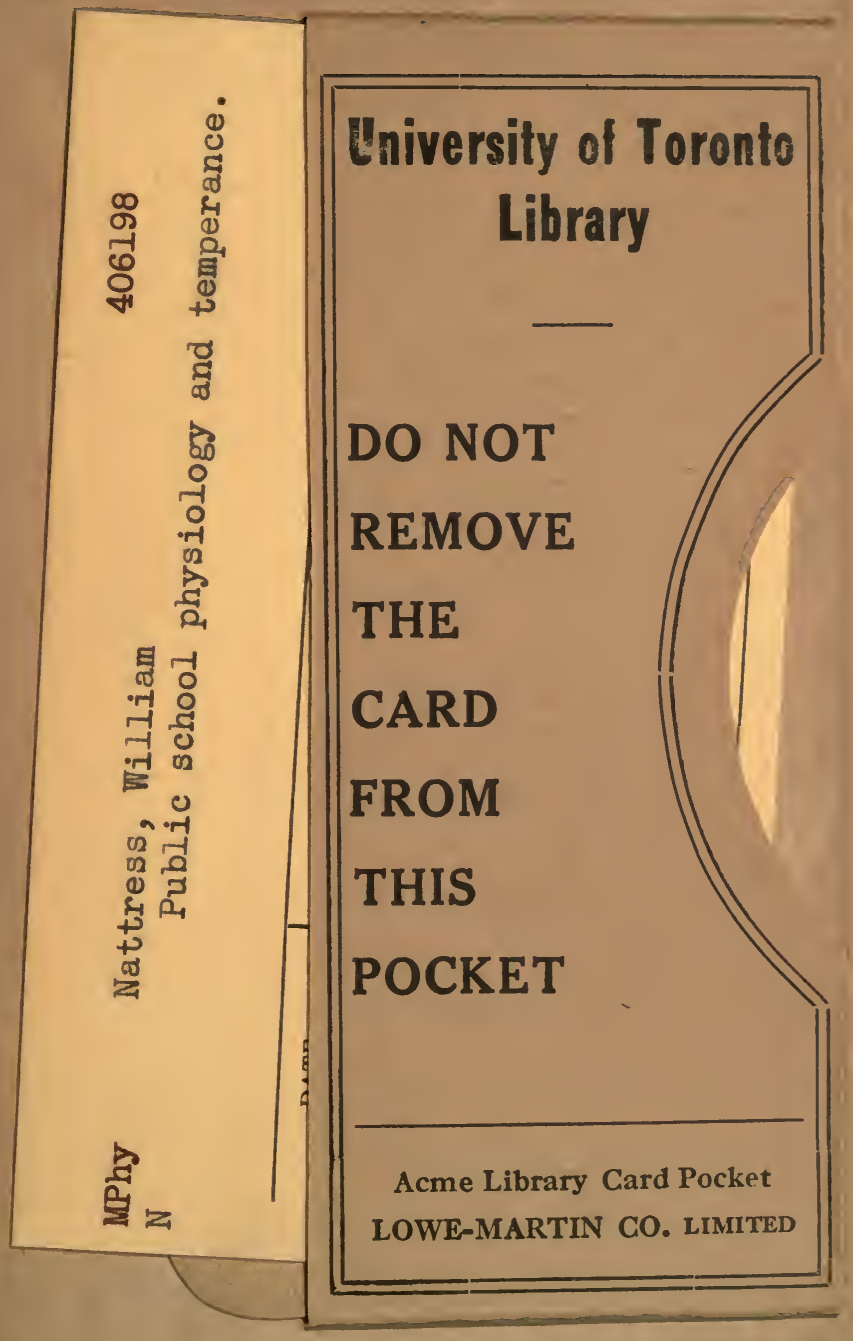


